Portland State University

PDXScholar

Spring 6-13-2014

\title{
Stress Analysis for Chip Scale Packages with Embedded Active Devices under Thermal Cycling
}

Hyunwook Yeo

Portland State University

Follow this and additional works at: https://pdxscholar.library.pdx.edu/open_access_etds

Part of the Manufacturing Commons, and the Materials Science and Engineering Commons Let us know how access to this document benefits you.

Recommended Citation

Yeo, Hyunwook, "Stress Analysis for Chip Scale Packages with Embedded Active Devices under Thermal Cycling" (2014). Dissertations and Theses. Paper 1782.

https://doi.org/10.15760/etd.1781

This Thesis is brought to you for free and open access. It has been accepted for inclusion in Dissertations and Theses by an authorized administrator of PDXScholar. Please contact us if we can make this document more accessible: pdxscholar@pdx.edu. 
Stress Analysis for Chip Scale Packages with Embedded Active Devices under Thermal Cycling

by

Hyunwook Yeo

A thesis submitted in partial fulfillment of the requirements for the degree of

\author{
Master of Science \\ in \\ Mechanical Engineering
}

Thesis Committee:

Sung Yi, Chair

Dave Turcic

Chien Wern

Portland State University

2014 
(C) 2014 Hyunwook Yeo 


\begin{abstract}
s
One of the main challenges in the electronics manufacturing and packaging development is how to integrate more functions inside the same or even smaller size. To meet the demand for higher integration, the interest toward passive and active component embedding has been increasing during the past few years. One of the main reasons for the growing interest toward embedded active components, in addition to demand for higher packaging density, is the need for better electrical performance of the component assemblies. However, it is little known how embedded IC and passives affect the reliability of IC packaging.

Solder joints have been used in the electronic industry as both structural and electrical interconnections between electronic packages and printed circuit boards (PCB). When solder joints are under thermal cyclic loading, mismatch in coefficients of thermal expansion (CTE) between the printed circuit boards and the solder balls creates thermal strains and stresses on the joints, which may finally result in cracking. Consequently, the mechanical interconnection is lost, leading to electrical failures (such as hard/intermittent open, parametric failure), which in turn causes malfunction of the circuit or whole system.

When a die is embedded into a substrate, Young's modulus of the die is larger than one of the core of the substrate and the CTEs of the die is smaller than those of the substrate. As a result, mismatch in coefficients of thermal expansions (CTE) between the substrate with the embedded device and the solder balls may increase.
\end{abstract}


In the present study, the stress of chip scale packages (CSP) with an embedded die under thermal cycling conditions is evaluated using the finite element method. The viscoplastic model for solders including matrix dislocation mechanism and grain boundary sliding model developed by Yi et al. (2002) is employed. 


\section{Table of Contents}

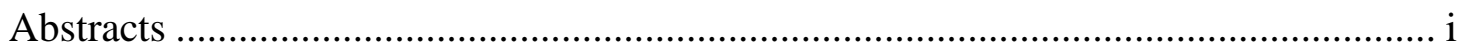

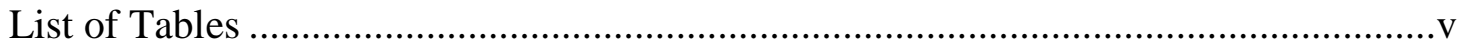

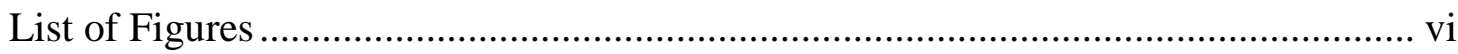

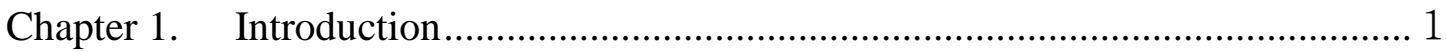

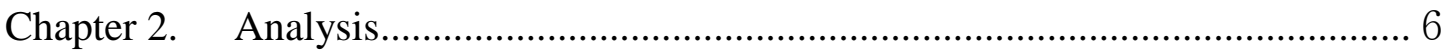

2.1 Constitutive Relationships for Solders ................................................... 6

Chapter 3. Verification Studies ................................................................. 9

3.1. Linear Elastic Analysis ...................................................................... 9

3.1.1. Isothermal Isotropic Linear Elasticity ………………………….... 9

3.1.2. Non-Isothermal Linear Elasticity ................................................ 10

Chapter 4. Finite Element Analysis of Embedded Ball Grid Array Packages under

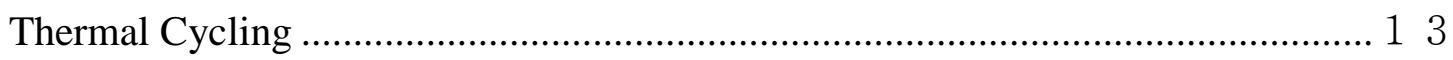

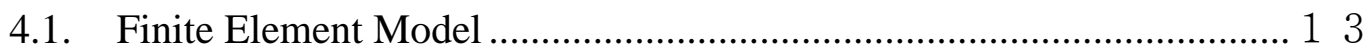

4.1.1. Geometries and Mechanical Properties ...................................... 13

4.1.2. Temperature Cycles ...................................................................... 19

4.1.3. Finite Element Modelling ............................................................. 20

4.2. Linear Elastic FEA Results.............................................................. 2

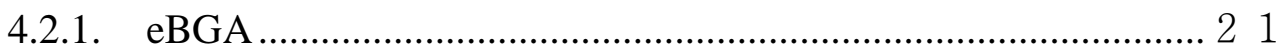

4.2.2. Chip Scale Package with eBGA ………………………………... 33 
4.3. Viscoplastic FEA Results

4.3.1. eBGA

4.3.2. Chip Scale Package with eBGA ........................................... 52

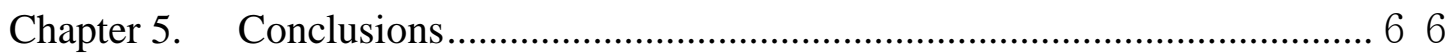

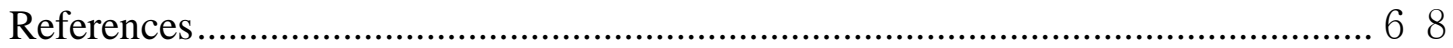




\section{List of Tables}

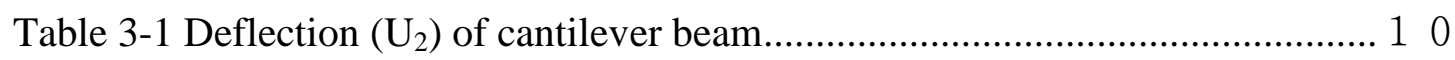

Table 3-2 Thermal stress and strain .................................................................... 12

Table 4-1 Geometry of CSP with eBGA …………………............................... 15

Table 4-2 Material properties of CSP with eBGA (Yi et al., 2012; Chu, 2006)..... 16

Table 4-3 Creep data for $\mathrm{Sn}-3 \mathrm{Ag}-0.5 \mathrm{Cu}$ at various temperatures (Chu, 2006) ........ 17

Table 4-4 Material parameters of Sn-3Ag-0.5Cu (Chu, 2006) ………………...... 18

Table 4-5 Shear stress and von Mises Stress of embedded die corner and all solder

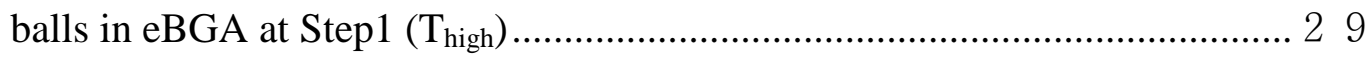

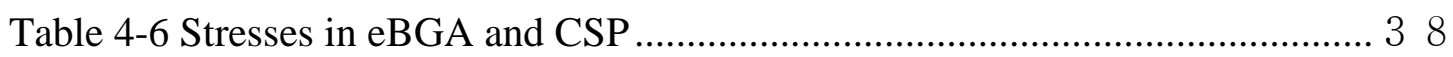

Table 4-7 Stress comparison with linear elastic response of eBGA at step1( $\left.\mathrm{T}_{\text {high }}\right) . .46$

Table 4-8 Stress comparison with the linear elastic case at step $1\left(\mathrm{~T}_{\text {high }}\right) \ldots \ldots \ldots \ldots \ldots \ldots . . .58$ 


\section{List of Figures}

Figure 1-1 Cross section of solder balls after 1000 thermal cycles $\left(-40\right.$ to $\left.150{ }^{\circ} \mathrm{C}\right)$

where the arrow indicates the crack (Zhong and Yi, 1999)............................ 4

Figure 3-1 Deflection $\left(\mathrm{U}_{2}\right)$ of cantilever beam analyzed with UMAT ................... 10

Figure 3-2 Beam with $\mathrm{U}_{\mathrm{x}}=\mathrm{U}_{1}=0$ displacement boundary condition .................... 11

Figure 3-3 Thermal stress and strain result applied UMAT ................................ 12

Figure 4-1 eBGA and CSP with eBGA ….................................................... 13

Figure 4-2 Geometry of half model for CSP with eBGA .................................. 14

Figure 4-3 Cross section of substrate........................................................... 15

Figure 4-4 Temperature profile used for the FEA simulation .............................. 20

Figure 4-5 Thermal cycle applied for linear elastic FEA .................................. 21

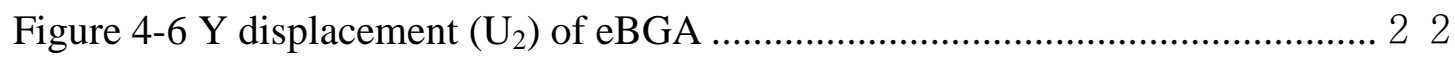

Figure 4-7 Variation of maximum displacement in the y-direction during thermal

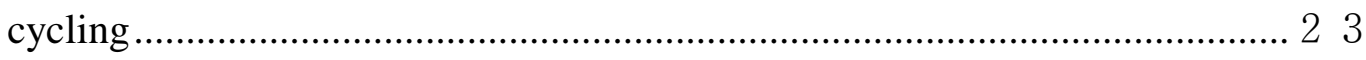

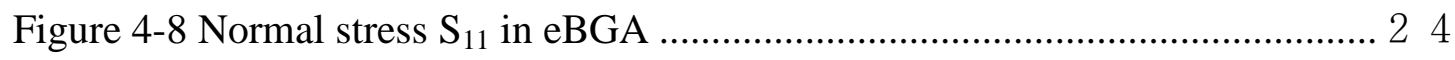

Figure 4-9 Normal stress $S_{11}$ in substrate at step1 $\left(\mathrm{T}_{\text {high }}\right)$................................ 24

Figure 4-10 Variation of the normal stress $S_{11}$ through the thickness of substrate at

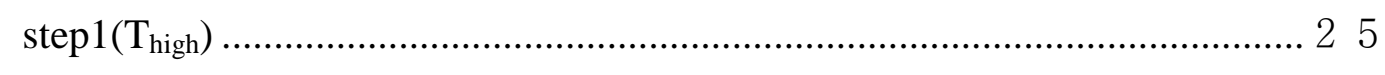

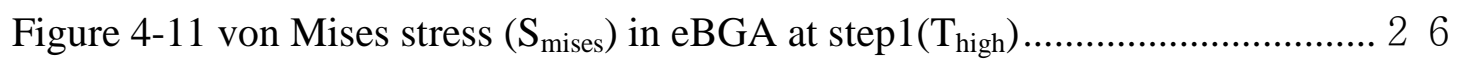

Figure 4-12 von Mises stress $\left(\mathrm{S}_{\text {mises }}\right)$ in embedded die at step1( $\left.\mathrm{T}_{\text {high }}\right) \ldots \ldots \ldots \ldots \ldots \ldots \ldots \ldots \ldots \ldots \ldots \ldots$ 
Figure 4-13 Shear stress $S_{12}$ in eBGA at step1 $\left(T_{\text {high }}\right)$ 28

Figure 4-14 Shear stresses $S_{12}$ in embedded die corner and solder joint at step1 ( $\left.T_{\text {high }}\right)$

Figure 4-15 Shear Stress $S_{12}$ in Solder Joints

Figure 4-16 Normal stresses $\left(S_{11}\right.$ and $\left.S_{22}\right)$ and shear stress $\left(S_{12}\right)$ during thermal cycling

Figure 4-17 von Mises stress $\left(\mathrm{S}_{\text {mises }}\right)$ during thermal cycling 33

Figure 4-18 Y displacement $\left(\mathrm{U}_{2}\right)$ in CSP with eBGA 34

Figure 4-19 Normal stress in the $\mathrm{x}$ direction of CSP with eBGA 35

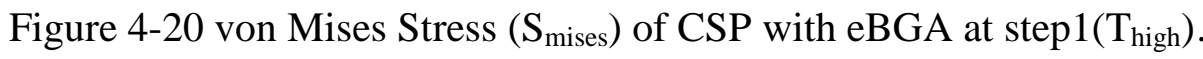
36

Figure 4-21 von Mises stress $\left(\mathrm{S}_{\text {mises }}\right)$ near embedded die corner at step1( $\left.\mathrm{T}_{\text {high }}\right) \ldots \ldots 36$

Figure 4-22 Shear stress $\mathrm{S}_{12}$ of CSP with eBGA at step1( $\left.\mathrm{T}_{\text {high }}\right)$

Figure 4-23 Shear stresses in embedded die corner and solder joint at step1( $\left.\mathrm{T}_{\text {high }}\right) .38$ Figure 4-24 Normal stress $\left(\mathrm{S}_{11}, \mathrm{~S}_{22}\right)$ and shear stress $\left(\mathrm{S}_{12}\right)$ during thermal cycling . 40 Figure 4-25 Y displacement $\left(\mathrm{U}_{2}\right)$ in eBGA................................................. 41

Figure 4-26 Maximum displacement in the y-direction during thermal cycling ...... 42

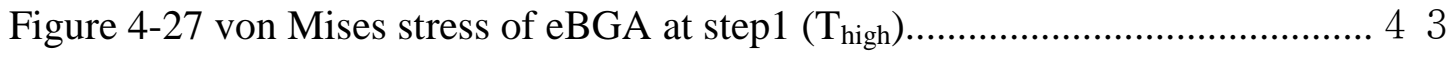

Figure 4-28 von Mises stress near embedded die corner at step1 $\left(\mathrm{T}_{\text {high }}\right)$................. 44

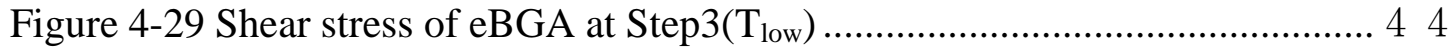


Figure 4-30 Shear stress in embedded die corner at step1 $\left(\mathrm{T}_{\text {high }}\right)$ and step3 $\left(\mathrm{T}_{\text {low }}\right) \ldots 45$

Figure 4-31 Shear stress in solder joint at step1 $\left(\mathrm{T}_{\text {high }}\right)$ and step3 $\left(\mathrm{T}_{\text {low }}\right) \ldots \ldots \ldots \ldots \ldots \ldots . . . . . .45$

Figure 4-32 Variation of shear stress $S_{12}$ during thermal cycling ......................... 48

Figure 4-33 Variation of normal stress $S_{11}$ during thermal cycling ...................... 49

Figure 4-34 Variation of normal stress $S_{22}$ during thermal cycling ...................... 50

Figure 4-35 Variation of von Mises stress $\left(S_{\text {mises }}\right)$ during thermal cycling ............. 51

Figure 4-36 Y displacement $\left(\mathrm{U}_{2}\right)$ of CSP with eBGA .................................... 53

Figure 4-37 Maximum displacement in the y-direction during thermal cycling ...... 54

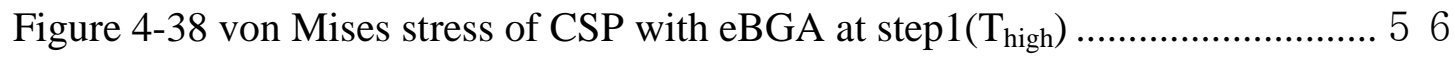

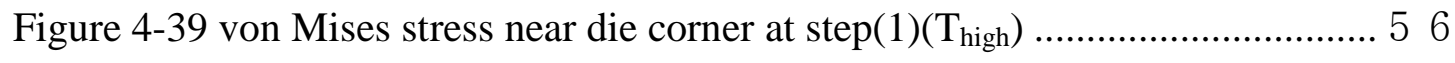

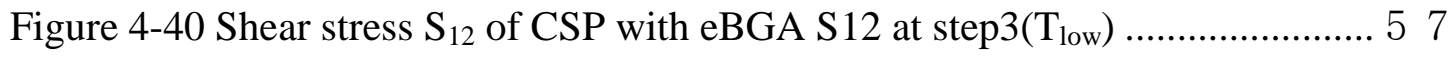

Figure 4-41 Shear stress $S_{12}$ in embedded die corner at step1 $\left(T_{\text {high }}\right)$ and step3( $\left.T_{\text {low }}\right) \ldots 5$ 7

Figure 4-42 Shear Stress $S_{12}$ in Solder Joint at step1 $\left(\mathrm{T}_{\text {high }}\right)$ and step3 $\left(\mathrm{T}_{\text {low }}\right) \ldots \ldots \ldots \ldots . . .58$

Figure 4-43 Variation of shear stress $S_{12}$ during thermal cycling ......................... 61

Figure 4-44 Variation of normal stress $S_{11}$ during thermal cycling ...................... 62

Figure 4-45 Variation of normal stress $S_{22}$ during thermal cycling ...................... 63

Figure 4-46 Variation of von Mises stress $\left(S_{\text {mises }}\right)$ and during thermal cycling ....... 64 


\section{Chapter 1. Introduction}

One of the main challenges in the electronics manufacturing and packaging development is how to integrate more functions inside the same or even smaller size. The electrical performance and the number of functions of every new product generation are increasing while the size and the weight of the products are decreasing. To meet this, the semiconductor industry is going toward 14 nano $\mathrm{m}$ process, which means that more transistors can be integrated into the same silicon area. This allows either to reduce the size of the IC or to increase the functionality and performance of the same size IC components. At the same time, there is also an interest to increase the packaging density even more by using 3D assembly, e.g. die stacking or package stacking. In both case the outcome is the same, the number of the contacts in same area is increasing and causing challenges for the packaging, assembly and substrate technologies.

To meet the demand for higher integration, the interest toward passive and active component embedding has been increasing during the past few years. Several institutes and companies have announced that they are developing technologies for embedding active and passive components. One of the main reasons for the growing interest toward embedded active components, in addition to demand for higher packaging density, is the need for better electrical performance of the component assemblies. Embedded passive components in printed circuit boards have been shown 
to reduce space requirements by $30 \%$ or more, achieve better HF signal integrity and also allow for cost reductions. In the reference (Yi et al., 2013), low cost and high performance duplexers have been developed for WiMAX front-end modules with multi-layered organic substrates and a new organic substrate manufacturing process has been proposed in order to improve the tolerance of embedded passives in organic substrates. The dual band front-end module for mobile devices includes a power amplifier die with a switch and has a very small package form factor.

Work on embedded active components is ongoing and is expected to achieve these same results and should additionally allow higher interconnect density and a dramatic functionality increase while maintain key PCB attributes of component and interconnects. However, this new technology itself may prove insufficient and/or nonoptimal without considering the system level impacts of the specific military and/or consumer design. What is also needed to further these design goals are both the fundamental technology improvements (such as embedded active discrete chips), as well as novel and appropriate system level integration of the chips into the specific devices. As the complexity and requirements of systems increase, this system level integration will become more and more important.

Solder joints have been used in the electronic industry as both structural and electrical interconnections between electronic packages and printed circuit boards (PCB). When solder joints are under thermal cyclic loading, mismatch in coefficients of thermal expansion (CTE) between the printed circuit boards and the solder balls creates thermal strains and stresses on the joints, which may finally result in cracking (Zhong 
and Yi, 1998; Zhong and Yi, 1999; Zhong et al., 2002). Consequently, the mechanical interconnection is lost, leading to electrical failures (such as hard/intermittent open, parametric failure), which in turn causes malfunction of the circuit or whole system. Such failure mechanism is called thermal fatigue. Thermal fatigue is a major failure mechanism of solder joints and plays an important role in determining the reliability of electronic packages. Figure 1 shows a typical solder joint fatigue crack after being subjected to a thermal cycling test. Many efforts have been spent on predicting thermal fatigue lifetime to assess product reliability, especially in the product design and development stage.

Thermal fatigue happens mostly at solder joints, thus it hinders the reliability of the product. The ability to predict thermal fatigue life accurately is valuable to industry because it saves time and cost for product development and optimization. In order to predict thermal fatigue life accurately, an appropriate constitutive model and finite element analysis are required.

Phenomenal-based models are often used to establish the constitutive relationship of materials. The mechanical behavior of solders is viscoplastic because its deformation is rate-dependent. Thermal stresses in electronic packages are often beyond yield strengths of solders and the solder joints deform plastically. The plastic strain may consist of two components: the time-independent plastic deformation and the timedependent creep deformation. 


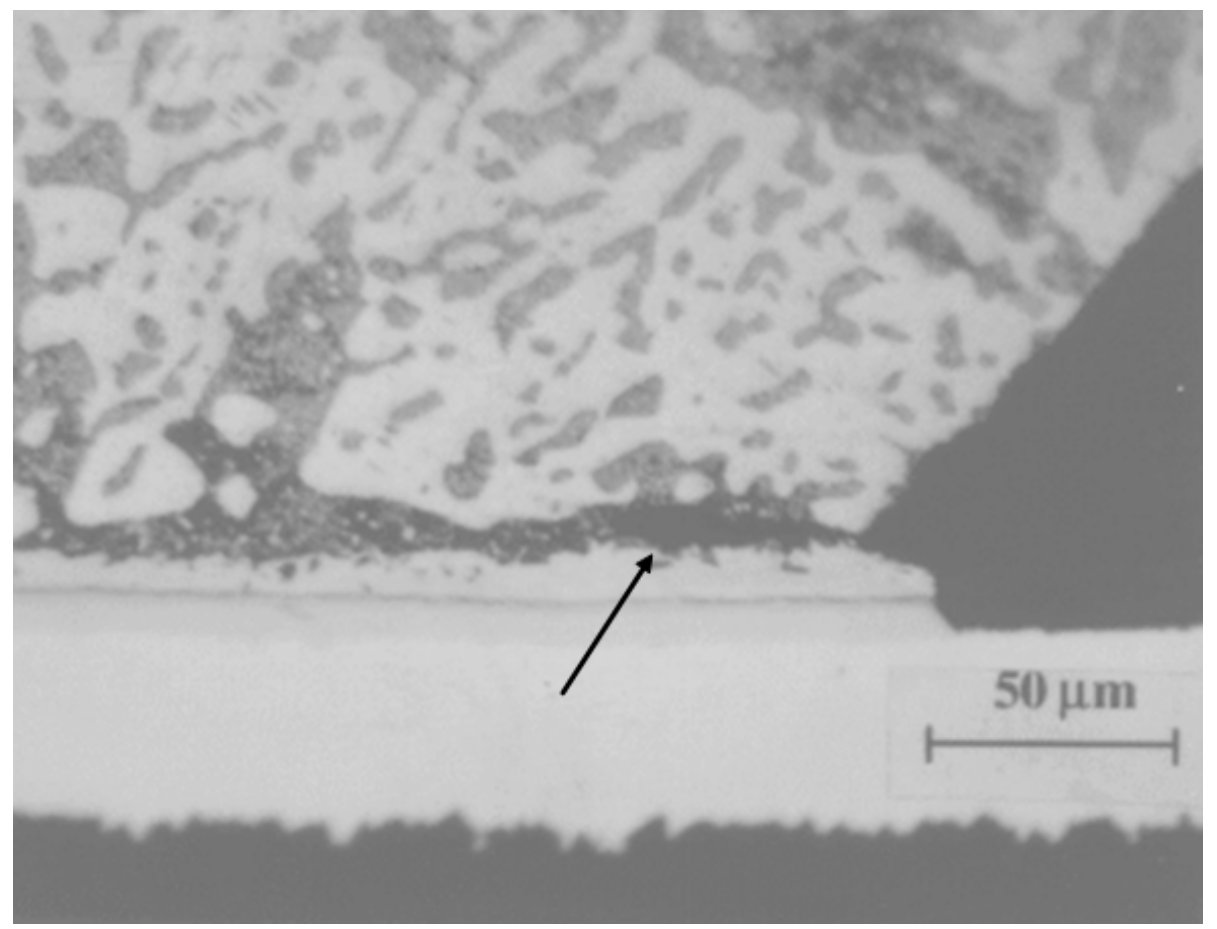

Figure 1-1 Cross section of solder balls after 1000 thermal cycles $\left(-40\right.$ to $\left.150{ }^{\circ} \mathrm{C}\right)$ where the arrow indicates the crack (Zhong and Yi, 1999).

In the past, many constitutive models were proposed for solders (Morris et al., 2003; Darveaus and Banerji, 1992; Yi et al., 2002; Joo and Yu, 2002; Wieses and Meusel, 2003). However, though many experimental studies show the strong influence of microstructure on solder mechanical properties, this phenomenon was not considered in most constitutive relationships. Yi et al. (2002) had established a constitutive relationship to take the microstructural grain size effect into account. In this model, matrix dislocation mechanism and grain boundary sliding are considered.

In the present study, the stress in solder joints of chip scale packages (CSP) with an embedded die under thermal cycling conditions is evaluated using the finite element 
method. The viscoplastic model for solders including matrix dislocation mechanism and grain boundary sliding model developed by Yi et al. (2002) is employed. 


\section{Chapter 2. Analysis}

\subsection{Constitutive Relationships for Solders}

The general form of the constitutive equation usually expresses the total strain rate $\dot{\varepsilon}_{i j}^{\text {total }}$ as the sum of the elastic $\dot{\varepsilon}_{i j}^{e}$, time independent plastic strain rate $\dot{\varepsilon}_{i j}^{p l}$, and timedependent creep strain rate $\dot{\varepsilon}_{i j}^{c r}$ :

$$
\dot{\varepsilon}_{i j}^{\text {total }}=\dot{\varepsilon}_{i j}^{e}+\dot{\varepsilon}_{i j}^{p l}+\dot{\varepsilon}_{i j}^{c r} \quad(\mathrm{i}, \mathrm{j}=1,2,3)
$$

In a unified model, the plastic and creep strain rates are unified as one inelastic term $\left(\dot{\varepsilon}_{i j}^{i n}\right)$ which is calculated by the same equations. Therefore, the total strain can be defined as

$$
\dot{\varepsilon}_{i j}^{\text {total }}=\dot{\varepsilon}_{i j}^{e}+\dot{\varepsilon}_{i j}^{\text {in }}
$$

According to Yi et al. (2002), there are two deformation mechanisms to account for $\dot{\varepsilon}_{i j}^{i n}$, so that

$$
\dot{\varepsilon}_{i j}^{i n}=\dot{\varepsilon}_{i j}^{m c}+\dot{\varepsilon}_{i j}^{g b}
$$

Finally,

$$
\dot{\varepsilon}_{i j}^{\text {total }}=\dot{\varepsilon}_{i j}^{e}+\dot{\varepsilon}_{i j}^{m c}+\dot{\varepsilon}_{i j}^{g b}
$$

where $\dot{\varepsilon}_{i j}^{m c}$ is the creep strain rate due to the matrix dislocation and $\dot{\varepsilon}_{i j}^{g b}$ is the creep strain rate due to the grain boundary sliding, respectively. 
Power law is used to model the deformation mechanism due to matrix dislocation (Yi et al. 2002).

$$
\dot{\varepsilon}_{i j}^{m c}=C^{m c} \frac{E(T)}{T} \exp \left(\frac{-\Delta H^{m c}}{k T}\right)\left(\frac{\left|\mathbf{S}-\mathbf{X}^{m c}\right|}{D_{0}}\right)^{n^{m c}} \frac{s_{i j}-x_{i j}^{m c}}{\left|\mathbf{S}-\mathbf{X}^{m c}\right|}
$$

The strain rate due to grain boundary sliding is given by a similar form of the equation. The grain size effect is introduced to the equation by a term $\frac{1}{d^{n}}$, where $d$ is the initial grain size in the solder material:

$$
\dot{\varepsilon}_{i j}^{g b}=C^{g b} \frac{1}{d^{n}} \frac{E(T)}{T} \exp \left(\frac{-\Delta H^{g b}}{k T}\right)\left(\frac{\left|\mathbf{S}-\mathbf{X}^{g b}\right|}{E(T)}\right)^{n^{g b}} \frac{s_{i j}-x_{i j}^{g b}}{\left|\mathbf{S}-\mathbf{X}^{g b}\right|}
$$

with

$$
\begin{aligned}
& \left|\mathbf{S}-\mathbf{X}^{m c}\right|=\sqrt{\frac{3}{2}\left(s_{i j}-x_{i j}^{m c}\right)\left(s_{i j}-x_{i j}^{m c}\right)} \\
& \left|\mathbf{S}-\mathbf{X}^{g b}\right|=\sqrt{\frac{3}{2}\left(s_{i j}-x_{i j}^{g b}\right)\left(s_{i j}-x_{i j}^{g b}\right)}
\end{aligned}
$$

In the above, $\mathbf{X}$ is the dynamic hardening back stress tensor, $\mathrm{x}_{\mathrm{ij}}$ is the index notation for $\mathbf{X}, \mathbf{S}$ is the deviatoric stress tensor, $s_{i j}$ is the index notation for $\mathbf{S}$ and given by

$$
s_{i j}=\sigma_{i j}-\frac{1}{3} \sigma_{k k} \delta_{i j}
$$

$C$ and $n$ are the material constants, $\Delta \mathrm{H}$ is the activation energy, $\mathrm{k}$ is the Boltzman Constant which is equal to $8.617 \times 10^{-5} \mathrm{eV} / \mathrm{K}$, T is the temperature in Kelvin, $\mathrm{D}_{0}$ is the isohardening drag stress, $\mathrm{E}(\mathrm{T})$ is the Young's Modulus which is a function of 
temperature. Superscript ' $\mathrm{gb}$ ' and ' $\mathrm{mc}$ ' denotes the parameters for grain boundary sliding and matrix dislocation, respectively. User-defined viscoplastic constitutive model is implemented to ABAQUS through a subroutine UMAT and semi-implicit time integration scheme is used. Large deformation analysis with the thermoviscoplastic constitutive law has been performed and the subsequent interval is determined by ABAQUS solver. User-defined viscoplastic constitutive model is implemented to ABAQUS through a subroutine UMAT and semi-implicit time integration scheme is used. Large deformation analysis with the thermo-viscoplastic constitutive law has been performed and the subsequent interval is determined by ABAQUS solver. 


\section{Chapter 3. Verification Studies}

Verification studies for Isothermal linear elasticity and non-isothermal linear elasticity are designed and conducted to check the accuracy of the result obtained by using the ABAQUS with the user-defined material subroutine (UMAT).

\subsection{Linear Elastic Analysis}

\subsubsection{Isothermal Isotropic Linear Elasticity}

A cantilever beam structure with a dimension of $10 \times 1 \times 1(m)$ is considered. A surface traction $(1000 \mathrm{~Pa})$ is applied at the right free end with left end fixed. Based on the Simple Beam Theory, the tip deflection of the cantilever beam is given by

$$
\delta=\frac{F L^{3}}{3 E I}
$$

where $\mathrm{F}=$ Force acting at the tip of the beam, $\mathrm{L}=$ Length of the beam (span), $\mathrm{E}=$ Modulus of elasticity and $\mathrm{I}=$ Area moment of inertia, respectively.

Area moment of inertia of a rectangular with a base width of $b$ and height $h$ is

$$
\mathrm{I}=\frac{b h^{3}}{12}
$$

The analytic result the tip deflection of the cantilever beam is $3.419 \mathrm{e}-5 \mathrm{~m}$ with $\mathrm{E}=117$ GPa. The finite element result of deflection $\left(\mathrm{U}_{2}\right)$ obtained with an isotropic isothermal elasticity UMAT designed in this study is 3.41e-5 $\mathrm{m}$ as shown in Figure 3-1. The analytic result agrees very to finite element one with UMAT and these results are tabulated in Table 3-1. 


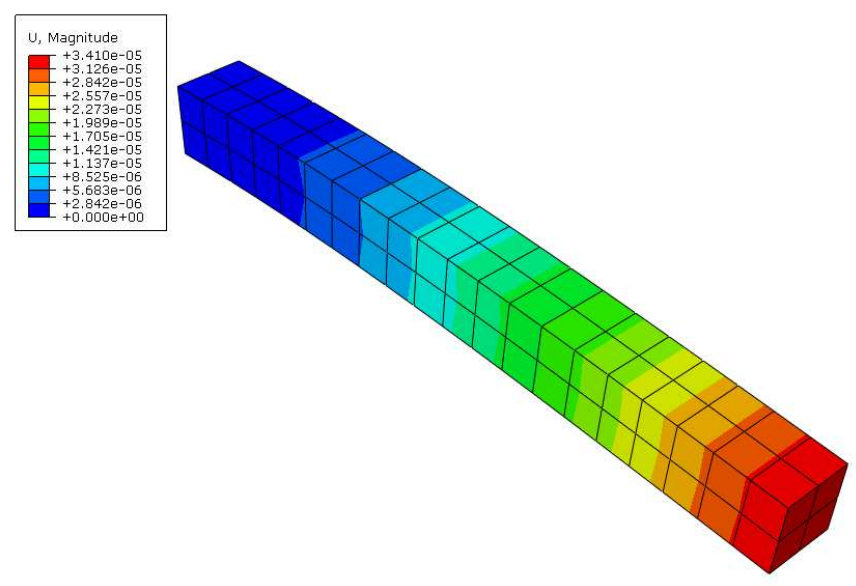

Figure 3-1 Deflection $\left(\mathrm{U}_{2}\right)$ of cantilever beam analyzed with UMAT

Table 3-1 Deflection $\left(\mathrm{U}_{2}\right)$ of cantilever beam

\begin{tabular}{|c|c|c|c|}
\hline & $\begin{array}{c}\text { Simple beam } \\
\text { theory }\end{array}$ & FEA (ABAQUS) & $\begin{array}{c}\text { FEA with UMAT } \\
\text { (ABAQUS) }\end{array}$ \\
\hline Tip deflection & $3.419 \times 10^{-5}(\mathrm{~m})$ & $3.41 \times 10^{-5}(\mathrm{~m})$ & $3.41 \times 10^{-5}(\mathrm{~m})$ \\
\hline
\end{tabular}

\subsubsection{Non-Isothermal Linear Elasticity}

A beam structure with fixed both ends is considered. The dimension of the beam is $4 \times 1 \times 1 \mathrm{~m}$. Thermal loading, $\Delta \mathrm{T}=1$ degree $\mathrm{C}$, is applied. In this case, the uniform temperature change through the beam is assumed. 


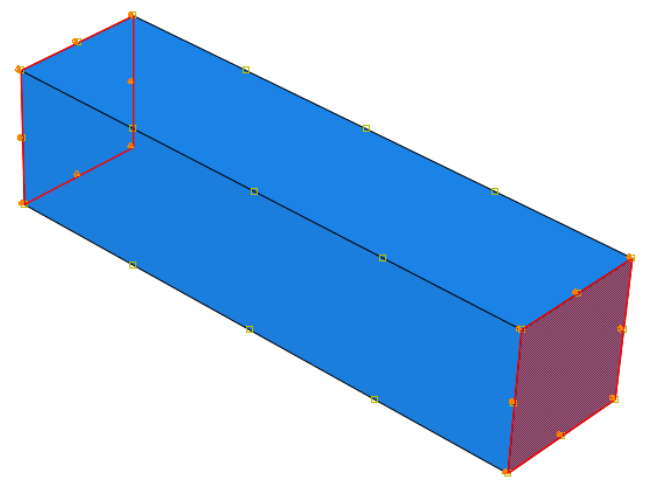

Figure 3-2 Beam with $\mathrm{U}_{\mathrm{x}}=\mathrm{U}_{1}=0$ displacement boundary condition

Theoretically, thermal displacement, thermal strain, and thermal stress can be obtained as

$$
\begin{gathered}
\Delta \delta=\alpha \mathrm{L}\left(\mathrm{T}_{\mathrm{F}}-\mathrm{T}_{0}\right) \\
\varepsilon^{*}=\Delta \delta / \mathrm{L}=\alpha\left(\mathrm{T}_{\mathrm{F}}-\mathrm{T}_{0}\right) \\
\sigma=\mathrm{E}\left(\varepsilon-\varepsilon^{*}\right)=-\mathrm{E} \alpha\left(\mathrm{T}_{\mathrm{F}}-\mathrm{T}_{0}\right)
\end{gathered}
$$

where $\varepsilon=$ total strain, $\varepsilon^{*}=$ thermal strain, $\sigma=$ thermal stress, $\alpha=$ coefficient of thermal expansion, $\mathrm{T}_{\mathrm{F}}=$ final temperature and $\mathrm{T}_{0}=$ initial temperature respectively .

With $\mathrm{E}=1 \mathrm{~Pa}, v=0.3, \alpha=1, \mathrm{~T}_{\mathrm{F}}=2, \mathrm{~T}_{0}=1$ for convenience, the thermal strain is 1 and thermal stress is $-1 \mathrm{~Pa}$ since the total strain is zero. Exactly same results were obtained by using ABAQUS. The thermal strain of 1 and thermal stress of -1 are calculated as shown in Figure 4-3. All results are tabulated in Table 3-2. 


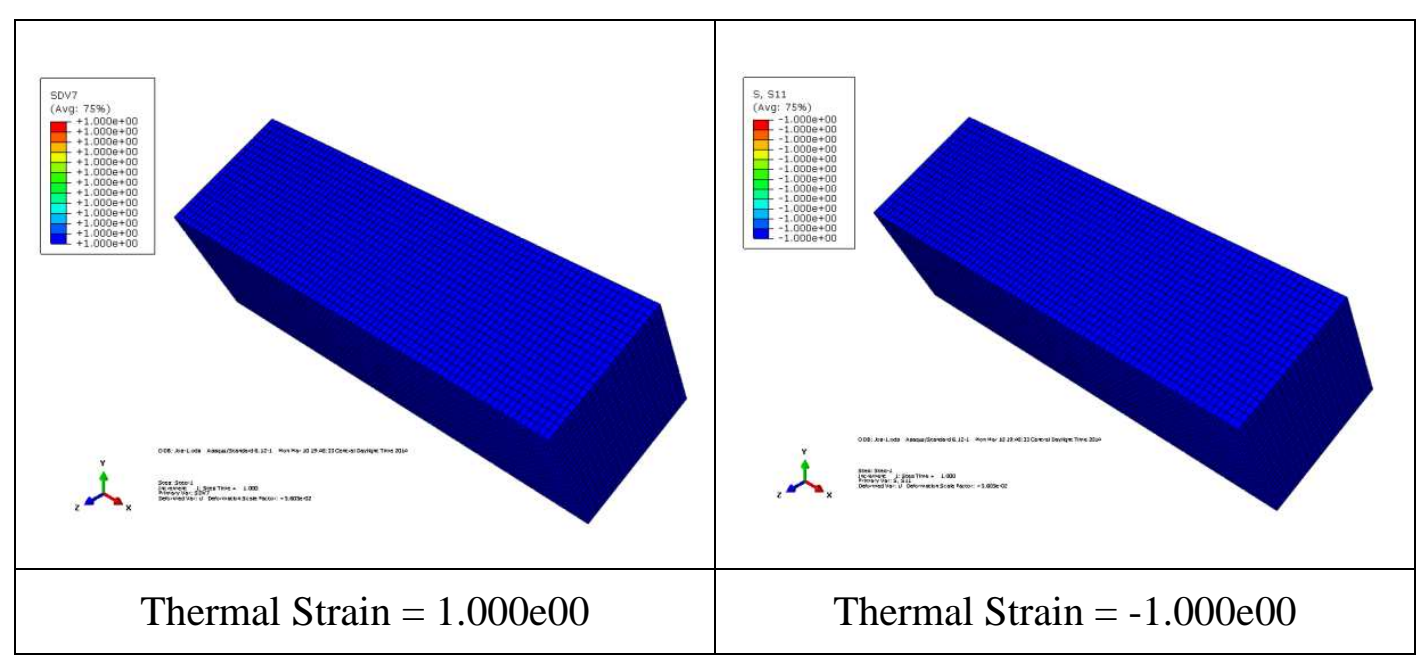

Figure 3-3 Thermal stress and strain result applied UMAT

Table 3-2 Thermal stress and strain

\begin{tabular}{|c|c|c|c|}
\hline & Theoretical Result & ABAQUS & $\begin{array}{c}\text { ABAQUS with } \\
\text { UMAT }\end{array}$ \\
\hline Thermal Strain & 1 & 1 & 1 \\
\hline Thermal Stress & -1 & -1 & -1 \\
\hline
\end{tabular}

The thermal stress and thermal strain results of using isotropic non-isothermal elasticity UMAT are agree to CAE result and theoretical result. 


\section{Chapter 4. Finite Element Analysis of Embedded Ball Grid Array Packages under Thermal Cycling}

Linear elastic and viscoplastic behaviors of solders are considered for the eBGA and the chip scale package (CSP) with an embedded chip to study the deformation and stresses during thermal cycle loading. The finite element formulation based on the viscoplastic constitutive relationship presented in the previous chapter is employed to analyze thermo-mechanical behaviors of solders.

\subsection{Finite Element Model}

\subsubsection{Geometries and Mechanical Properties}

Two different geometries are considered for this study. One is the eBGA and the other is the chip scale package (CSP) with the eBGA. They are illustrated in Figure 4-1.

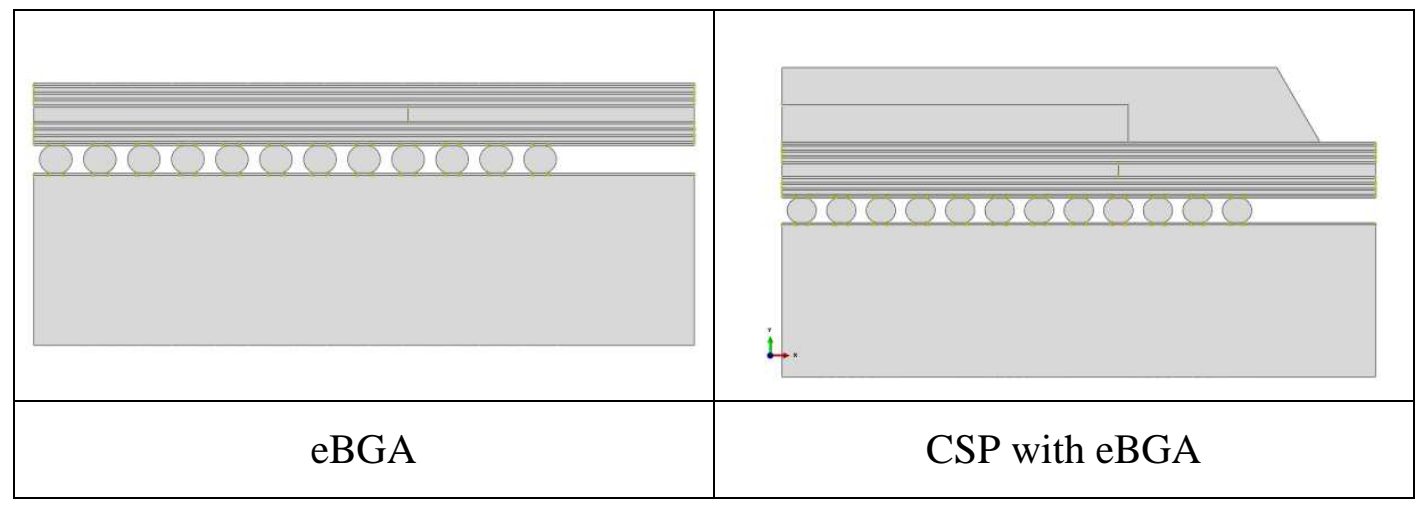

Figure 4-1 eBGA and CSP with eBGA

A plane strain condition is considered which simplifies the problem to twodimensional one. Half of the model is constructed due to geometric symmetry about the vertical axis. Figure 4-2 illustrates the FEA model for the CSP with the eBGA. 
An 8-node biquadratic plane stress quadrilateral element with reduced integration (CPS8R in ABAQUS) is used.

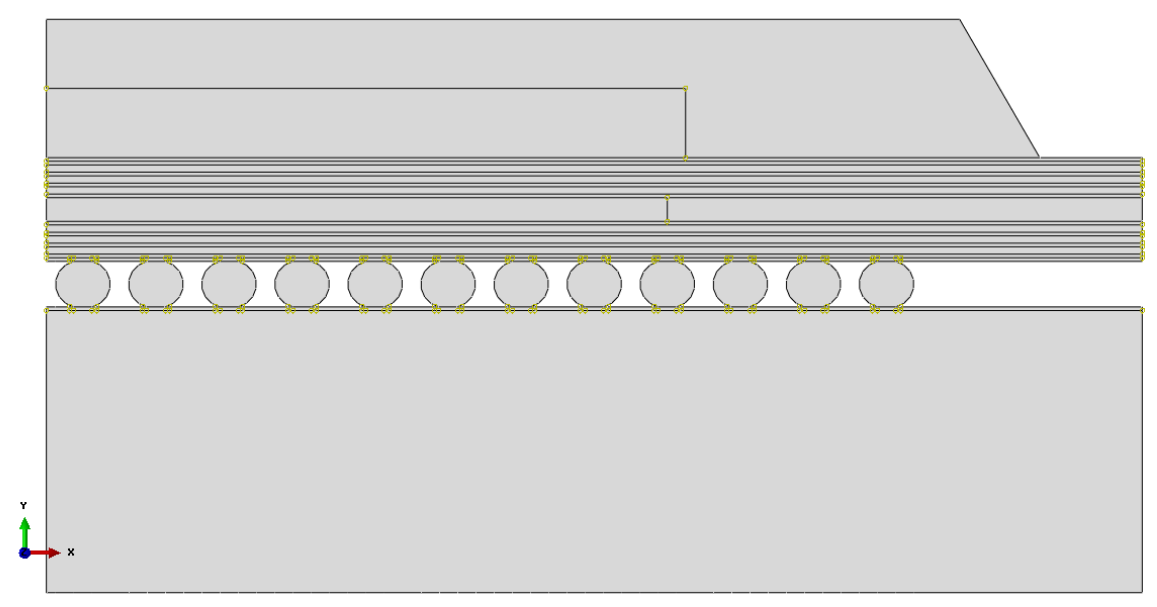

Figure 4-2 Geometry of half model for CSP with eBGA

The geometry and mechanical properties of the CSP with the eBGA used for the present study are given in Tables 4-1 and 4-2, respectively. BT (Bismaleimide Triazine) and PCB are elastic and orthotropic because of their laminar structures. The mechanical properties in the $\mathrm{x}$ and $\mathrm{z}$-directions are identical, but are different from those in the y-direction. The substrate consists of several layers with various materials including build-up layer, $\mathrm{Cu}$ layer, Core, and solder mask as shown in Figure 4-3. In addition, a die is embedded in the middle of the substrate. The remaining materials are assumed to be elastic and isotropic (Morris et al., 2002; Yi et al., 2005). 


\begin{tabular}{|c|}
\hline Solder Mask : $20 \mu \mathrm{m}$ \\
\hline $\mathrm{Cu}: 20 \mu \mathrm{m}$ \\
\hline Build up : $40 \mu \mathrm{m}$ \\
\hline $\mathrm{Cu}: 20 \mu \mathrm{m}$ \\
\hline Build up : $40 \mu \mathrm{m}$ \\
\hline $\mathrm{Cu}: 20 \mu \mathrm{m}$ \\
\hline Build up : $40 \mu \mathrm{m}$ \\
\hline $\mathrm{Cu}: 20 \mu \mathrm{m}$ \\
\hline Embedded Die : $130 \mu \mathrm{m} \quad$ \\
\hline $\mathrm{Cu}: 20 \mu \mathrm{m}$ \\
\hline $\mathrm{Build} \mathrm{up}: 40 \mu \mathrm{m}$ \\
\hline $\mathrm{Cu}: 20 \mu \mathrm{m}$ \\
\hline $\mathrm{Cuild} \mathrm{up}: 40 \mu \mathrm{m}$ \\
\hline Build up $: 40 \mu \mathrm{m}$ \\
\hline $\mathrm{Cu}: 20 \mu \mathrm{m}$ \\
\hline Solder Mask $: 20 \mu \mathrm{m}$ \\
\hline
\end{tabular}

Figure 4-3 Cross section of substrate

Table 4-1 Geometry of CSP with eBGA

\begin{tabular}{|c|c|c|}
\hline Materials & $\begin{array}{c}\text { Full dimension } \\
\text { LengthxWidthxThickness } \\
(\mathrm{mm})\end{array}$ & Additional information \\
\hline Mold compound & $10 \times 10 \times 0.76$ & Angle $: 120^{\circ}$ \\
\hline Die (upper) & $7.0 \times 7.0 \times 0.38$ & \\
\hline Embedded die & $6.8 \times 6.8 \times 0.13$ & \\
\hline Substrate & $12 \times 12 \times 0.57$ & \\
\hline PCB & $12 \times 12 \times 1.57$ & \\
\hline Solder ball & $\begin{array}{c}\text { Diameter }: 0.3 \mathrm{~mm} \\
\text { Btandoff height }: 0.25 \mathrm{~mm}\end{array}$ & $\begin{array}{c}\text { Total numbers of solder } \\
\text { balls }: 576 \\
\text { Bitch }: 0.4 \mathrm{~mm}\end{array}$ \\
\hline
\end{tabular}


Table 4-2 Material properties of CSP with eBGA (Yi et al., 2012; Chu, 2006).

\begin{tabular}{|c|c|c|c|c|}
\hline Material & $\begin{array}{l}\text { Young's } \\
\text { modulus } \\
(\mathrm{MPa})\end{array}$ & $\begin{array}{l}\text { Poisson's } \\
\text { ratio }\end{array}$ & $\begin{array}{c}\mathrm{CTE} \\
(\mathrm{ppm} / \mathrm{K})\end{array}$ & $\begin{array}{l}\text { Additional } \\
\text { information }\end{array}$ \\
\hline $\begin{array}{c}\text { Mold } \\
\text { compound }\end{array}$ & 15000 & 0.25 & 16.0 & \\
\hline Die & 131000 & 0.28 & 2.6 & \\
\hline Solder mask & 2549 & 0.29 & 55 & \\
\hline Copper layer & 121000 & 0.35 & 17 & \\
\hline $\begin{array}{c}\text { BT } \\
\text { Build-up layer }\end{array}$ & $\begin{array}{c}x, z=26000 \\
y=11000\end{array}$ & $\begin{array}{c}x z=0.11 \\
x y, z y=0.3\end{array}$ & $\begin{array}{c}x, z=15 \\
y=40\end{array}$ & $\begin{array}{r}\text { Gxy }=8250(\mathrm{MPa}) \\
\mathrm{Gyz}=8250(\mathrm{MPa}) \\
\mathrm{xz}=11712(\mathrm{MPa})\end{array}$ \\
\hline Core & $\begin{array}{c}x, z=26000 \\
y=11000\end{array}$ & $\begin{array}{c}x z=0.11 \\
x y, z y=0.3\end{array}$ & $\begin{array}{c}x, z=15 \\
y=40\end{array}$ & $\begin{array}{r}\text { Gxy }=8250(\mathrm{MPa}) \\
\mathrm{Gyz}=8250(\mathrm{MPa}) \\
\mathrm{Gxz}=11712(\mathrm{MPa})\end{array}$ \\
\hline $\begin{array}{c}\text { Solder ball } \\
\text { Sn3Ag0.5Cu } \\
(\mathrm{SAC} 305)\end{array}$ & $\begin{array}{l}\text { 74419- } \\
110 \mathrm{~T}(\mathrm{~K})\end{array}$ & 0.36 & $\begin{array}{l}24 ., \text { Temp }<218 \mathrm{~K} \\
25.6,218 \mathrm{~K}<\mathrm{Temp}<300 \mathrm{~K} \\
27.9,300 \mathrm{~K}<\mathrm{Temp}<398 \mathrm{~K}\end{array}$ & See Table 4-3 \\
\hline PCB & $\begin{array}{l}x, z=18000, \\
y=7380 \mathrm{Mpa}\end{array}$ & $\begin{array}{c}x z=0.11 \\
x y, z y=0.39\end{array}$ & $\begin{array}{c}x, z=14.5 \\
y=67.2\end{array}$ & $\begin{array}{l}\text { Gxy }=5535(\mathrm{MPa}) \\
\mathrm{Gyz}=5535(\mathrm{MPa})\end{array}$ \\
\hline
\end{tabular}

$\mathrm{Sn}-3 \mathrm{Ag}-0.5 \mathrm{Cu}$ is employed for solders. Although there are numerous studies on the creep data of $\mathrm{SnAgCu}$ solders published, few was found suitable to use for curvefitting purpose for the GM constitutive model. Firstly, creep data of solder joint (instead of bulk solder) is preferred since solder joints behave differently compared 
with bulk solders. Secondly, creep data with several grain sizes at various temperatures and strain rates are required in order to obtain the full set of model parameters. A Pb-free solder, Sn3Ag0.5Cu, reported by Morris et al. (2003) is considered. As its creep data was obtained from actual solder joints rather than from bulk solders, it is expected to predict the thermo-mechanical of solder joints accurately. In their study, the experiment for the SAC solder reported by Morris et al. (2003) was conducted by applying a constant shear force to shear a specimen with nine solder joints of thickness $160 \mu \mathrm{m}$. This composition of alloy is considered in this study due to its gaining popularity. However, as the grain size data was not reported, the parameters for grain boundary deformation mechanism could not be determined.

Table 4-3 Creep data for $\mathrm{Sn}-3 \mathrm{Ag}-0.5 \mathrm{Cu}$ at various temperatures (Chu, 2006)

\begin{tabular}{|c|c|c|c|c|c|}
\hline \multicolumn{2}{|c|}{$60^{\circ} \mathrm{C}$} & \multicolumn{2}{c|}{$95^{\circ} \mathrm{C}$} & \multicolumn{2}{c|}{$130^{\circ} \mathrm{C}$} \\
\hline$\tau(\mathrm{MPa})$ & $\dot{\gamma}^{\text {total }}(1 / \mathrm{s})$ & $\tau(\mathrm{MPa})$ & $\dot{\gamma}^{\text {total }}(1 / \mathrm{s})$ & $\tau(\mathrm{MPa})$ & $\dot{\gamma}^{\text {total }}(1 / \mathrm{s})$ \\
\hline 5.44 & $1.0 \times 10^{-8}$ & 5.44 & $8.0 \times 10^{-8}$ & 3.6 & $1.5 \times 10^{-8}$ \\
\hline 7.25 & $1.5 \times 10^{-8}$ & 7.25 & $7.0 \times 10^{-7}$ & 4.5 & $3.0 \times 10^{-8}$ \\
\hline 9.07 & $3.0 \times 10^{-8}$ & 9.07 & $2.0 \times 10^{-6}$ & 5.44 & $2.5 \times 10^{-6}$ \\
\hline 10.88 & $1.0 \times 10^{-7}$ & 10.88 & $1.0 \times 10^{-5}$ & 7.25 & $1.2 \times 10^{-5}$ \\
\hline 12.7 & $2.0 \times 10^{-6}$ & 12.7 & $4.0 \times 10^{-5}$ & 9.07 & $3.5 \times 10^{-5}$ \\
\hline 15 & $4.0 \times 10^{-6}$ & - & - & 10.88 & $2.0 \times 10^{-5}$ \\
\hline
\end{tabular}


The strain rates at various temperatures and stresses are given in Table 4-3. The steady state stresses are obtained for various temperatures and the corresponding secondary creep strain rates are extracted. A summary of model parameters is given in Table 4-4.

Table 4-4 Material parameters of $\mathrm{Sn}-3 \mathrm{Ag}-0.5 \mathrm{Cu}$ (Chu, 2006)

\begin{tabular}{|c|c|}
\hline Material parameters & Values \\
\hline $\mathrm{C}^{\mathrm{mc}}$ & $4.0 \times 10^{-6}$ \\
\hline $\mathrm{D}_{0}$ & 1.0 \\
\hline $\mathrm{n}_{\mathrm{mc}}$ & 6.7 \\
\hline$\Delta \mathrm{H}^{\mathrm{mc}}(\mathrm{eV})$ & 0.697 \\
\hline $\mathrm{H}^{\mathrm{mc}}(\mathrm{MPa})$ & $8885-21 \mathrm{~T}(\mathrm{~K})$ \\
\hline $\mathrm{r}^{\mathrm{mc}}$ & 500 \\
\hline $\mathrm{E}(\mathrm{T})(\mathrm{MPa})$ & $74419-110 \mathrm{~T}(\mathrm{~K})$ \\
\hline$v$ & 0.36 \\
\hline
\end{tabular}

*Experimental conditions: $60-130^{\circ} \mathrm{C}$, with strain rates ranging from $10^{-8}$ to $4 \times 10^{-5} / \mathrm{s}$.

The predicted steady state stresses are calculated in this study and the creep curves are constructed. Comparison is made between the predicted steady state stresses and the experimental data. The discrepancies are found to be within $10 \%$, showing that the model gives a good estimation of the experimental data. These set of parameters work best in the range of $60-130{ }^{\circ} \mathrm{C}$ with shear strain rates ranging from $10^{-8}$ to $4 \times 10^{-5} / \mathrm{s}$. 


\subsubsection{Temperature Cycles}

The temperature profile has an important effect on solder joint deformation since solder behavior is rate-dependent and the creep is a time-dependent strain. The temperature profile of thermal cycling has a strong influence on solder deformation. Fast temperature ramp rate increases the strain and stress as solder behavior is ratedependent. The dwell time is also another factor because it allows creep to develop. Therefore, the choice of temperature profile affects the reliability of solder balls significantly.

The temperature profile of thermal cycling chosen in the present study consists of $\mathrm{T}_{\text {initial }}=25^{\circ} \mathrm{C}(298 \mathrm{~K}), \mathrm{T}_{\text {high }}=125^{\circ} \mathrm{C}(398 \mathrm{~K}), \mathrm{T}_{\text {low }}=-40^{\circ} \mathrm{C}(233 \mathrm{~K})$, dwell time $=10 \mathrm{mins}$, and $\operatorname{ramp} \operatorname{rate}\left(10^{\circ} \mathrm{C} / \mathrm{min}\right)$.

A common standard used by the electronic packaging industry is JEDEC. With standards, comparisons can be made between test results performed by different parties. Temperature profile used in this present study corresponds to 'Condition G' from the JEDEC standard which is commonly used by industry to conduct solder joint reliability studies. Temperature profile is plotted in Figure 4-4. 


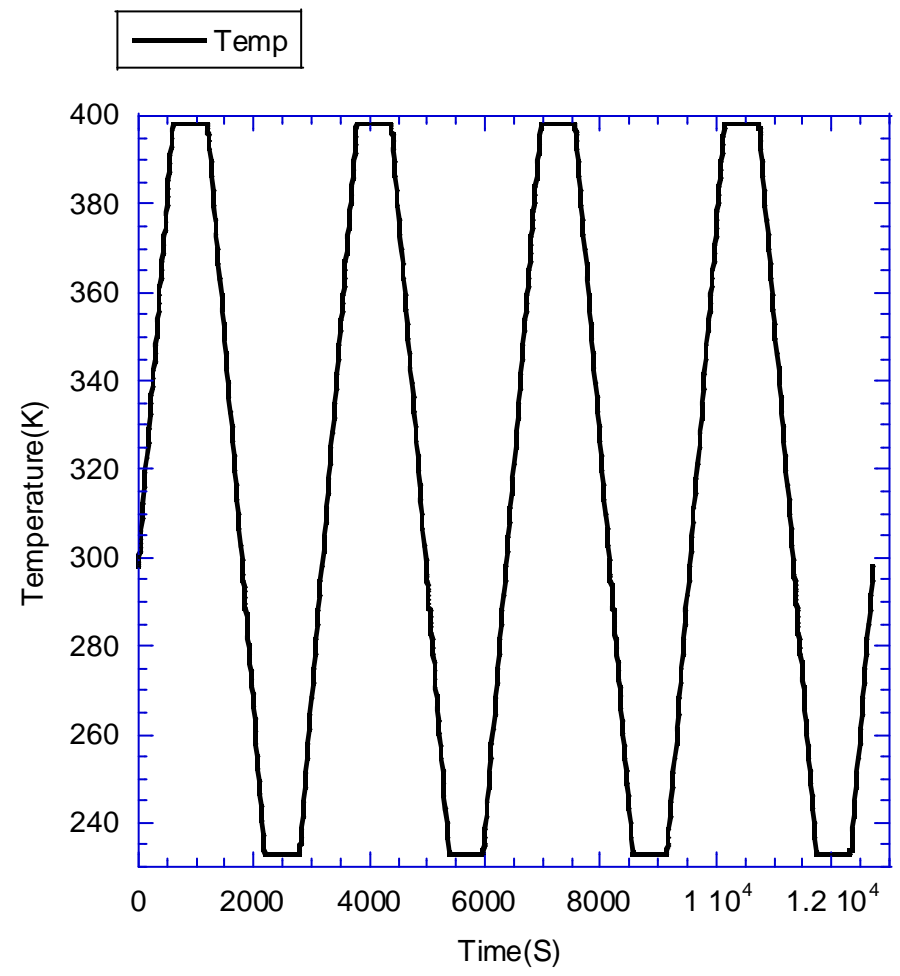

Figure 4-4 Temperature profile used for the FEA simulation

\subsubsection{Finite Element Modelling}

The coordinate system $(1,2,3)$ is interchangeably used with the coordinate system (x, $y, z$ ), and the 3 axis (z axis) is out-of-plane. The boundary conditions are set as fixed $\left(\mathrm{U}_{1}=\mathrm{U}_{2}=\mathrm{UR}_{3}=0\right)$ at the left bottom point of PCB and symmetry about the vertical axis $\left(\mathrm{U}_{1}=0\right)$ along left line of the chip scale package with eBGA. The stress-free state is considered at $\mathrm{T}_{\text {initial }}=25^{\circ} \mathrm{C}(298 \mathrm{~K})$.

Half of model is constructed due to geometric symmetry about the $\mathrm{x}$ axis. Linear elastic and viscoplastic behaviors of solders are considered. In addition, the eBGA and 20 
the chip scale package with the eBGA are studied. The eBGA consists of 14,352

elements and 44,354 nodes, while the chip scale package with the eBGA has 21,947

elements and 67,209 nodes.

\subsection{Linear Elastic FEA Results}

\subsection{1. eBGA}

As shown in Fig 4-5, one thermal cycle is considered.

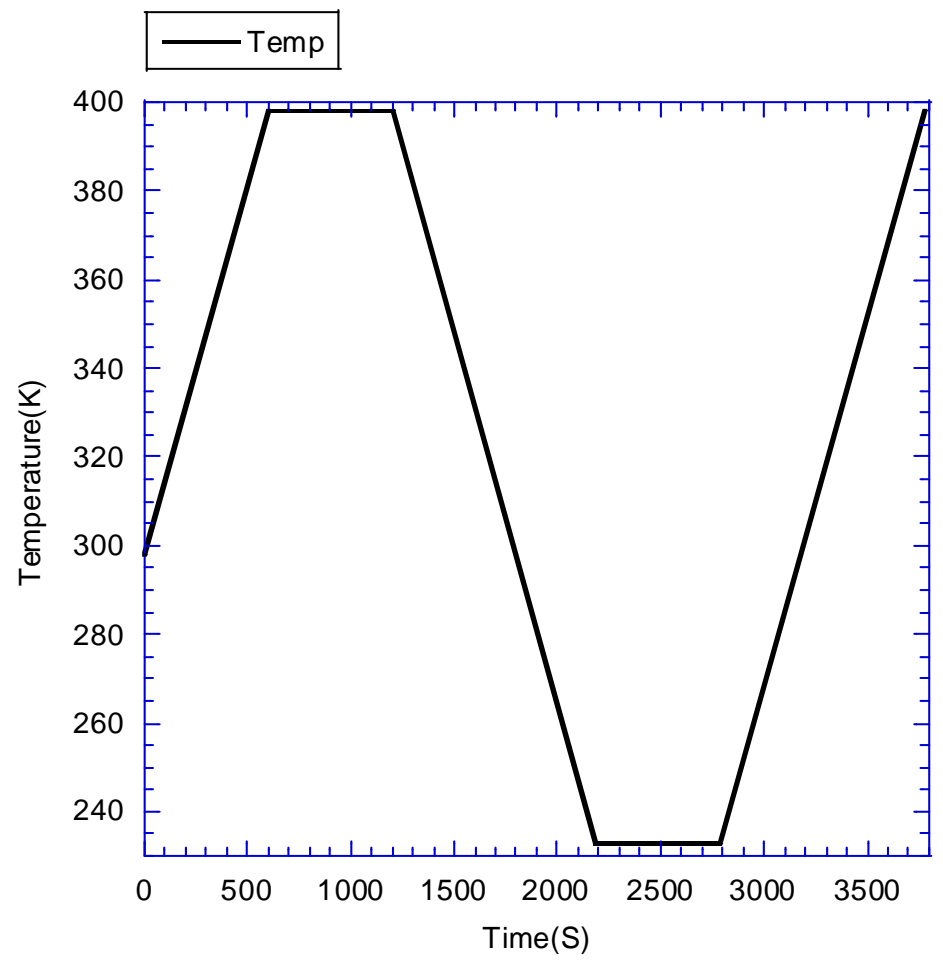

Figure 4-5 Thermal cycle applied for linear elastic FEA 


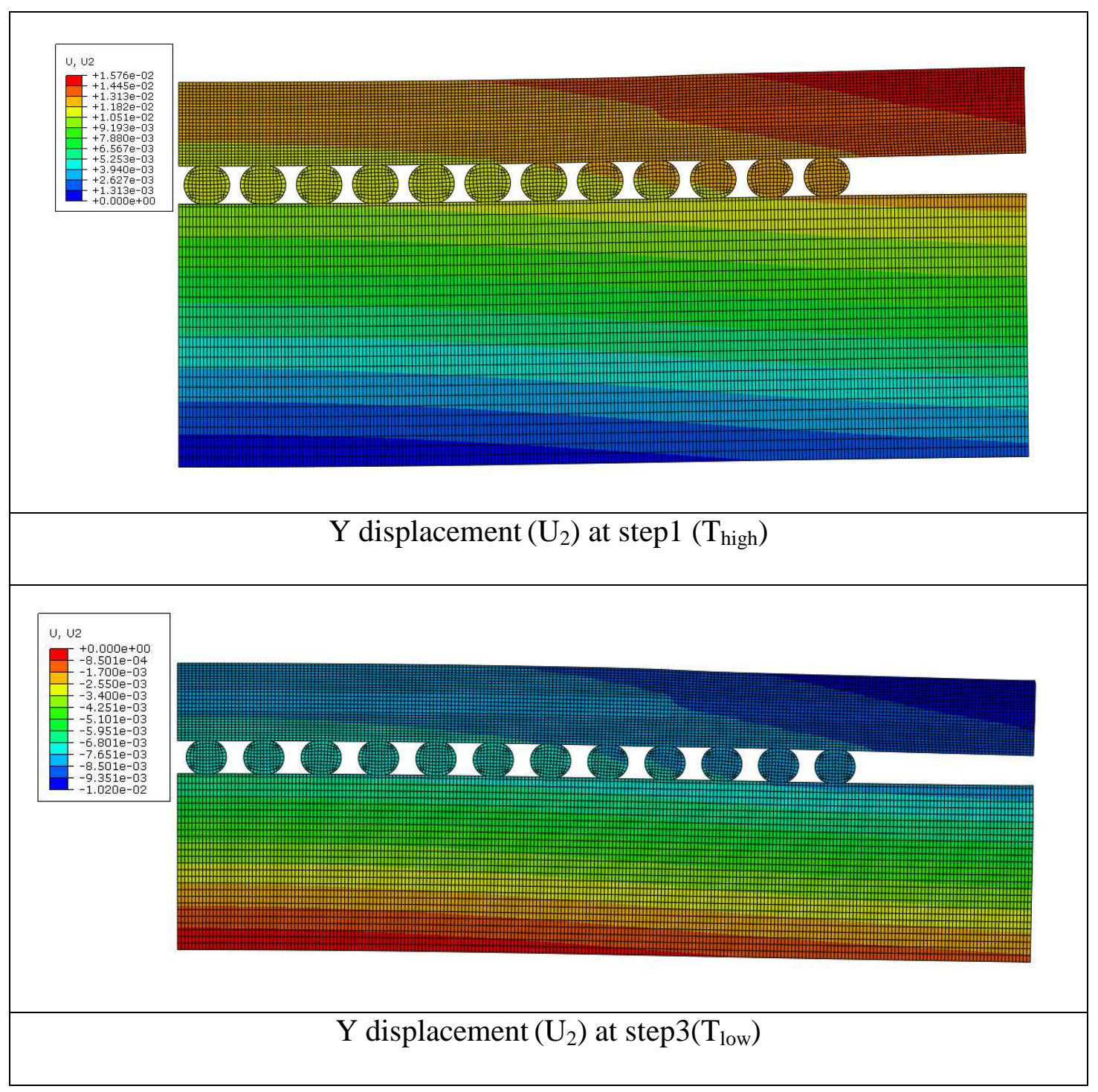

Figure 4-6 Y displacement $\left(\mathrm{U}_{2}\right)$ of eBGA 


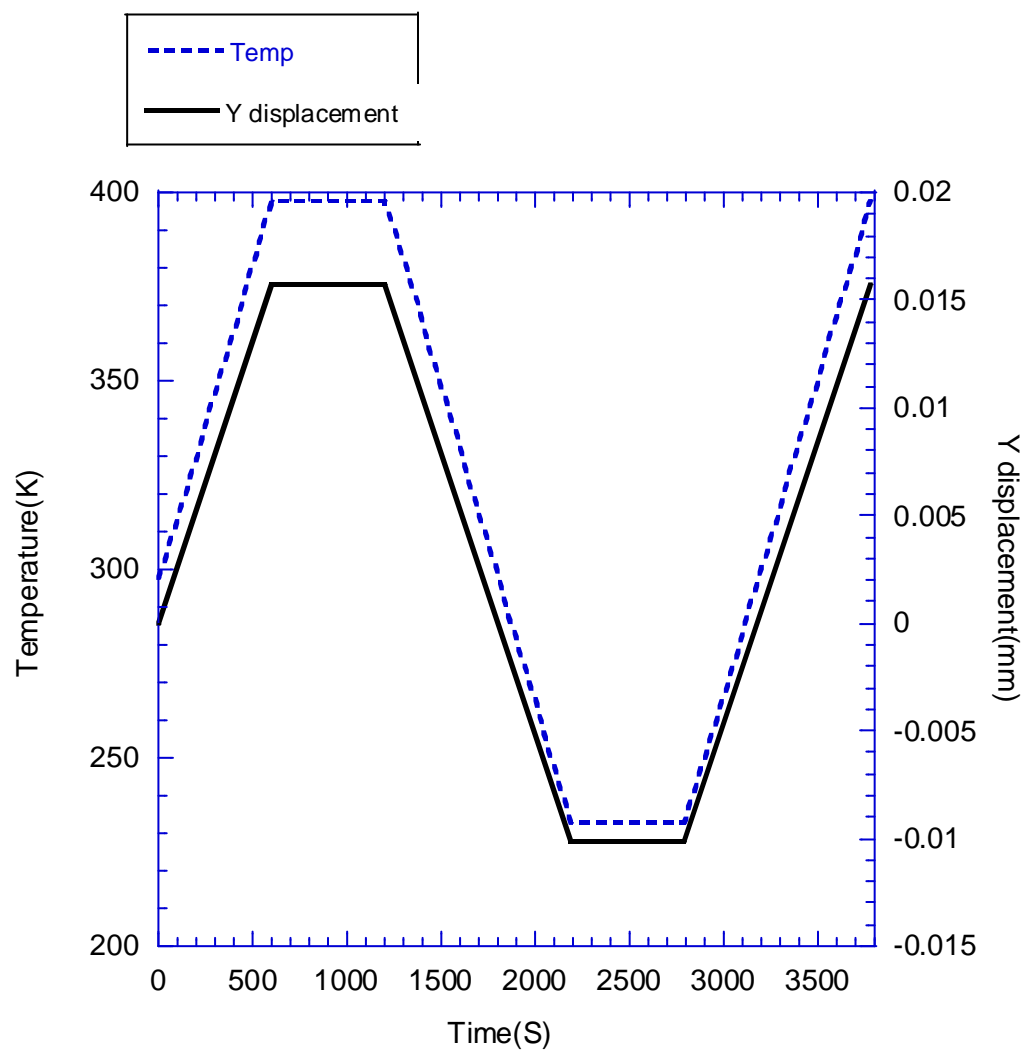

Figure 4-7 Variation of maximum displacement in the y-direction during thermal cycling

As shown in Figs. 4-6 to 4-7, for positive temperature change ( $\Delta T>0)$, the eBGA assembly bends upward (U-shape) because of the mismatch of CTEs among the materials, while it bends downward for negative temperature changes $(\Delta \mathrm{T}<0)$. The results agree with the results published in the reference (Yi et al., 2005). The maximum displacement in the y-direction of the eBGA package is obtained at the edge of the eBGA. For $\Delta \mathrm{T}=100$ and -65 degree $\mathrm{C}$, the maximum displacements are $0.01576 \mathrm{~mm}$ and $-0.0102 \mathrm{~mm}$, respectively. 


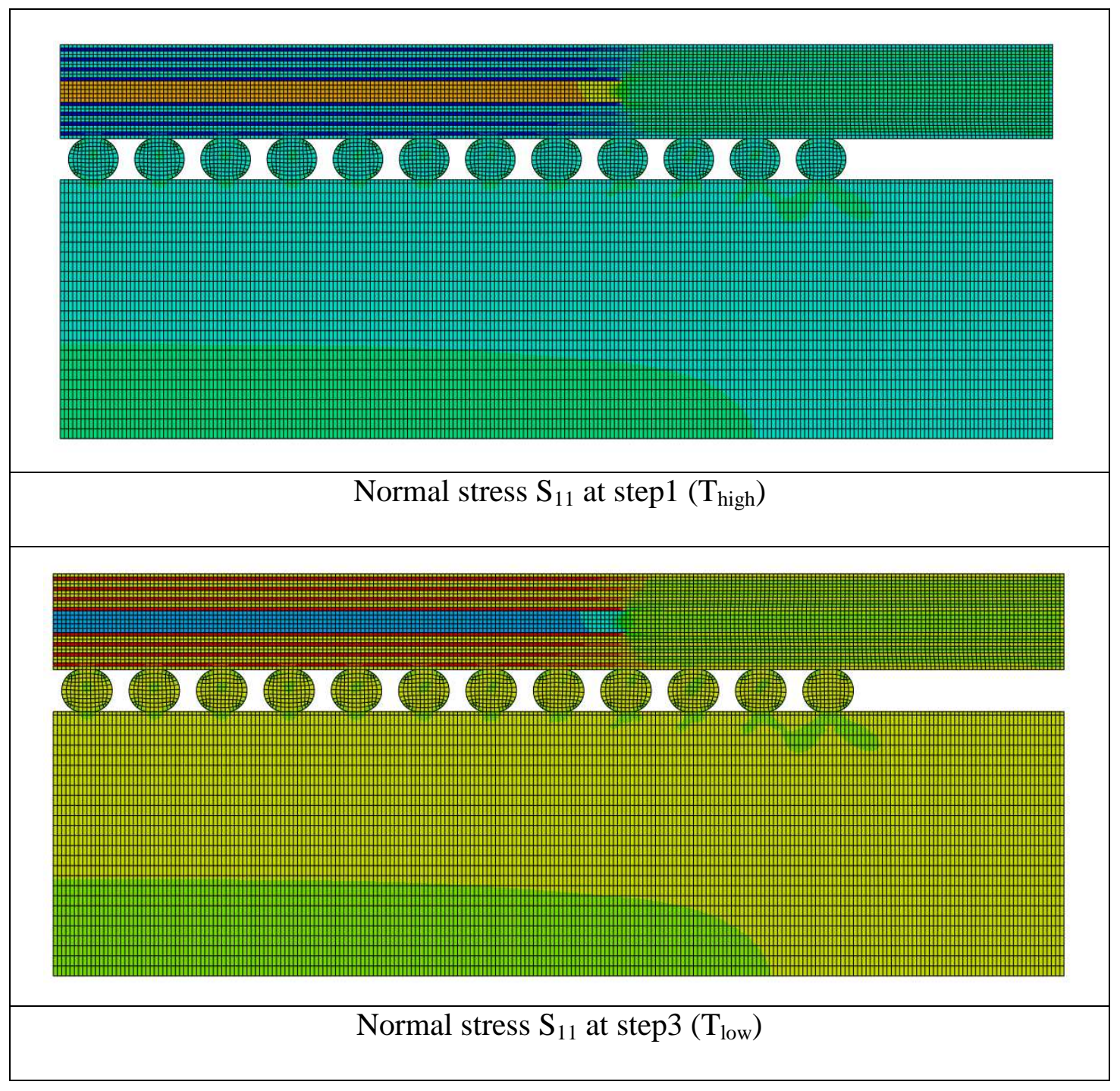

Figure 4-8 Normal stress $S_{11}$ in eBGA

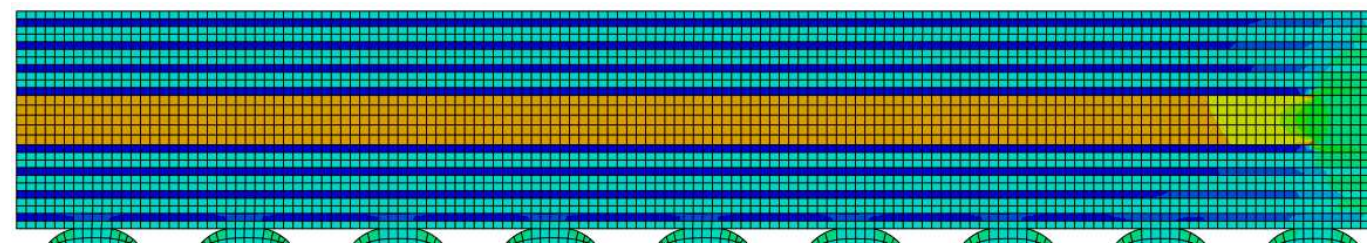

Figure 4-9 Normal stress $S_{11}$ in substrate at step1 ( $\left.T_{\text {high }}\right)$ 


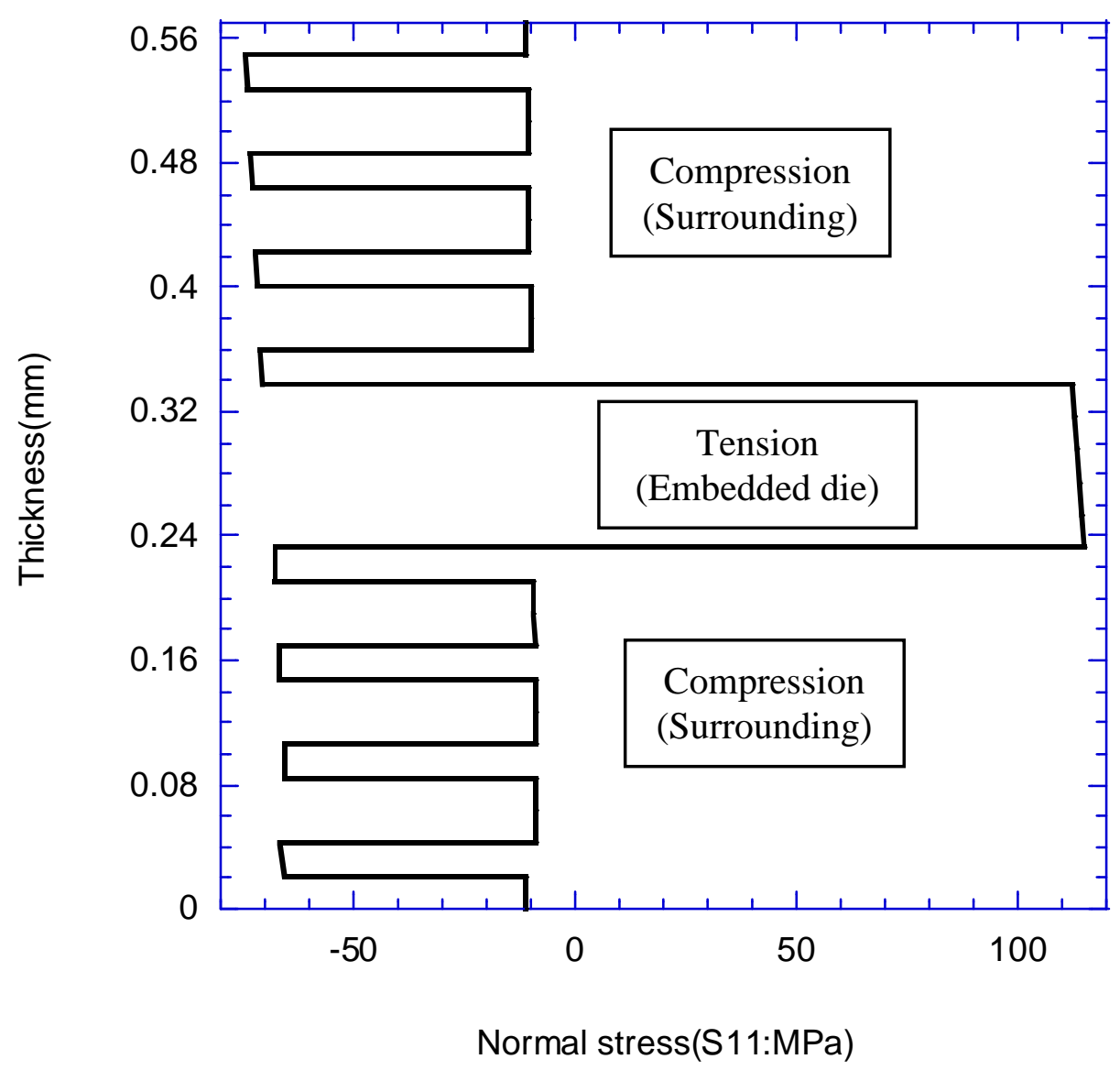

Figure 4-10 Variation of the normal stress $S_{11}$ through the thickness of substrate at step1 $\left(\mathrm{T}_{\text {high }}\right)$

As shown in Figs. 4-8, 4-9, and 4-10, for positive temperature change $(\Delta \mathrm{T}>0)$, the embedded die is in tension, while the surrounding of embedded die is in compression along the $\mathrm{x}$ axis since the surrounding of embedded die tries to expand more than the 25 
embedded die and these two parts are held together. The opposite is observed at $\Delta \mathrm{T}<0$ as shown in Fig 4-8. These agree with the results published in the reference (Yi et al., 2012).

As shown in Fig. 4-10, the maximum tensile stress $S_{11}$ in the substrate at step1 $\left(T_{\text {high }}\right)$ is 115.028 MPa and is observed at the bottom of the embedded die. The surroundings of the embedded die in the substrate are in compression and high compressive stresses are observed in the copper layers. The maximum compressive stress in the copper layer at step1 $\left(\mathrm{T}_{\text {high }}\right)$ is $-74.3921 \mathrm{MPa}$, which is observed at the first copper layer from the top. The maximum compressive stress of other surroundings except copper layers is $-11.2614 \mathrm{MPa}$, which is observed at the first solder mask layer from the top.

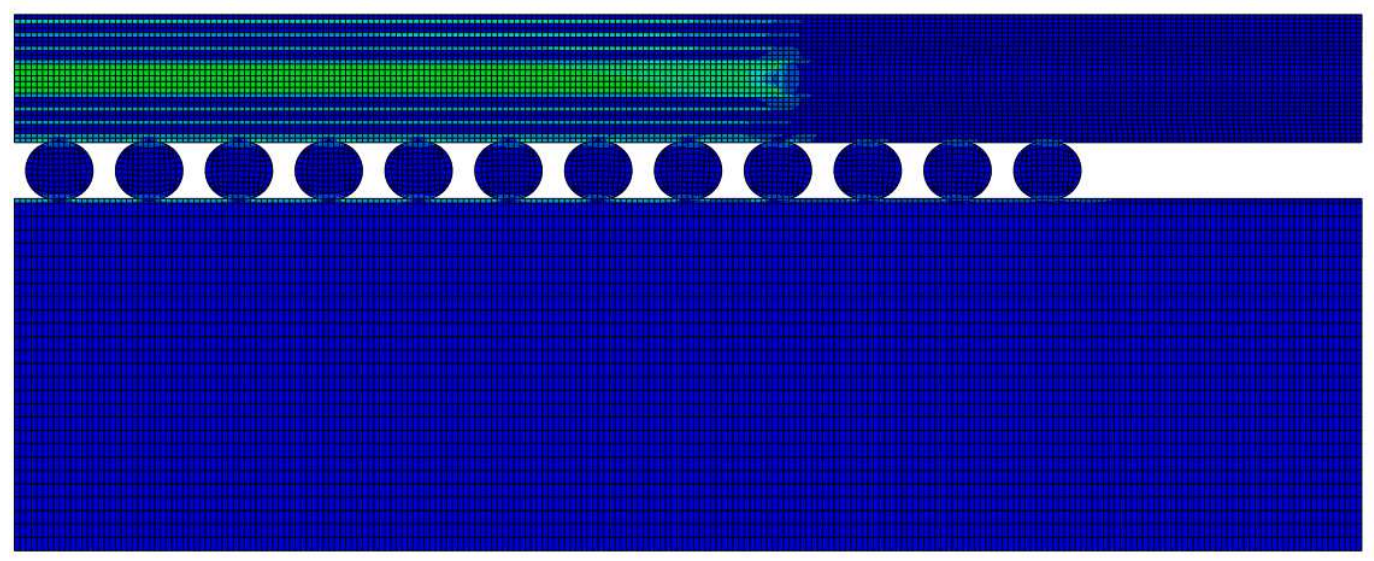

Figure 4-11 von Mises stress $\left(\mathrm{S}_{\text {mises }}\right)$ in eBGA at step1 $\left(\mathrm{T}_{\text {high }}\right)$ 


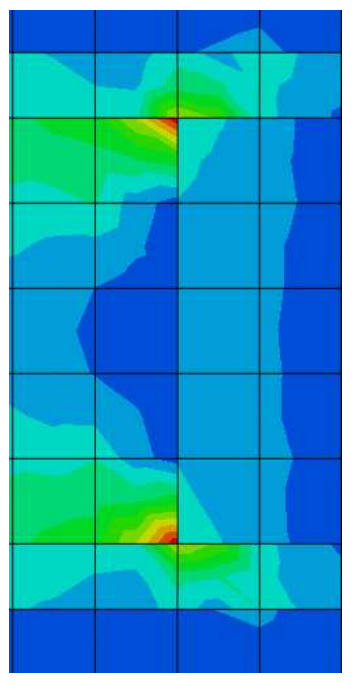

Figure 4-12 von Mises stress $\left(\mathrm{S}_{\text {mises }}\right)$ in embedded die at step1( $\left.\mathrm{T}_{\text {high }}\right)$

As shown in Figs. 4-11 and 4-12, the highest von Mises stress $\left(\mathrm{S}_{\mathrm{mises}}\right)$ is observed at the contact area between the embedded die and the core. Actually, the die corner and the core corner experience the highest von Mises stress at both high and low temperatures. This is because geometric discontinuities and stress concentration happen in these corners. The high von Mises stress at the die corner may exceed the adhesive strength between the build-up layer and the die surface, resulting in delamination. This agrees to the well-known die corner delamination phenomenon seen in industry during reliability test (Yi et al, 2005). The von Mises stresses of the embedded die corner and all solder balls in eBGA at step1 $\left(\mathrm{T}_{\text {high }}\right)$ are tabulated in Table 4-5. 


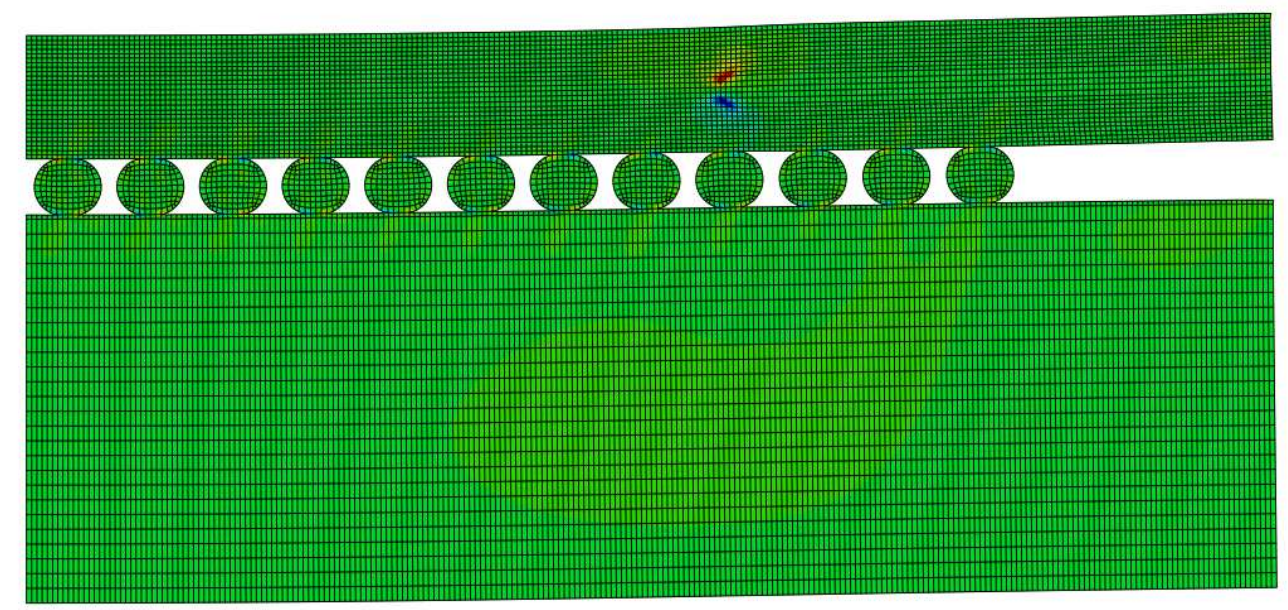

Figure 4-13 Shear stress $S_{12}$ in eBGA at step1 $\left(T_{\text {high }}\right)$

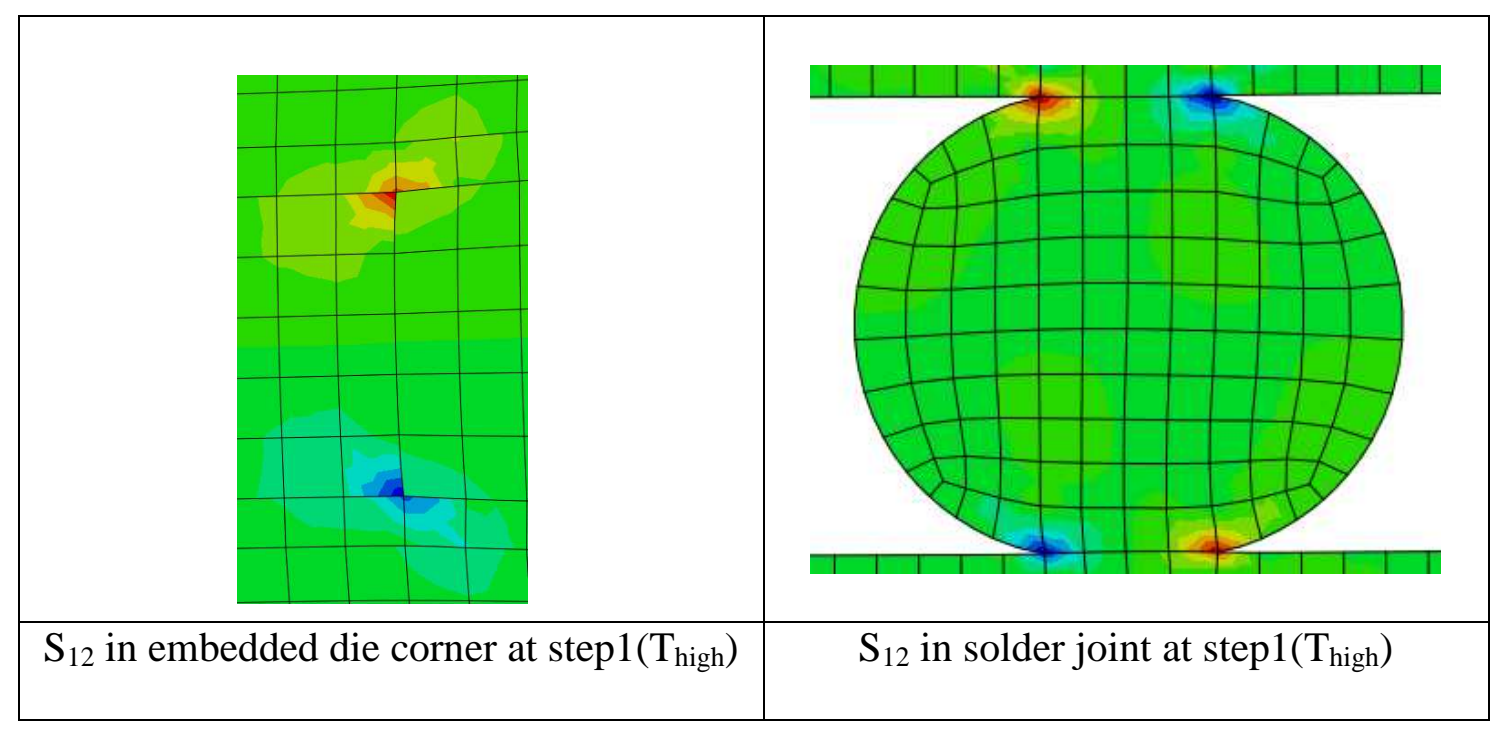

Figure 4-14 Shear stresses $S_{12}$ in embedded die corner and solder joint at step1 $\left(T_{\text {high }}\right)$

As shown Figs. 4-11 and 4-12, high shear stresses $S_{12}$ are observed in the embedded die corner and the solder joint. The maximum shear stress $S_{12}$ in the eBGA exists at the embedded die corner and is $50.9775 \mathrm{MPa}$. Also, the $9^{\text {th }}$ solder joint from the $\mathrm{x}$ 
origin has the highest shear stress $\mathrm{S}_{12}$ of $-16.51 \mathrm{MPa}$ among solder joints. The shear stresses $S_{12}$ of the embedded die corner and all solder balls in the eBGA at step1 ( $T_{\text {high }}$ ) are tabulated in Table 4-5.

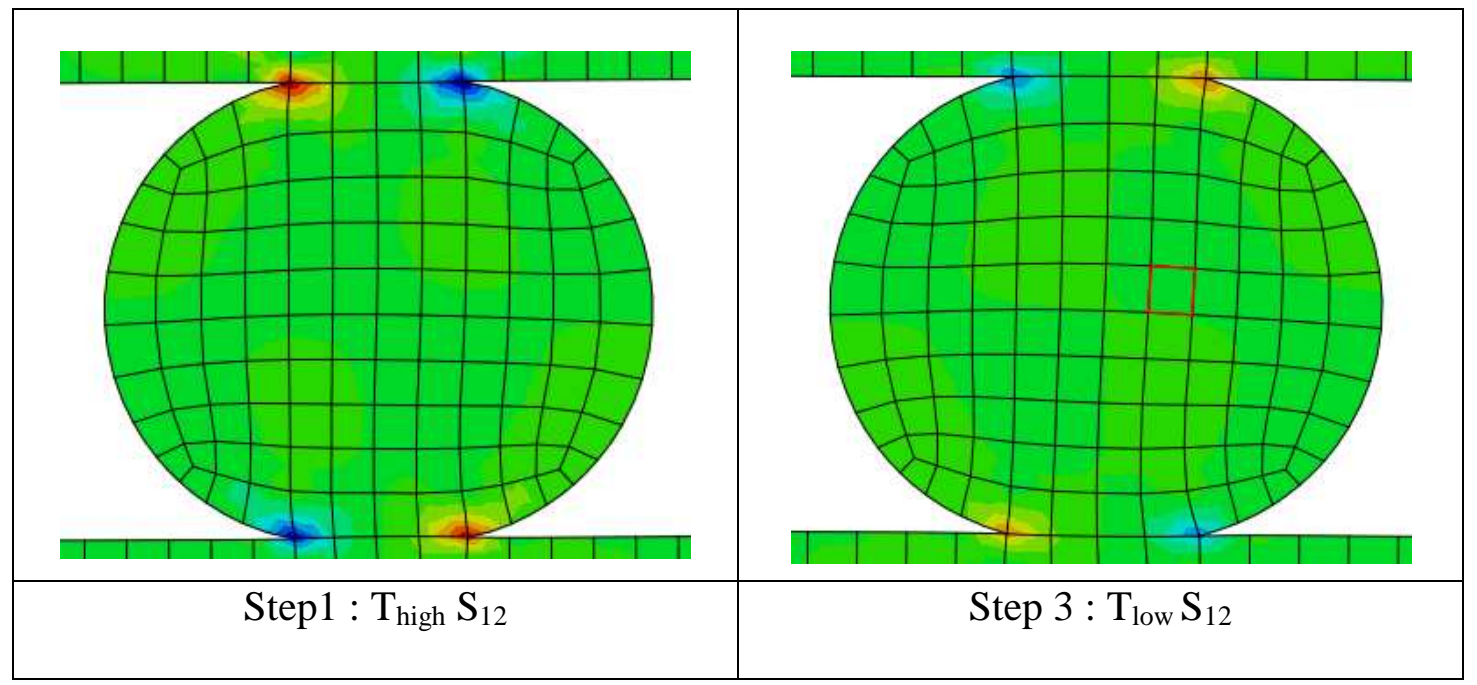

Figure 4-15 Shear Stress $\mathbf{S}_{12}$ in Solder Joints

As shown in Fig 4-15, the positive and negative shear stress is developed in the solder joint during thermal cycles. The shear stress near the right corner of the solder ball is compressive at $\mathrm{T}_{\text {high, }}$, while it is tensile at $\mathrm{T}_{\text {low. }}$. The distribution of shear stress in solder joint is almost diagonally symmetric.

Table 4-5 Shear stress and von Mises Stress of embedded die corner and all solder balls in eBGA at Step1 $\left(\mathrm{T}_{\text {high }}\right)$

\begin{tabular}{|c|c|c|}
\hline Solder & $\begin{array}{c}\text { Shear Stress }\left(\mathrm{S}_{12}\right) \\
(\mathrm{MPa})\end{array}$ & $\begin{array}{c}\text { von Mises Stress }\left(\mathrm{S}_{\text {mises }}\right) \\
(\mathrm{MPa})\end{array}$ \\
\hline $1^{\text {st }}$ Solder Ball & -13.91 & 33.51 \\
\hline $2^{\text {th }}$ Solder Ball & -14.20 & 33.99 \\
\hline
\end{tabular}




\begin{tabular}{|c|c|c|}
\hline $3^{\text {th }}$ Solder Ball & -13.89 & 32.01 \\
\hline $4^{\text {th }}$ Solder Ball & -14.91 & 35.24 \\
\hline $5^{\text {th }}$ Solder Ball & -15.33 & 36.03 \\
\hline $6^{\text {th }}$ Solder Ball & -14.88 & 34.10 \\
\hline $7^{\text {th }}$ Solder Ball & -15.43 & 35.22 \\
\hline $8^{\text {th }}$ Solder Ball & -15.67 & 35.43 \\
\hline $9^{\text {th }}$ Solder Ball & -16.51 & 37.15 \\
\hline (near the end of embedded die) & -13.72 & 31.56 \\
\hline $10^{\text {th }}$ Solder Ball & -12.34 & 27.90 \\
\hline $11^{\text {th }}$ Solder Ball & -10.94 & 24.60 \\
\hline $12^{\text {th }}$ Solder Ball & 50.98 & 116.46 \\
\hline The lower corner of embedded die & -49.91 & 115.06 \\
\hline The Upper corner of embedded die & & \\
\hline
\end{tabular}

Note that stresses in solder joints are measured at the most upper right element.

As seen from Table 4-6, the shear stress and the von Mises stress in the solder ball tend to increase except the $3^{\text {th }}$ solder ball and the $6^{\text {th }}$ solder ball as the distance in the $\mathrm{x}$-direction increases until the $9^{\text {th }}$ solder ball. Then, those stresses in the $10^{\text {th }} \sim 12^{\text {th }}$ solder joints decrease as the $\mathrm{x}$ distance increases. Namely, the highest stress among the solder joints occurs in the $9^{\text {th }}$ solder joint, which is near the end of the embedded die. The shear strain in the solder join can be expressed as

$$
\gamma=\frac{l}{2 h}\left(\alpha_{s}-\alpha_{p}\right) \square T
$$


where $\gamma=$ the shear strain, $\alpha_{S}=$ the coefficient of thermal expansion(CTE) of substrate, $\alpha_{p}=$ the coefficient of thermal expansion(CTE) of PCB, l= the length, $h=$ the height of solder, and $\Delta \mathrm{T}=$ temperature difference.

According to the equation above, the shear stress $\mathrm{S}_{12}$ of solder joint is proportional to the distance from origin. Therefore, it is reasonable that the $9^{\text {th }}$ solder joint has the highest shear stress in the eBGA.

During thermal cycling, the various stresses including the normal stress, the shear stress, and the von Mises stress in the right corner of $9^{\text {th }}$ solder ball are plotted in Figs. 4-16 and 4-17. The stresses of solder joints are proportional to temperature change linearly and don't change during dwelling. 


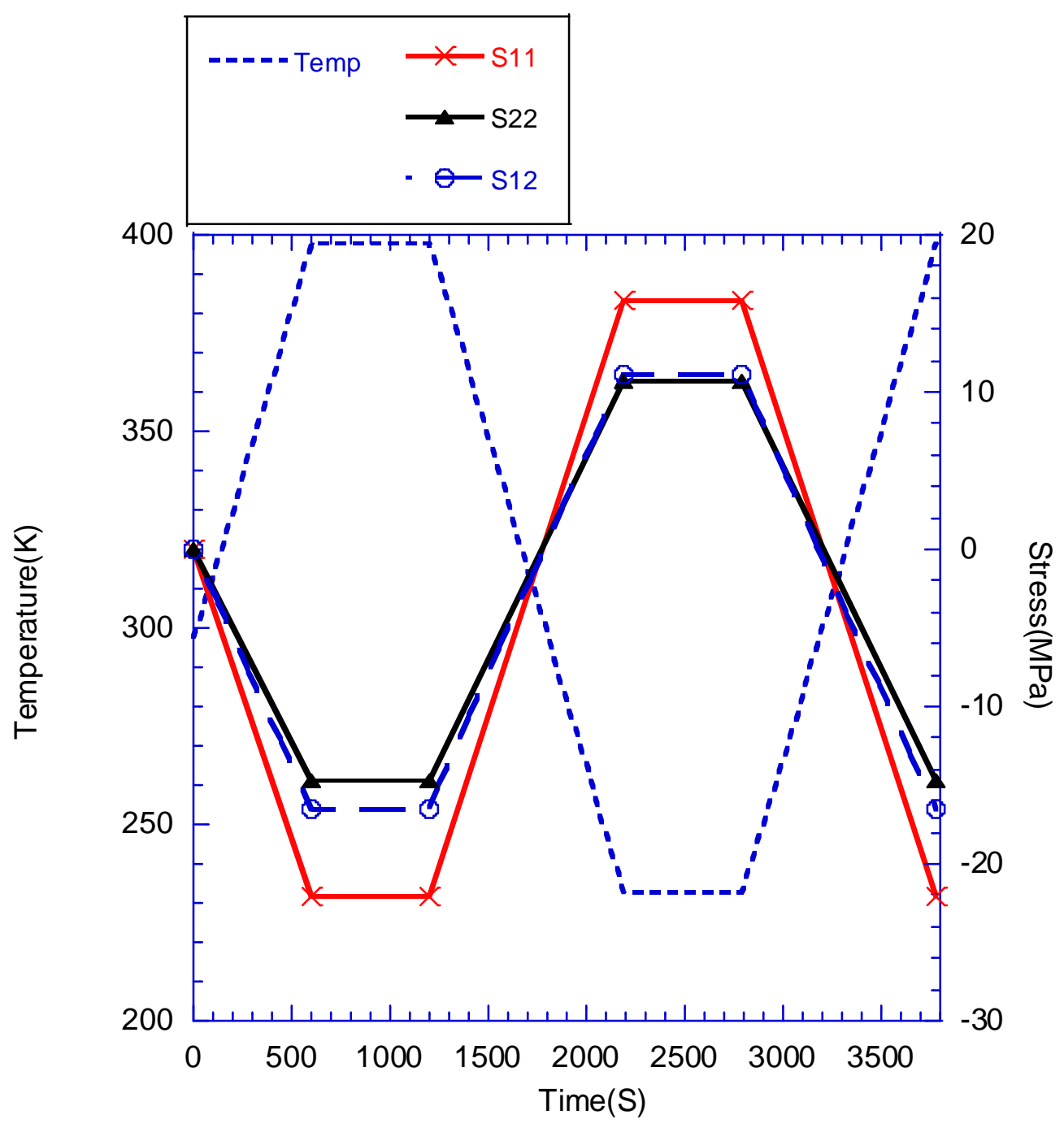

Figure 4-16 Normal stresses $\left(\mathrm{S}_{11}\right.$ and $\left.\mathrm{S}_{22}\right)$ and shear stress $\left(\mathrm{S}_{12}\right)$ during thermal cycling 


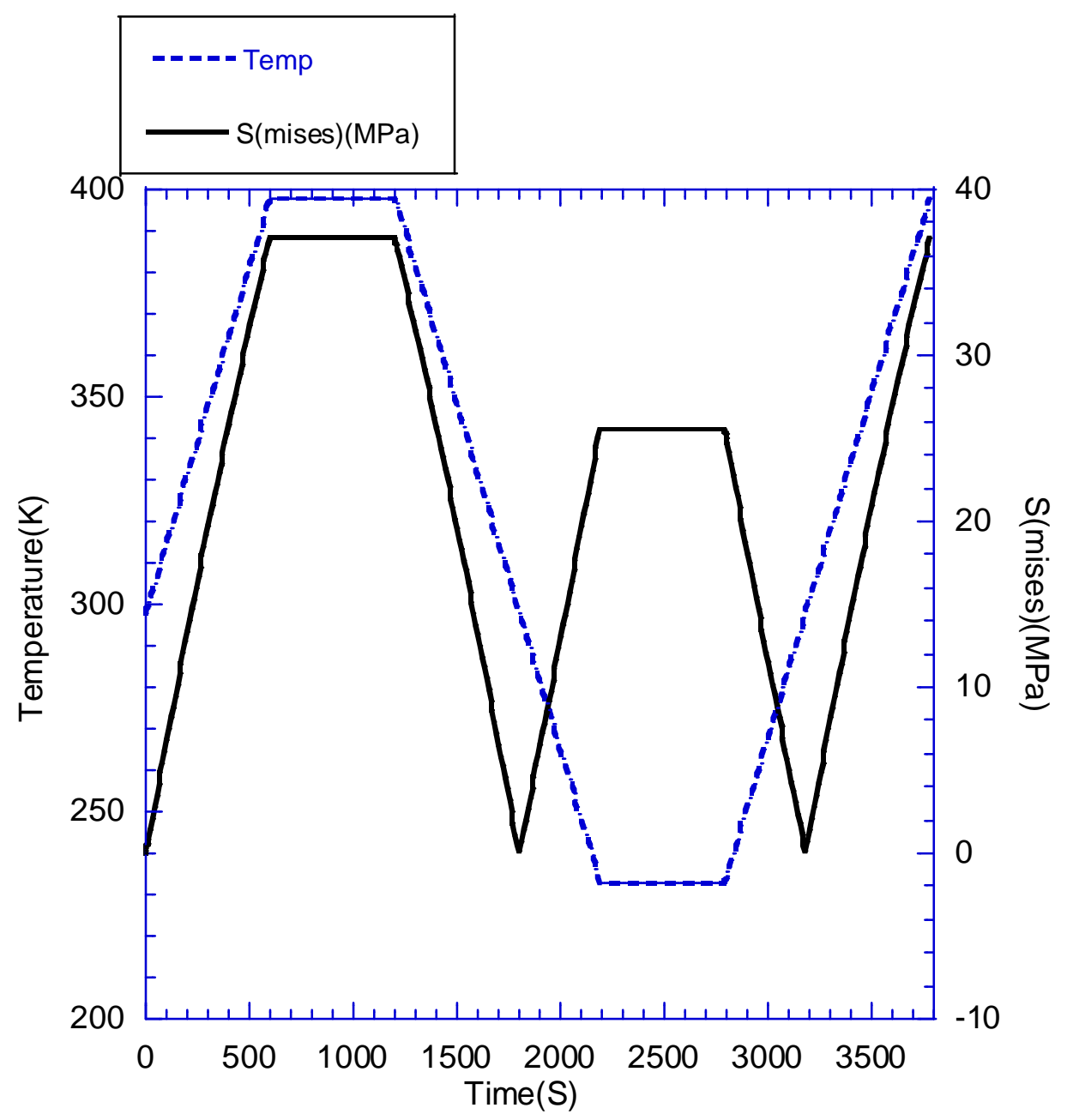

Figure 4-17 von Mises stress ( $\left.\mathrm{S}_{\text {mises }}\right)$ during thermal cycling

\subsubsection{Chip Scale Package with eBGA}

The linear elastic response of the chip scale package with the eBGA is analyzed with ABAQUS. In this case, one thermal cycle that is described in the previous section is considered. 


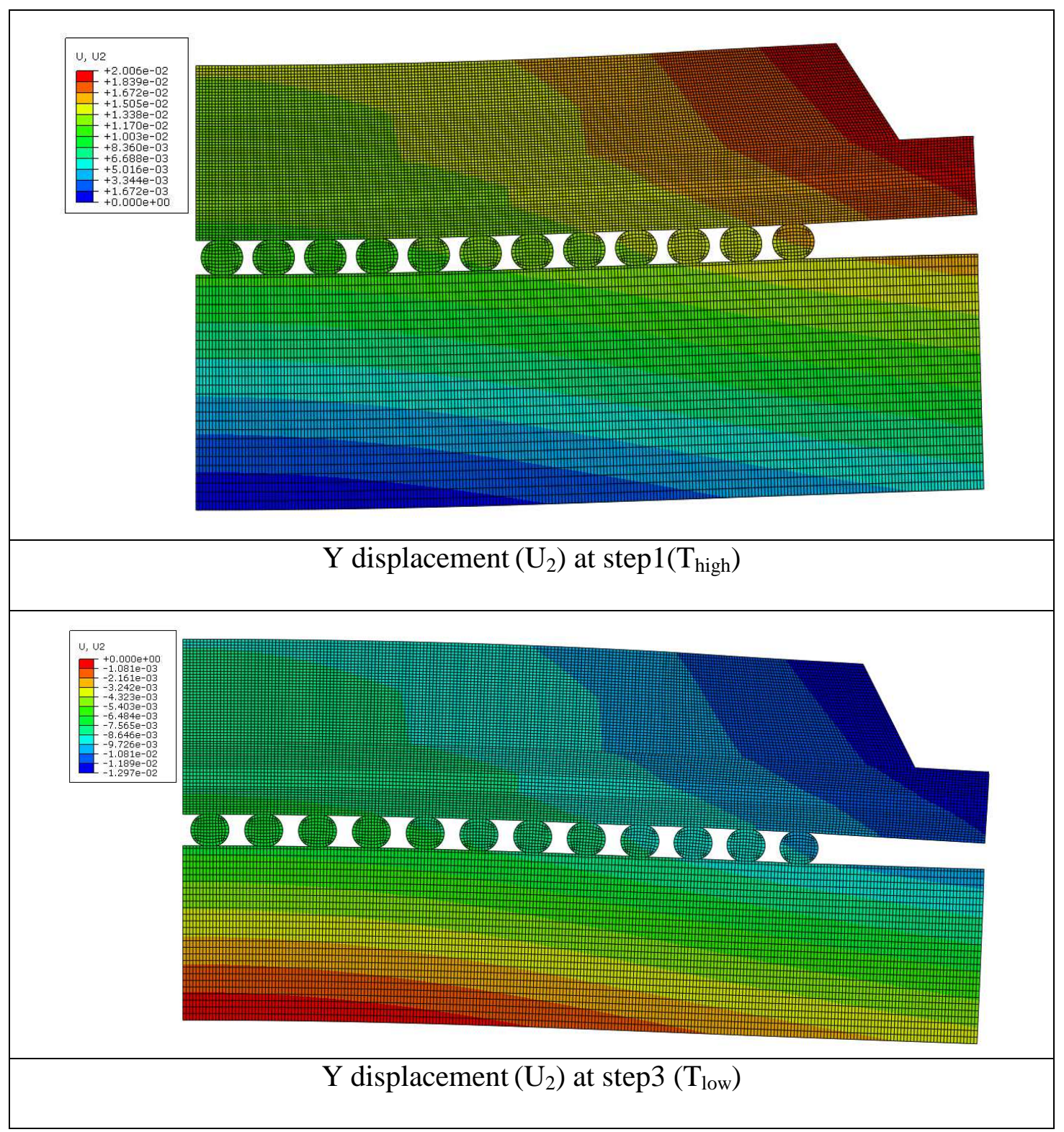

Figure 4-18 Y displacement $\left(\mathrm{U}_{2}\right)$ in CSP with eBGA

As seen in Fig. 4-18, for positive temperature change $(\Delta \mathrm{T}>0)$, the eBGA assembly bends upward (U-shape) due to the thermal expansion/mismatch among the materials, while it bends downward for negative temperature changes $(\Delta \mathrm{T}<0)$. These agree with the results of previous eBGA case. The maximum displacement in the y-direction of 
the CSP with eBGA package is obtained at the edge of the CSP which is the same location with previous eBGA. For positive temperature change $\Delta \mathrm{T}=100$ degree $\mathrm{C}$, it is $0.02006 \mathrm{~mm}$ and is increased by $27.3 \%$ when compared with the eBGA. For negative temperature change $\Delta \mathrm{T}=-65$ degree $\mathrm{C}$, it is $-0.01297 \mathrm{~mm}$ and is $27.15 \%$ larger when compared with the eBGA.

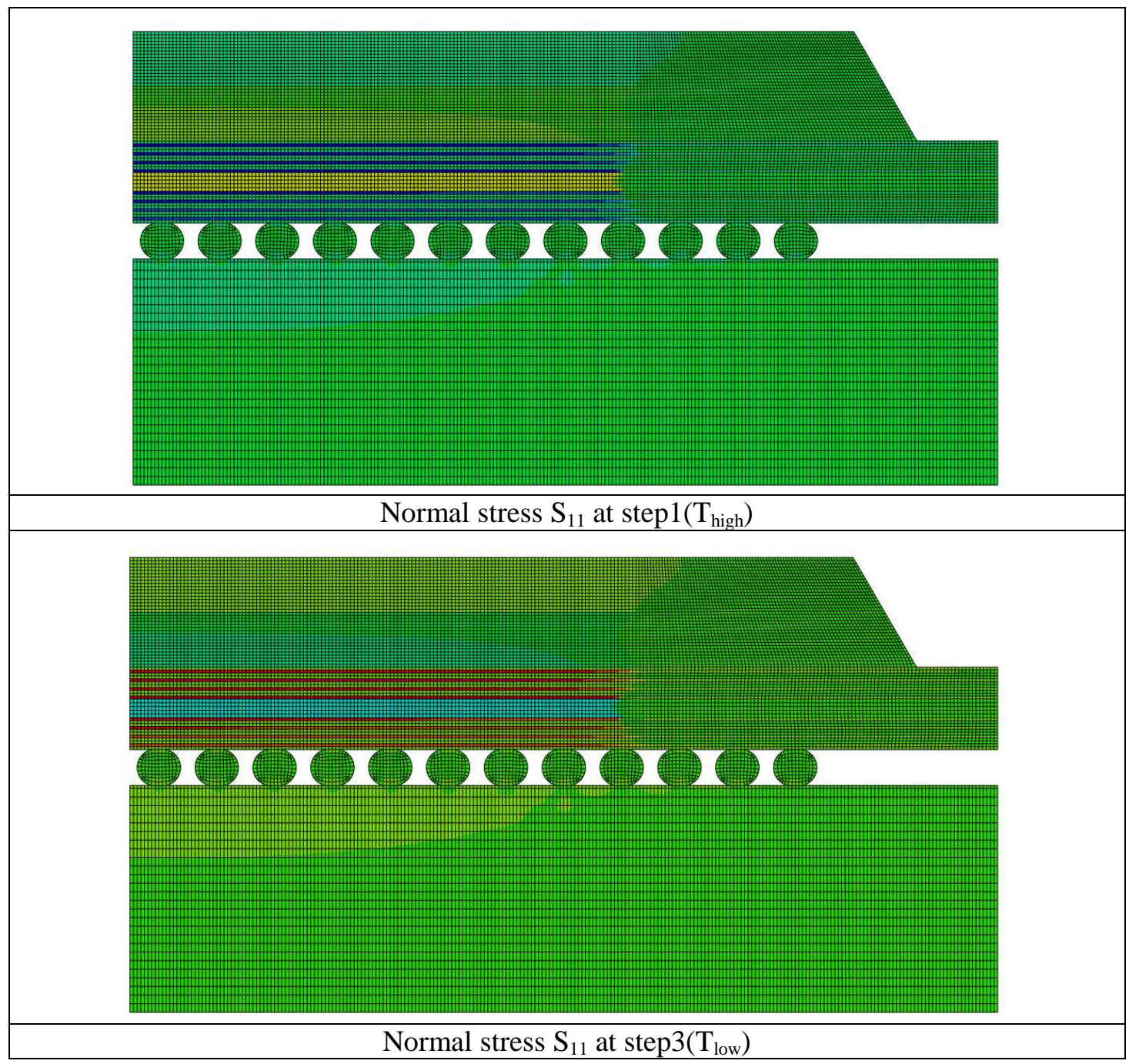

Figure 4-19 Normal stress in the $\mathrm{x}$ direction of CSP with eBGA 
As plotted in Fig. 4-19, for positive temperature change $(\Delta \mathrm{T}>0)$, the upper die and the embedded die are in tension, while the surroundings of the upper die and the embedded die are in compression along the $\mathrm{x}$ axis since the surroundings of those dies expand more than those die. The opposite is observed at $\Delta \mathrm{T}<0$ as shown in Fig 4-19. These agree with the results of the previous eBGA.

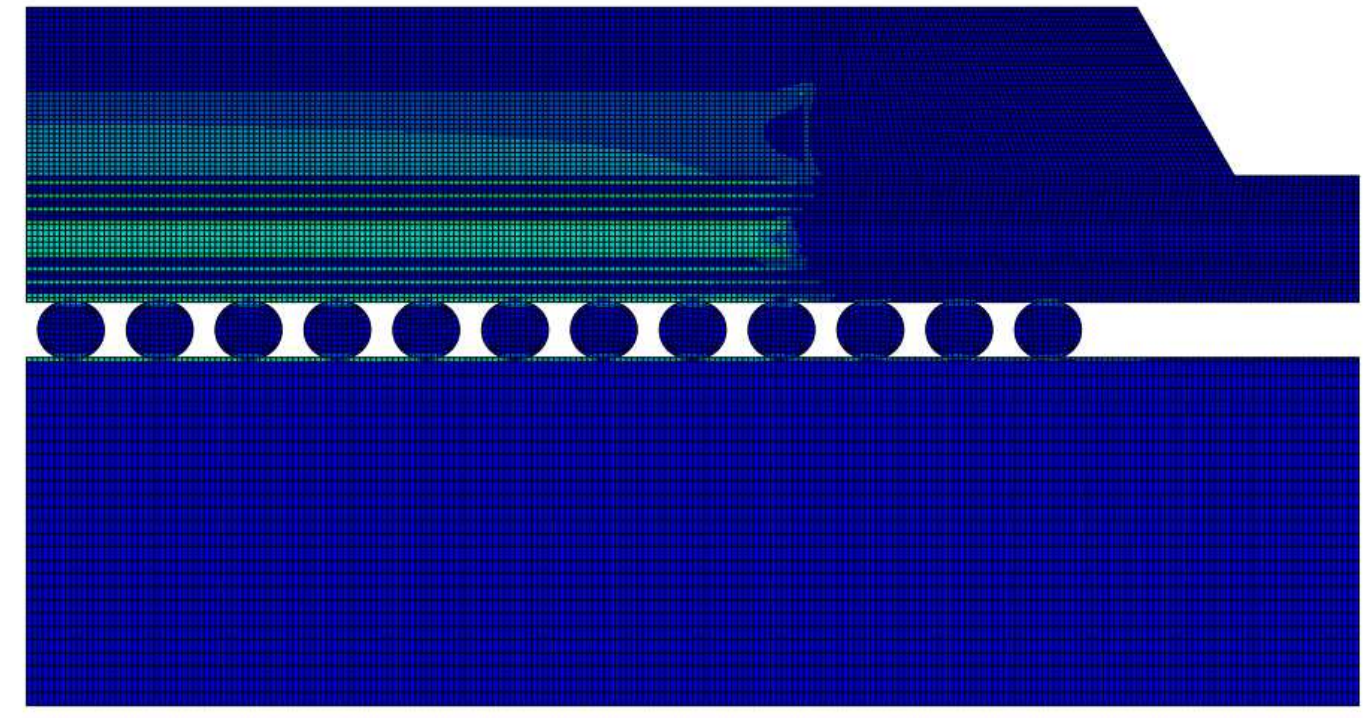

Figure 4-20 von Mises Stress ( $\left.\mathrm{S}_{\text {mises }}\right)$ of CSP with eBGA at step1( $\left.\mathrm{T}_{\mathrm{high}}\right)$

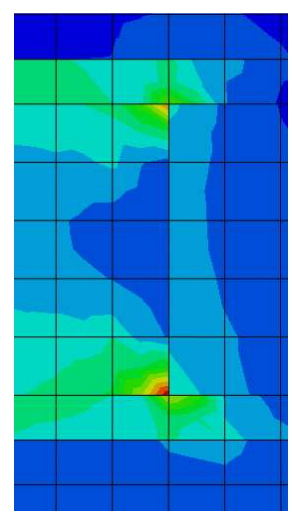

Figure 4-21 von Mises stress ( $\left.S_{\text {mises }}\right)$ near embedded die corner at step1( $\left.T_{\text {high }}\right)$ 
As shown in Figs. 4-20 and 4-21, the highest von Mises stress $\left(S_{\text {mises }}\right)$ is observed at the contact area between the embedded die and the core. This agrees with the result of the previous eBGA. The von Mises stresses of the embedded die corner and all solder balls in the CSP with the eBGA at step1 $\left(\mathrm{T}_{\text {high }}\right)$ are tabulated in Table 4-7.

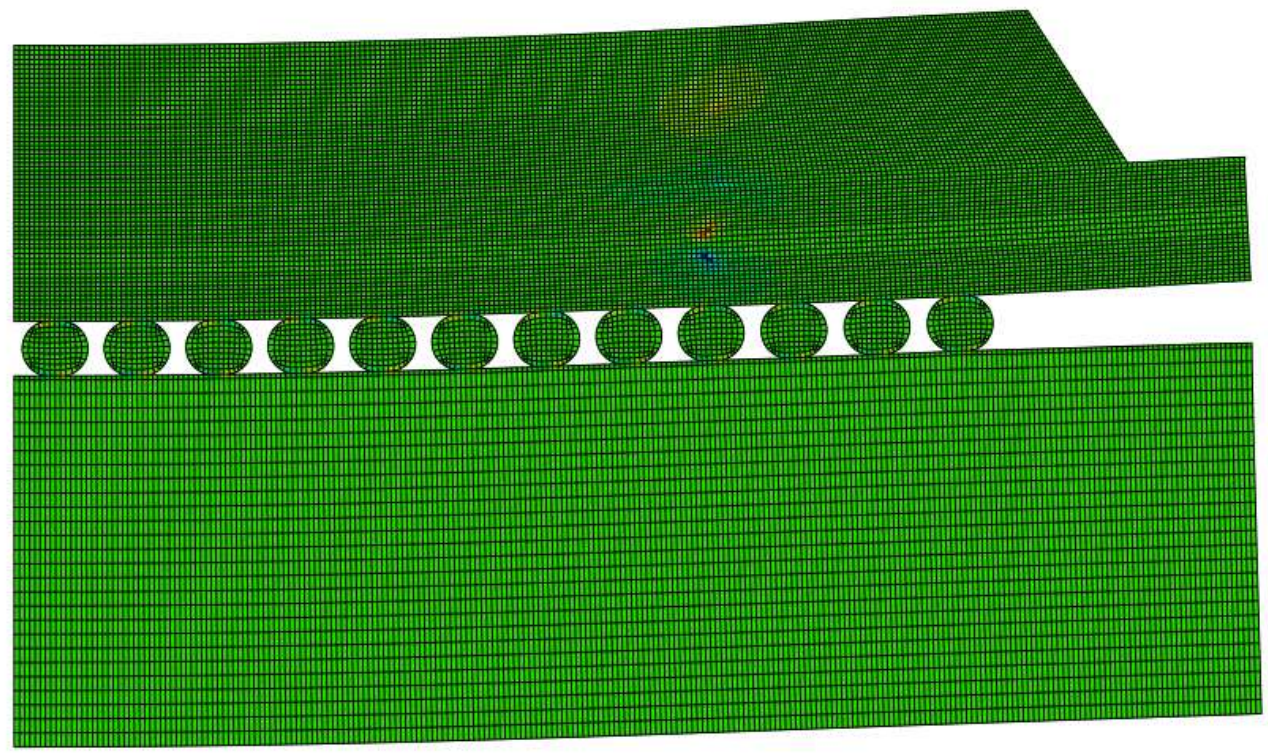

Figure 4-22 Shear stress $S_{12}$ of CSP with eBGA at step1( $\left.T_{\text {high }}\right)$

As illustrated in Figs. 4-22 and 4-23, high shear stresses $S_{12}$ are observed in the embedded die corner and the solder joint. For the CSP with eBGA, a maximum shear stress of $-52.19 \mathrm{MPa}$ exists at the embedded die corner. Also, the $9^{\text {th }}$ solder joint has the highest shear stress among the solder joints and the shear stress value is -16.61 MPa. The shear stresses of the embedded die corner and all solder balls in the CSP with eBGA at step1 ( $\left.\mathrm{T}_{\text {high }}\right)$ are tabulated in Table 4-6. 


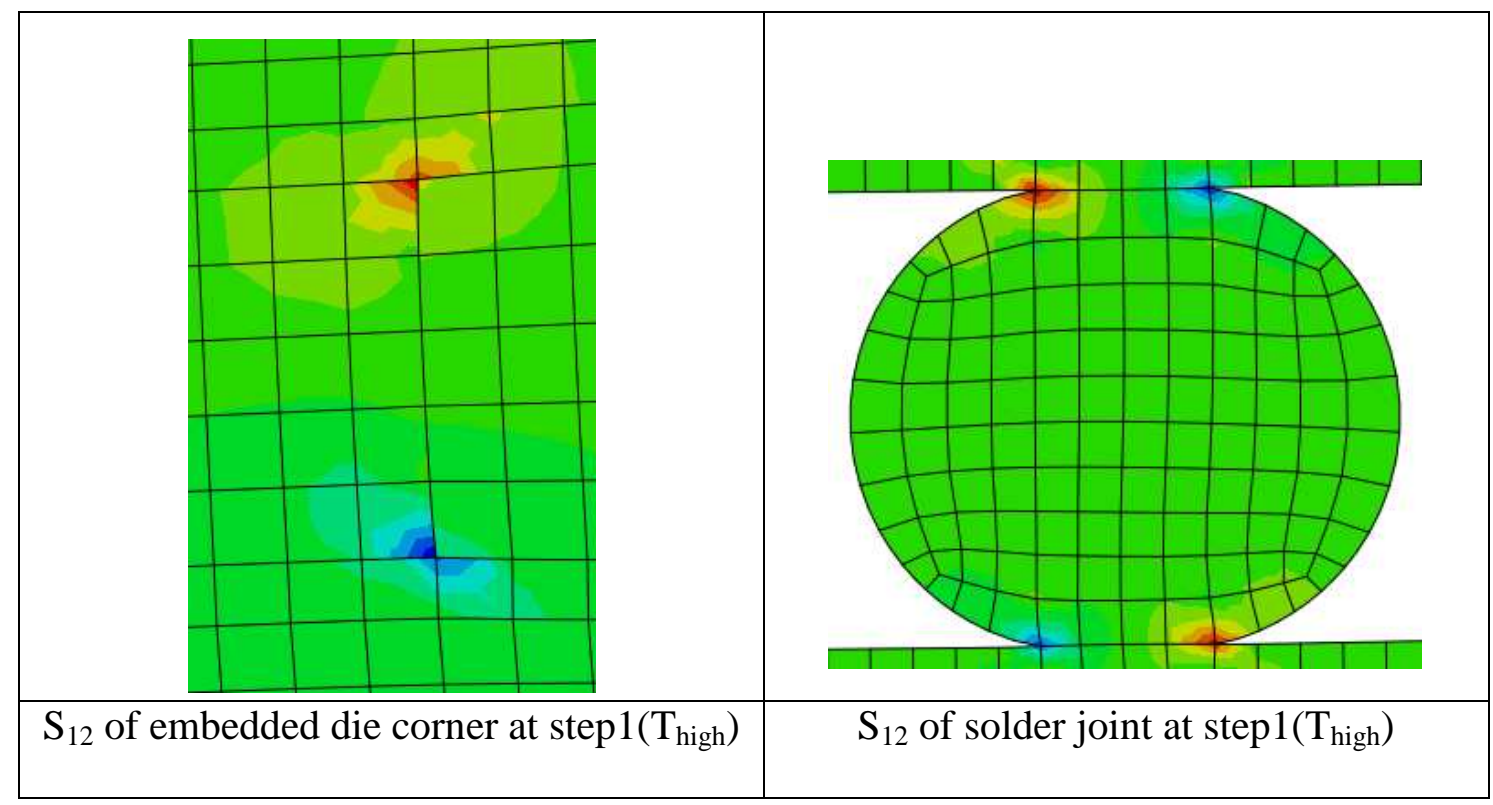

Figure 4-23 Shear stresses in embedded die corner and solder joint at step1( $\left.\mathrm{T}_{\mathrm{high}}\right)$

Table 4-6 Stresses in eBGA and CSP

\begin{tabular}{|c|c|c|c|c|c|c|c|c|}
\hline \multirow{2}{*}{ Location } & \multicolumn{2}{|c|}{ eBGA } & \multicolumn{2}{c|}{ CSP with eBGA } & \multicolumn{2}{c|}{ Shear Stress $\left(\mathrm{S}_{12}\right)$} & \multicolumn{2}{|c|}{$\begin{array}{c}\text { von Mises Stress } \\
\left(\mathrm{S}_{\text {mises })}\right.\end{array}$} \\
\cline { 2 - 9 } & $\begin{array}{c}\mathrm{S}_{12} \\
(\mathrm{MPa})\end{array}$ & $\begin{array}{c}\mathrm{S}_{\text {mises }} \\
(\mathrm{MPa})\end{array}$ & $\begin{array}{c}\mathrm{S}_{12} \\
(\mathrm{MPa})\end{array}$ & $\begin{array}{c}\mathrm{S}_{\text {mises }} \\
(\mathrm{MPa})\end{array}$ & $\begin{array}{c}\text { Diffe } \\
\text { rence }\end{array}$ & $\begin{array}{c}\text { Percent } \\
(\%)\end{array}$ & $\begin{array}{c}\text { Diffe } \\
\text { rence }\end{array}$ & $\begin{array}{c}\text { Percent } \\
(\%)\end{array}$ \\
\hline $1^{\text {st }}$ Solder & -13.91 & 33.51 & -15.01 & 36.37 & -1.10 & 7.91 & 2.86 & 8.52 \\
\hline $2^{\text {th }}$ Solder & -14.20 & 33.99 & -15.01 & 36.36 & -0.81 & 5.67 & 2.38 & 7.00 \\
\hline $3^{\text {th }}$ Solder & -13.89 & 32.01 & -14.47 & 33.92 & -0.59 & 4.22 & 1.91 & 5.96 \\
\hline $4^{\text {th }}$ Solder & -14.91 & 35.24 & -15.02 & 36.39 & -0.12 & 0.78 & 1.15 & 3.27 \\
\hline $5^{\text {th }}$ Solder & -15.33 & 36.03 & -15.06 & 36.41 & 0.27 & -1.78 & 0.37 & 1.03 \\
\hline
\end{tabular}




\begin{tabular}{|c|c|c|c|c|c|c|c|c|}
\hline $6^{\text {th }}$ Solder & -14.88 & 34.10 & -14.42 & 33.62 & 0.46 & -3.09 & -0.47 & -1.39 \\
\hline $7^{\text {th }}$ Solder & -15.43 & 35.22 & -14.77 & 34.13 & 0.66 & -4.29 & -1.09 & -3.09 \\
\hline $8^{\text {th }}$ Solder & -15.67 & 35.43 & -15.11 & 34.29 & 0.56 & -3.59 & -1.14 & -3.22 \\
\hline $9^{\text {th }}$ Solder & -16.51 & 37.15 & -16.61 & 37.10 & -0.10 & 0.62 & -0.05 & -0.13 \\
\hline $10^{\text {th }}$ Solder & -13.72 & 31.56 & -13.19 & 30.43 & 0.53 & -3.85 & -1.13 & -3.57 \\
\hline $11^{\text {th }}$ Solder & -12.34 & 27.90 & -10.68 & 24.55 & 1.65 & -13.40 & -3.35 & -12.02 \\
\hline \begin{tabular}{c}
$12^{\text {th }}$ Solder \\
\hline $\begin{array}{c}\text { Upper corner } \\
\text { of Embedded } \\
\text { Die }\end{array}$
\end{tabular} & -10.94 & 24.60 & -7.89 & 23.53 & 3.05 & -27.90 & -1.08 & -4.37 \\
\hline $\begin{array}{c}\text { Lower corner } \\
\text { of Embedded } \\
\text { Die }\end{array}$ & -49.92 & 115.06 & -52.19 & 116.24 & -2.28 & 4.56 & 1.18 & 1.03 \\
\hline
\end{tabular}

As seen from Table 4-6, in the CSP with eBGA, the maximum shear stress and von Mises stress among the solder joints are also observed at the $9^{\text {th }}$ solder joint, which is similar to the eBGA. As shown in Table 4-6, the magnitudes of those stresses at the $9^{\text {th }}$ solder joint for both eBGA and CSP are almost identical. The shear stress and the von Mises stress in the $1^{\text {st }}$ solder joint of the CSP with eBGA is about $8.5 \%$ higher than one of the eBGA. However, the shear stress and the von Mises stress in the $11^{\text {th }}$ solder joint and the $12^{\text {th }}$ solder joint of the CSP with eBGA are less compared with those of the eBGA. The shear stress in the $11^{\text {th }}$ solder is $1.65 \mathrm{MPa}$ which is $13.4 \%$ less than one of the eBGA, while the shear stress in the $12^{\text {th }}$ solder is $3.05 \mathrm{MPa}$ which is $27.9 \%$ less. 
In addition, the shear stress and the von Mises stress at the upper corner of embedded die decreases by about $18 \%$. Adding the upper die makes the stress at the upper corner of the embedded die decrease

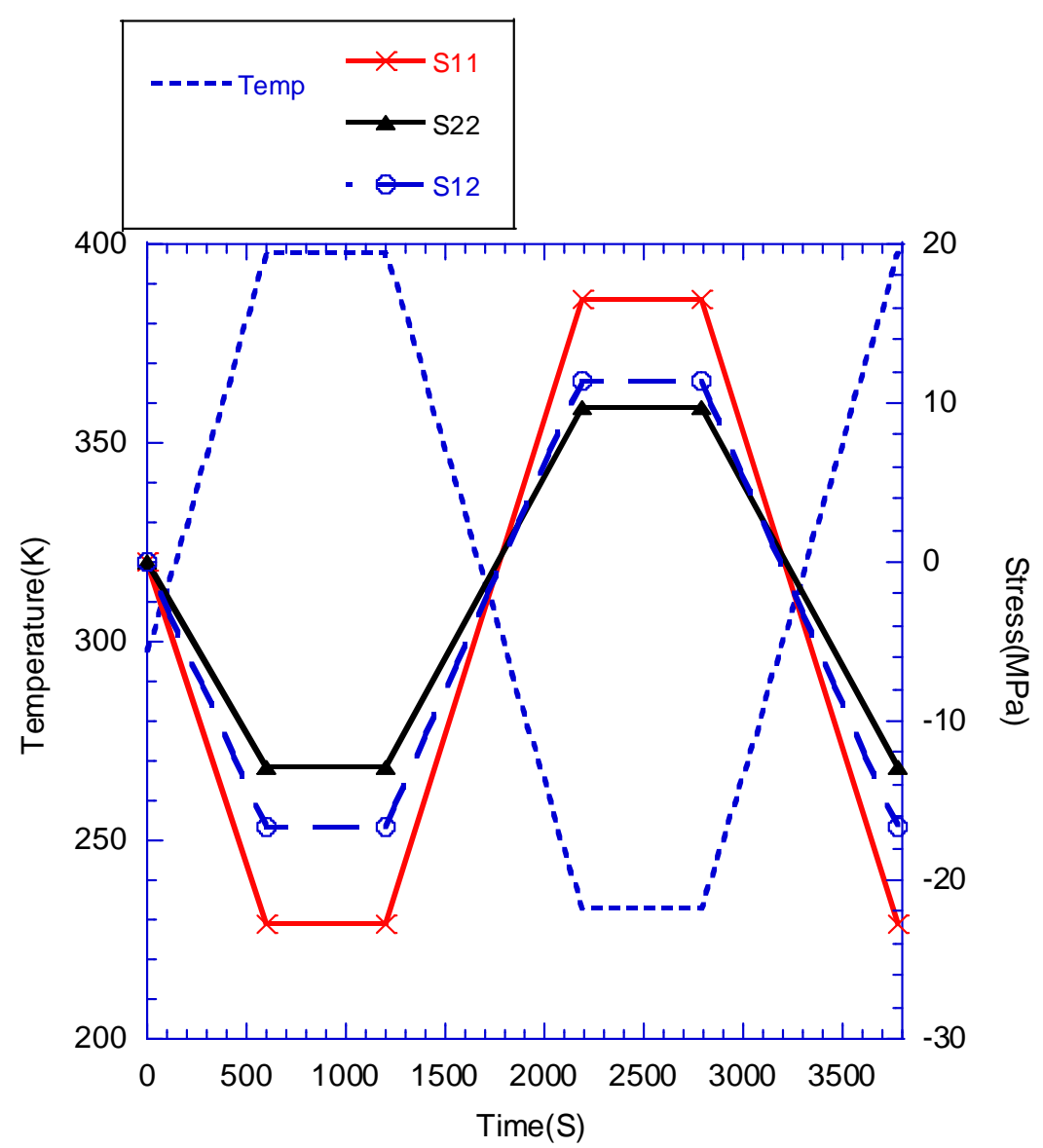

Figure 4-24 Normal stress $\left(\mathrm{S}_{11}, \mathrm{~S}_{22}\right)$ and shear stress $\left(\mathrm{S}_{12}\right)$ during thermal cycling

During thermal cycling, the various stresses including the normal stress and the shear stress in the right corner of $9^{\text {th }}$ solder ball are plotted in Figs. 4-24. The stresses of the solder joint are proportional to temperature change linearly. 


\subsection{Viscoplastic FEA Results}

\subsection{1. eBGA}

The viscoplastic response of the eBGA is analyzed with ABAQUS. In this case, four thermal cycles loading is considered.

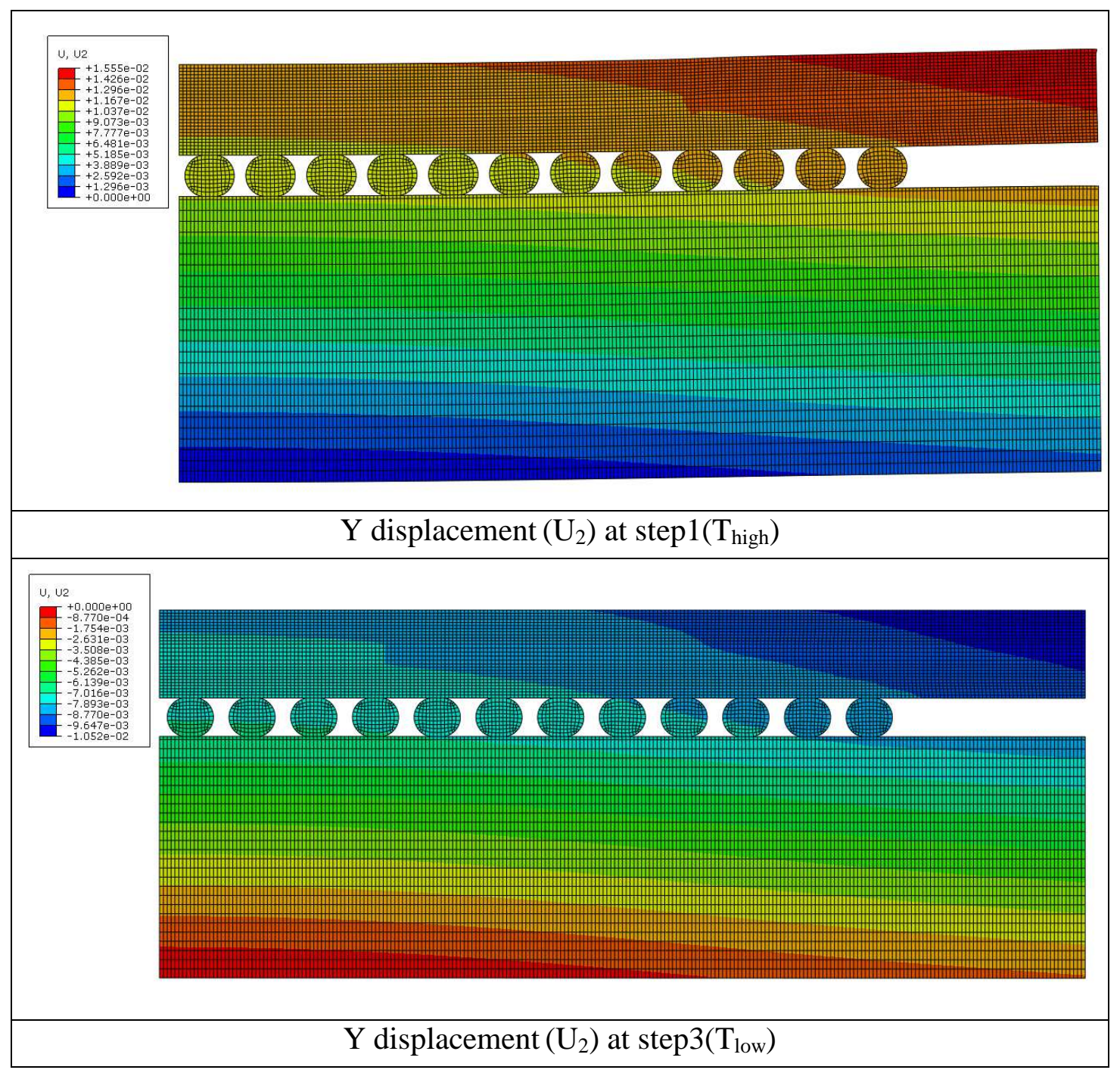

Figure 4-25 Y displacement $\left(\mathrm{U}_{2}\right)$ in eBGA 


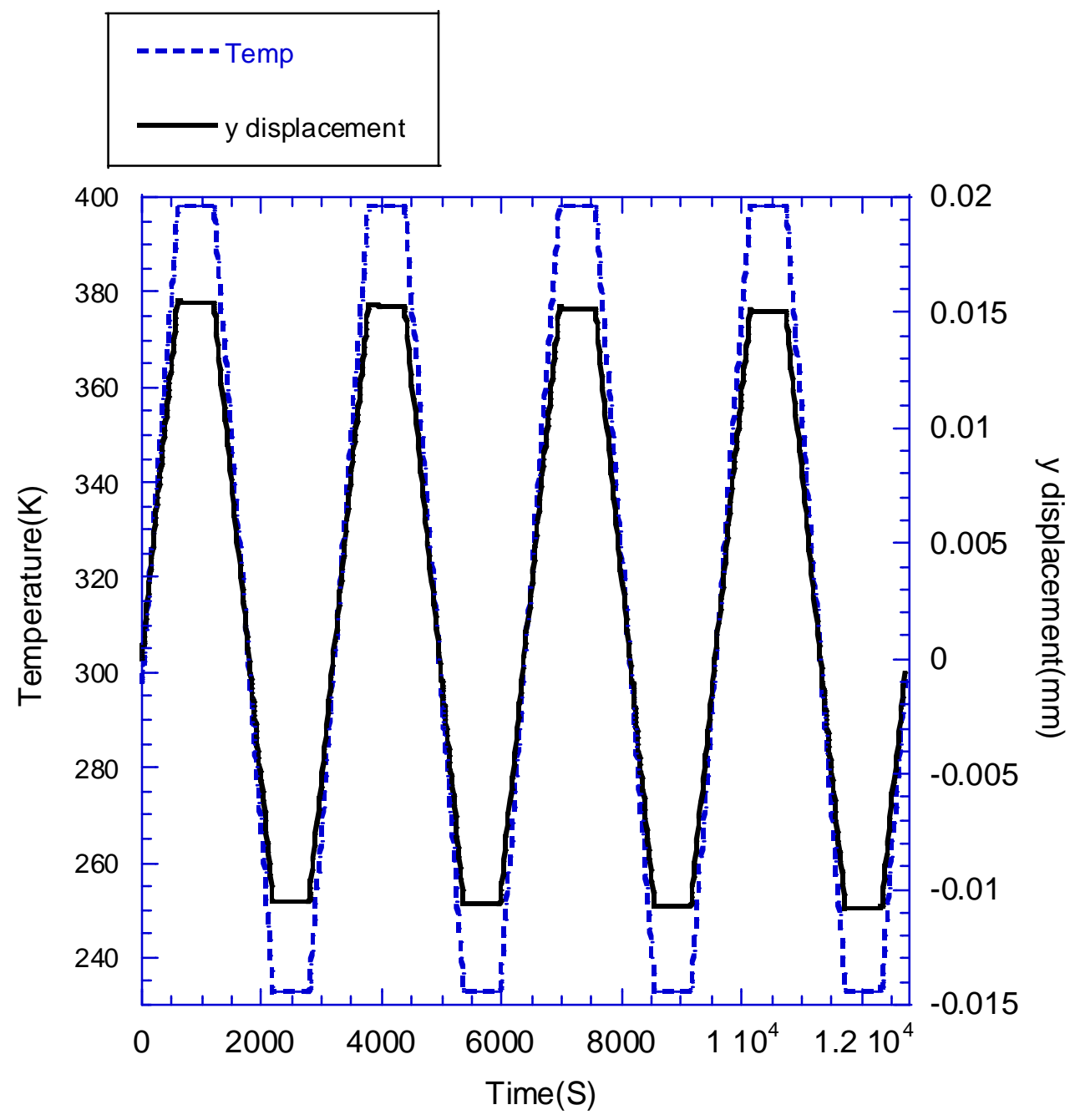

Figure 4-26 Maximum displacement in the y-direction during thermal cycling

As illustrated in Figs. 4-25 and 4-26, for positive temperature change $(\Delta \mathrm{T}>0)$, the eBGA assembly bends upward (U-shape) because of the thermal expansion mismatch among the materials, while it bends downward for negative temperature changes $(\Delta \mathrm{T}$ $<0)$. It agrees with the previous linear elastic result of the eBGA. 
The maximum y-displacement in the eBGA is obtained at the edge of the eBGA which is the same location with the previous linear elastic case. For positive temperature change $(\Delta \mathrm{T}>0)$, it is changed from $0.01555 \mathrm{~mm}$ at the start of the first hot $\left(\mathrm{T}_{\text {high }}\right)$ dwell to $0.0151 \mathrm{~mm}$ at the end of the fourth hot $\left(\mathrm{T}_{\text {high }}\right)$ dwell. The result of the previous linear elastic case which is $0.01576 \mathrm{~mm}$, for the viscoplastic case, it gradually decreases from $1.33 \%$ to $4.19 \%$. For negative temperature change $(\Delta \mathrm{T}<0)$, the maximum $y-$ displacement in the eBGA is changed from $-0.01052 \mathrm{~mm}$ at the start of the first cold $\left(\mathrm{T}_{\text {low }}\right)$ dwell to $-0.01085 \mathrm{~mm}$ at the end of the fourth cold $\left(\mathrm{T}_{\text {low }}\right)$ dwell. For the linear elastic case, it is $-0.0102 \mathrm{~mm}$, while, for the viscoplastic case, it increases in the negative direction from $3.14 \%$ to $6.37 \%$.

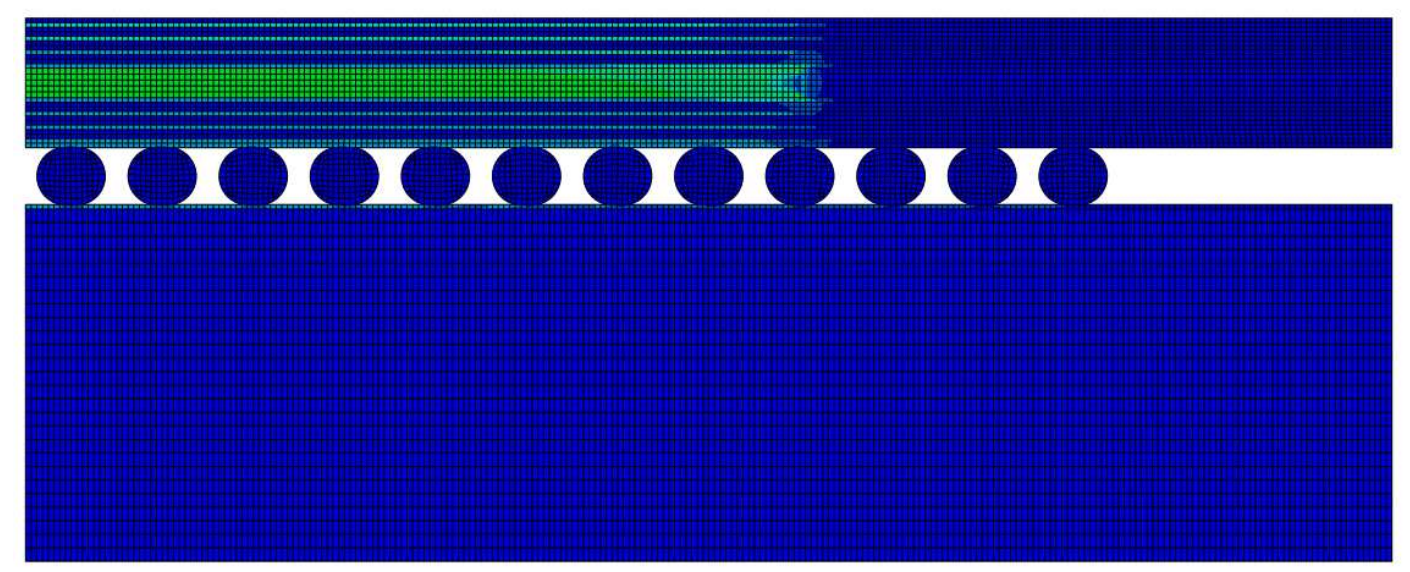

Figure 4-27 von Mises stress of eBGA at step1 ( $\left.\mathrm{T}_{\text {high }}\right)$ 


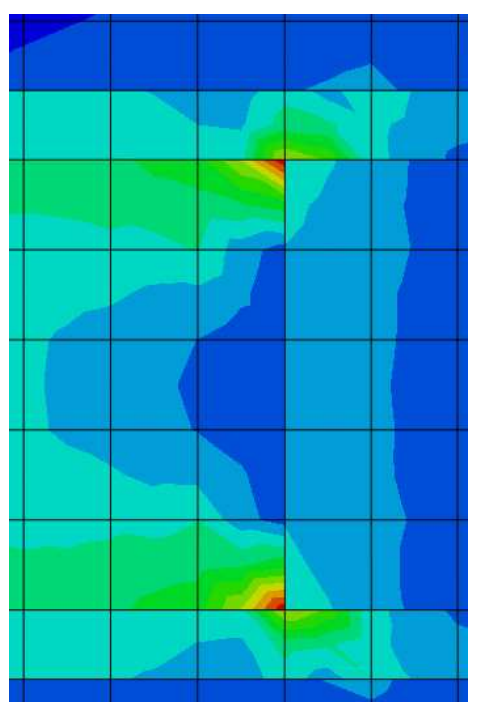

Figure 4-28 von Mises stress near embedded die corner at step1 $\left(\mathrm{T}_{\text {high }}\right)$

As shown in Figs. 4-27 and 4-28, the highest von Mises stress $\left(\mathrm{S}_{\text {mises }}\right)$ is observed at the contact area between the embedded die and the core. This agrees with the results of the previous linear elastic response. The von Mises stresses of the embedded die corner and all solder joints in eBGA at step1 $\left(\mathrm{T}_{\text {high }}\right)$ are tabulated in Table 4-8.

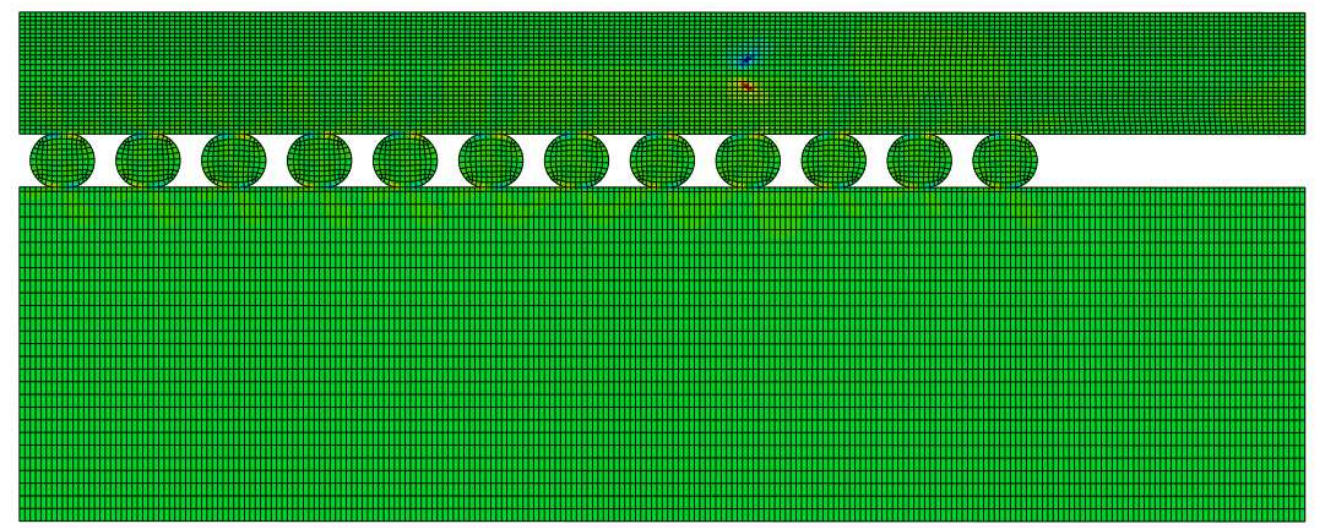

Figure 4-29 Shear stress of eBGA at Step3( $\left.\mathrm{T}_{\text {low }}\right)$ 


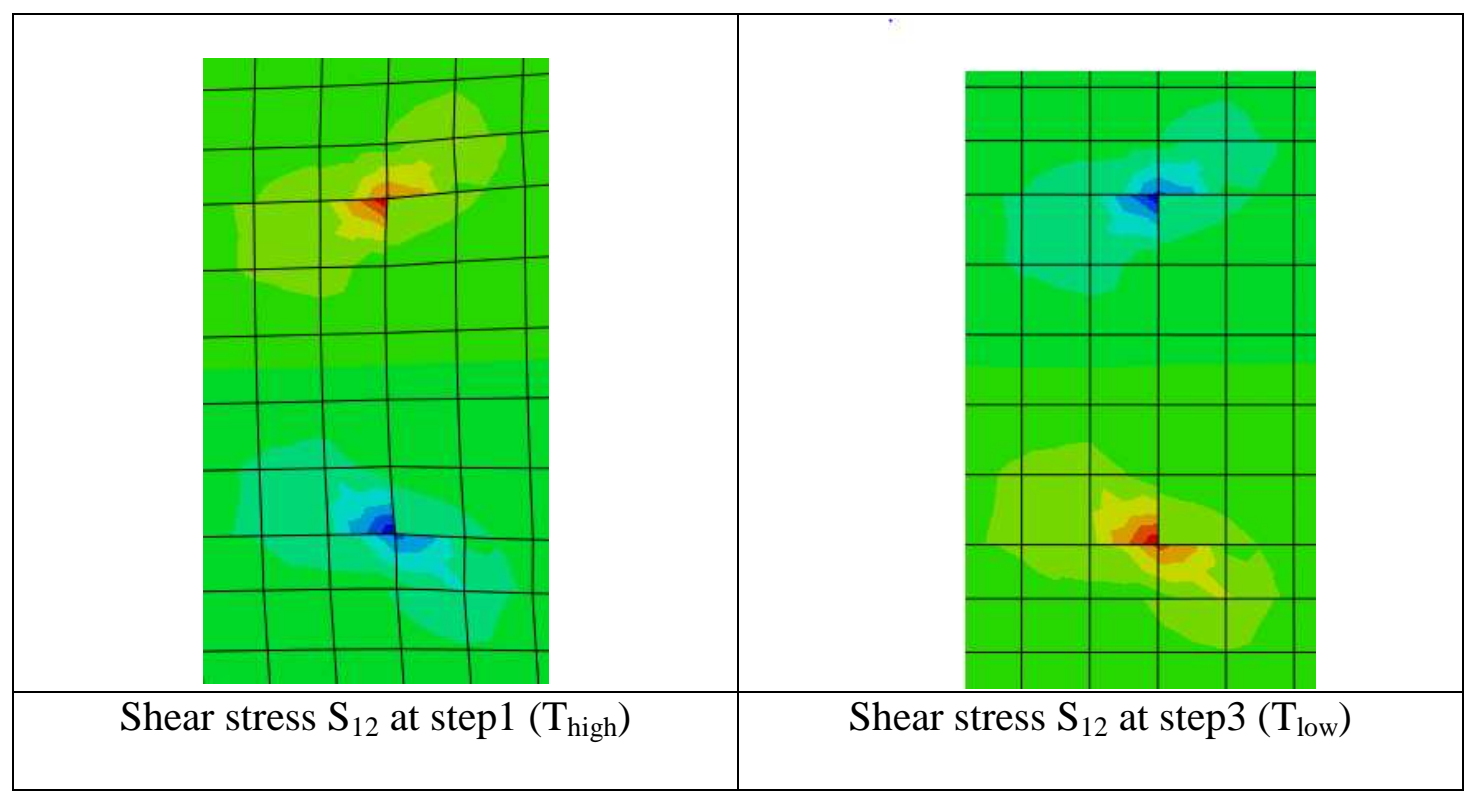

Figure 4-30 Shear stress in embedded die corner at step1 $\left(\mathrm{T}_{\text {high }}\right)$ and step3 $\left(\mathrm{T}_{\text {low }}\right)$

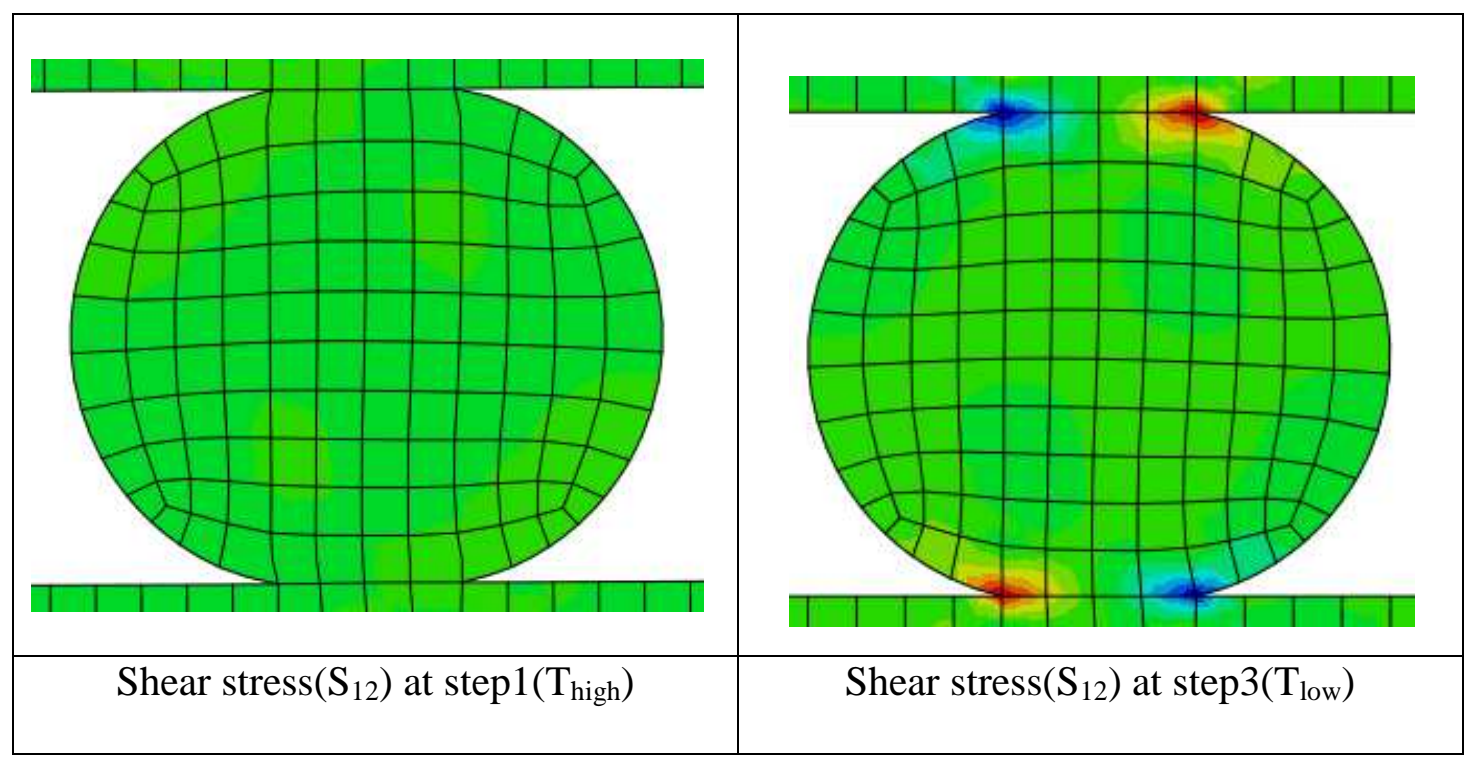

Figure 4-31 Shear stress in solder joint at step1 $\left(\mathrm{T}_{\text {high }}\right)$ and step3 $\left(\mathrm{T}_{\text {low }}\right)$

As shown in Figs 4-29 to 4-31, the viscoplastic shear stress in the eBGA is smaller than one for the linear elastic case. However, the distributions of shear stress in the 
solder joints and the embedded die corner are similar to those for the linear elastic case.

The shears stresses at the embedded die corner and all solder joints in the eBGA at step1 $\left(\mathrm{T}_{\text {high }}\right)$ are tabulated in Table 4-7.

Table 4-7 Stress comparison with linear elastic response of eBGA at step1( $\left.\mathrm{T}_{\text {high }}\right)$

\begin{tabular}{|c|c|c|c|c|c|c|c|c|}
\hline \multirow{2}{*}{ Solder } & \multicolumn{2}{|c|}{ Linear elastic case } & \multicolumn{2}{|c|}{ Viscoplastic case } & \multicolumn{2}{|c|}{ Shear stress $\left(S_{12}\right)$} & \multicolumn{2}{|c|}{$\begin{array}{c}\text { von Mises stress } \\
\text { (Smises) }\end{array}$} \\
\hline & $\begin{array}{c}\mathrm{S}_{12} \\
(\mathrm{MPa})\end{array}$ & $\begin{array}{l}\mathrm{S}_{\text {mises }} \\
(\mathrm{MPa})\end{array}$ & $\begin{array}{c}\mathrm{S}_{12} \\
(\mathrm{MPa})\end{array}$ & $\begin{array}{l}\mathrm{S}_{\text {mises }} \\
(\mathrm{MPa})\end{array}$ & $\begin{array}{l}\text { Diffe } \\
\text { rence }\end{array}$ & $\begin{array}{c}\text { Percent } \\
(\%)\end{array}$ & $\begin{array}{l}\text { Diffe } \\
\text { rence }\end{array}$ & $\begin{array}{c}\text { Percent } \\
(\%)\end{array}$ \\
\hline $1^{\text {st }}$ Solder & -13.91 & 33.51 & -5.20 & 9.71 & 8.71 & -62.60 & -23.80 & -71.02 \\
\hline $2^{\text {th }}$ Solder & -14.20 & 33.99 & -5.34 & 9.99 & 8.86 & -62.37 & -24.00 & -70.62 \\
\hline $3^{\text {th }}$ Solder & -13.89 & 32.01 & -5.33 & 10.09 & 8.56 & -61.64 & -21.92 & -68.47 \\
\hline $4^{\text {th }}$ Solder & -14.91 & 35.24 & -5.62 & 10.78 & 9.29 & -62.33 & -24.46 & -69.41 \\
\hline $5^{\text {th }}$ Solder & -15.33 & 36.03 & -5.74 & 11.29 & 9.59 & -62.57 & -24.74 & -68.66 \\
\hline $6^{\text {th }}$ Solder & -14.88 & 34.10 & -5.59 & 11.50 & 9.29 & -62.44 & -22.59 & -66.26 \\
\hline $7^{\text {th }}$ Solder & -15.43 & 35.22 & -5.76 & 12.08 & 9.67 & -62.70 & -23.14 & -65.71 \\
\hline $8^{\text {th }}$ Solder & -15.67 & 35.43 & -5.86 & 12.31 & 9.82 & -62.63 & -23.12 & -65.25 \\
\hline $9^{\text {th }}$ Solder & -16.51 & 37.15 & -5.74 & 13.25 & 10.77 & -65.22 & -23.90 & -64.33 \\
\hline $10^{\text {th }}$ Solder & -13.72 & 31.56 & -5.45 & 12.88 & 8.26 & -60.24 & -18.68 & -59.18 \\
\hline
\end{tabular}




\begin{tabular}{|c|c|c|c|c|c|c|c|c|}
\hline $11^{\text {th }}$ Solder & -12.34 & 27.90 & -5.45 & 11.11 & 6.89 & -55.85 & -16.79 & -60.17 \\
\hline $12^{\text {th }}$ Solder & -10.94 & 24.60 & -5.23 & 9.64 & 5.71 & -52.24 & -14.96 & -60.80 \\
\hline $\begin{array}{c}\text { Upper corner } \\
\text { of Embedded } \\
\text { Die }\end{array}$ & 50.98 & 116.46 & 50.82 & 116.06 & -0.16 & -0.31 & -0.40 & -0.35 \\
\hline $\begin{array}{c}\text { Lower corner } \\
\text { of Embedded } \\
\text { Die }\end{array}$ & -49.92 & 115.06 & -49.84 & 114.79 & 0.07 & -0.15 & -0.26 & -0.23 \\
\hline
\end{tabular}

As seen from Table 4-7, in viscoplastic case, the maximum von Mises stress among solder joints is also observed at the $9^{\text {th }}$ solder. In the viscoplastic case, the von Mises stress in the solder joints tends to increase as the distance in the $\mathrm{x}$-direction increase until the $9^{\text {th }}$ solder. Afterward those stresses in the solder joints decrease as the $\mathrm{x}$ distance increases. This is similar to the linear elastic case. The magnitudes of viscoplastic shear stresses in solder joints of the eBGA are $52.24 \% \sim 65.22 \%$ of those for the linear elastic case. The von Mises stresses in the solder joints are 59.18\% $\sim 71.02 \%$ less compared with those for the linear elastic case. However, the magnitudes of those stresses at the embedded die corner are almost identical. The shear stresses at the die corner are $0.31 \%$ and $0.15 \%$ less and von Mises stresses are $0.35 \%$ and $0.23 \%$ less. During thermal cycling, the various stresses including the normal stress, the shear stress, and the von Mises stress in the right corner of the $9^{\text {th }}$ solder ball are plotted in Figs. 4-32 to 4-35. 


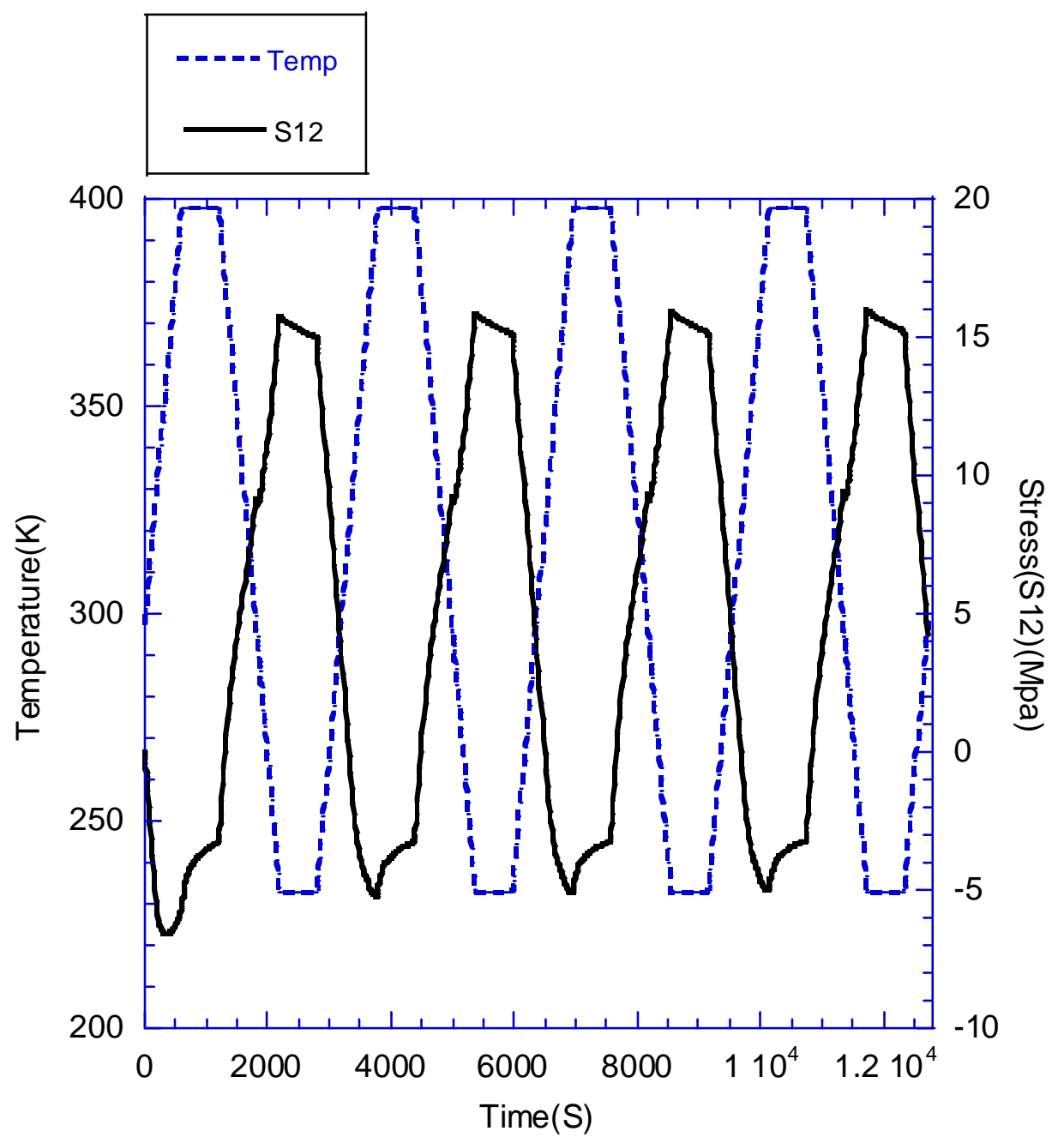

Figure 4-32 Variation of shear stress $S_{12}$ during thermal cycling 


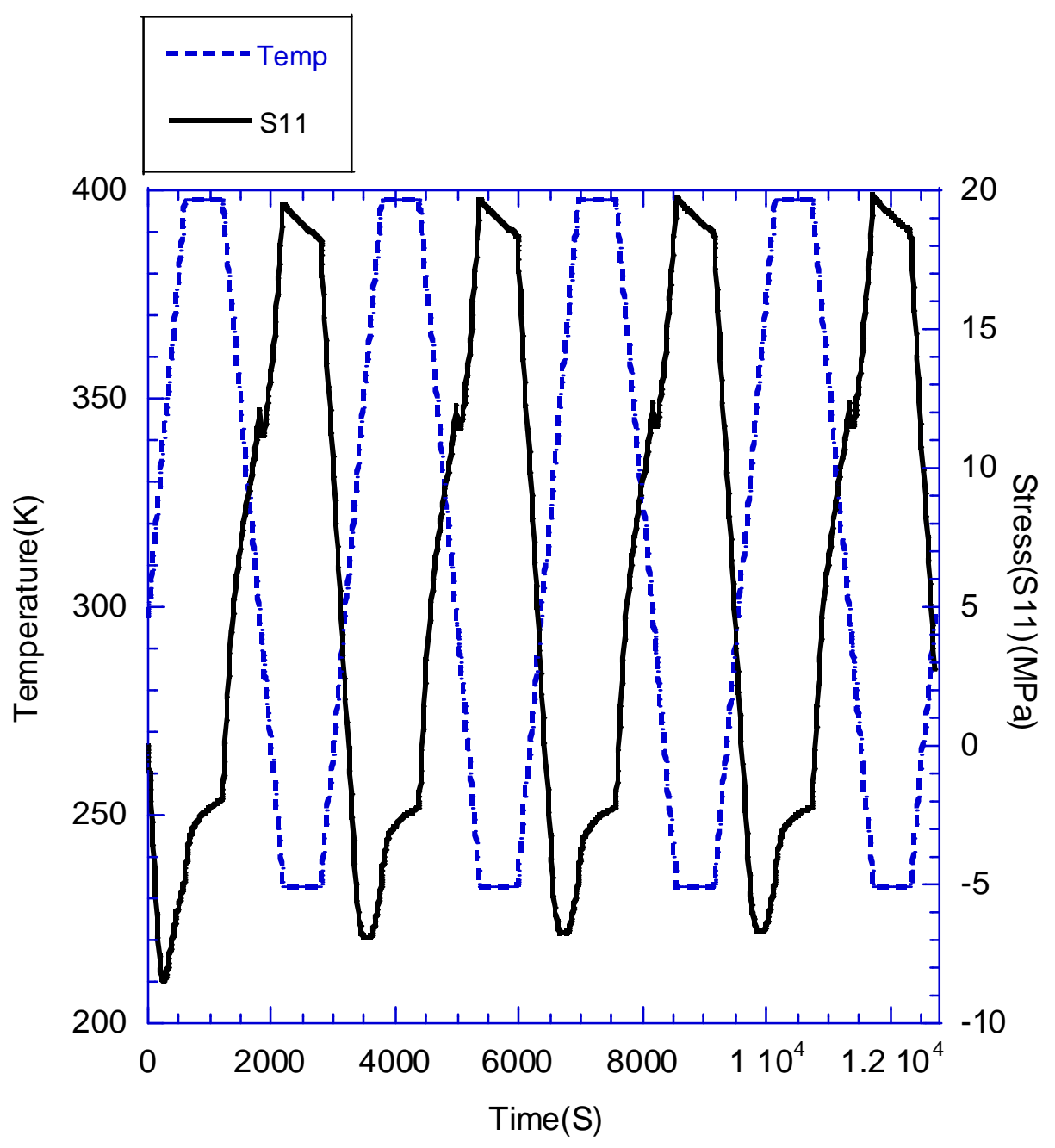

Figure 4-33 Variation of normal stress $S_{11}$ during thermal cycling 


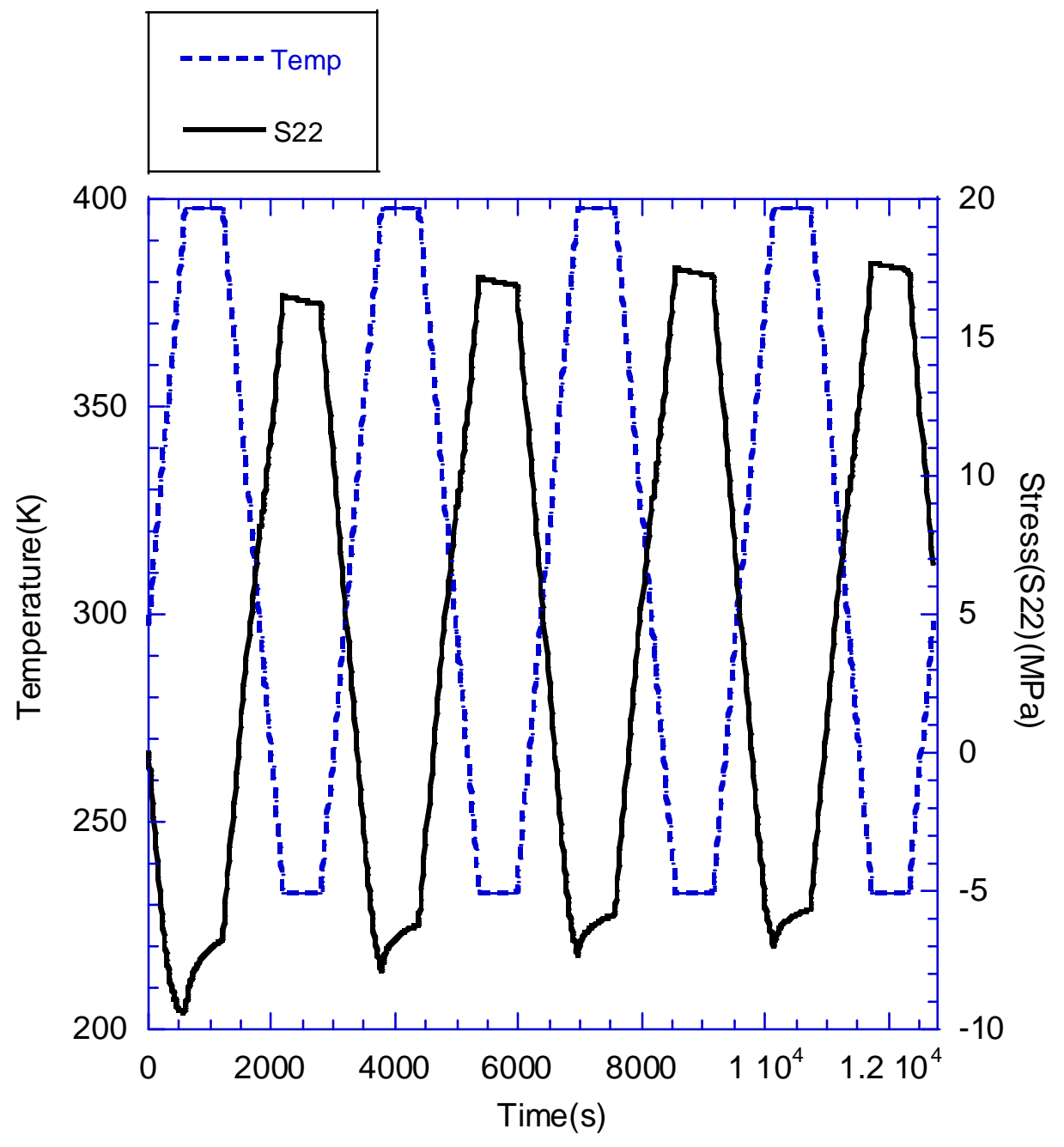

Figure 4-34 Variation of normal stress $\mathrm{S}_{22}$ during thermal cycling 


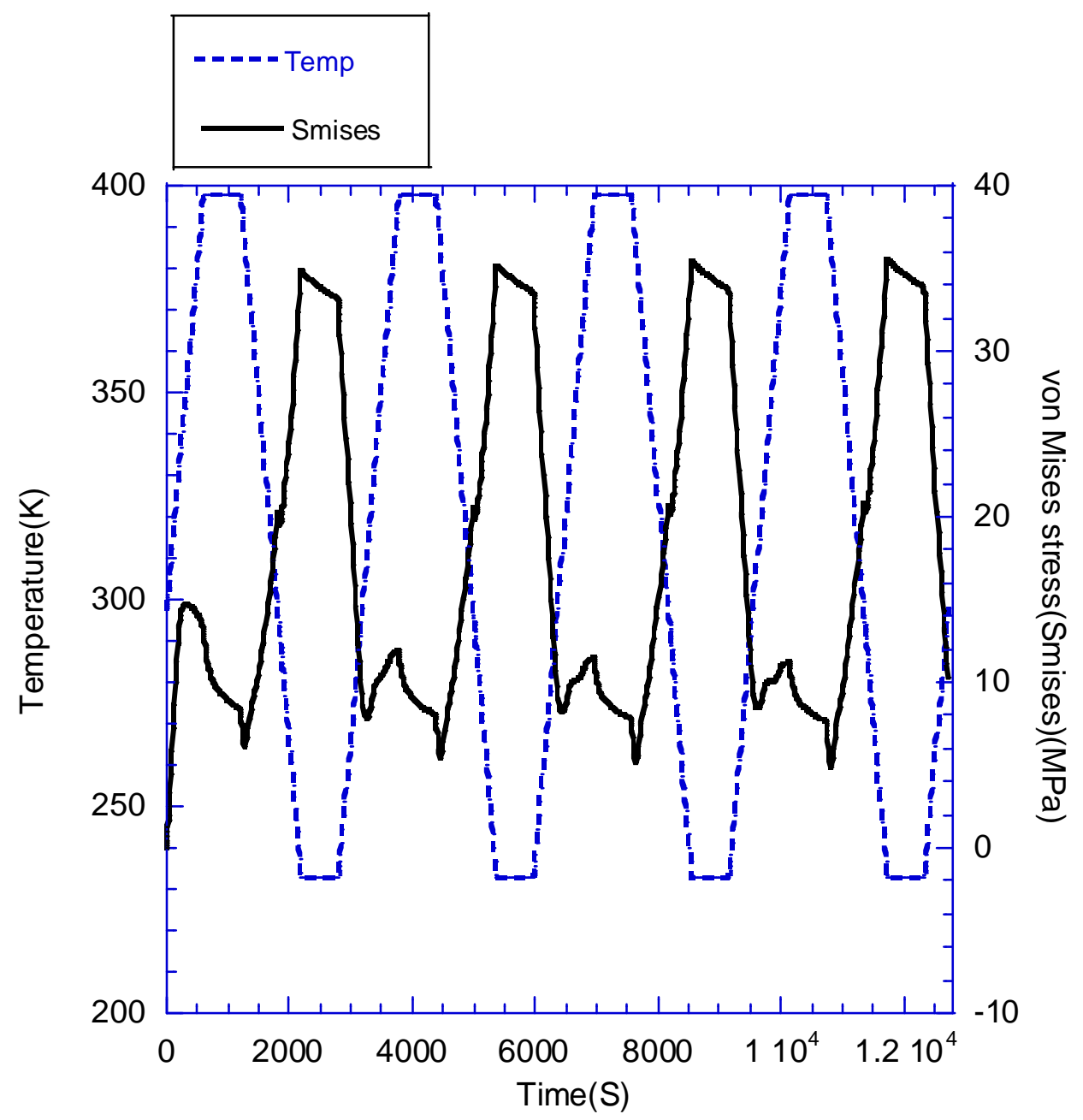

Figure 4-35 Variation of von Mises stress $\left(\mathrm{S}_{\text {mises }}\right)$ during thermal cycling As plotted in Figs. 4-32 to 4-35, the viscoplastic stresses in the eBGA are nonlinear and the magnitudes of stresses relax during dwelling. 
During the temperature ramp up, the magnitudes of stresses decrease due to reduction of Young's modulus of the solder. The von Mises stress $\left(\mathrm{S}_{\text {mises }}\right)$ in the right corner of the $9^{\text {th }}$ solder ball decrease from $33.17 \mathrm{MPa}$ to $7.89 \mathrm{MPa}$ when temperature increases from $233 \mathrm{~K}$ to $308 \mathrm{~K}$, but it increases from $7.89 \mathrm{MPa}$ to $11.92 \mathrm{MPa}$ for when temperature increases further from 308K to 398K. During the cool or hot dwell period, the magnitudes of stresses decrease as stress relaxation occurs. The von Mises stress $\left(\mathrm{S}_{\text {mises }}\right)$ decreases from 11.92MPa to $8.03 \mathrm{MPa}$ during the hot dwell period (398K).

During the temperature ramp down, the magnitudes of stresses increase due to increase of Young's modulus of the solder. The von Mises stress $\left(\mathrm{S}_{\text {mises }}\right)$ in the right corner of the $9^{\text {th }}$ solder ball increases from 8.03MPa to $35.21 \mathrm{MPa}$, which is maximum, when temperature decreases from $398 \mathrm{~K}$ to $233 \mathrm{~K}$.

During the cold dwell, cycle, the magnitudes of stresses decrease because of stress relaxation. As shown in Figure 4-32, the behavior of shear stress in the right corner of the $9^{\text {th }}$ solder ball is very similar to one of the von Mises stress.

\subsubsection{Chip Scale Package with eBGA}

The viscoplastic response of chip scale package with eBGA is analyzed with ABAQUS. In this case, four thermal cycles loading is considered. 


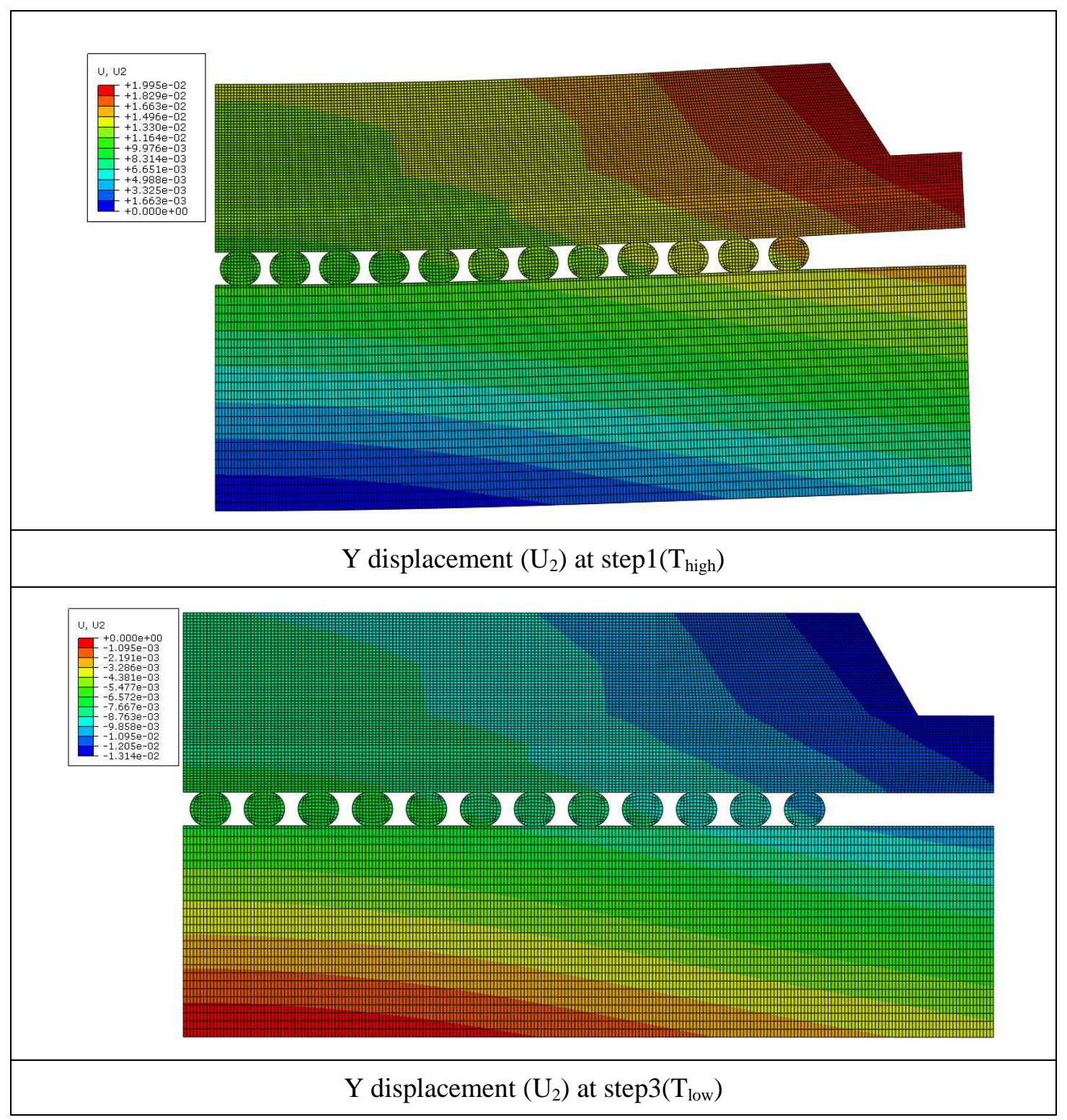

Figure 4-36 Y displacement $\left(\mathrm{U}_{2}\right)$ of CSP with eBGA 


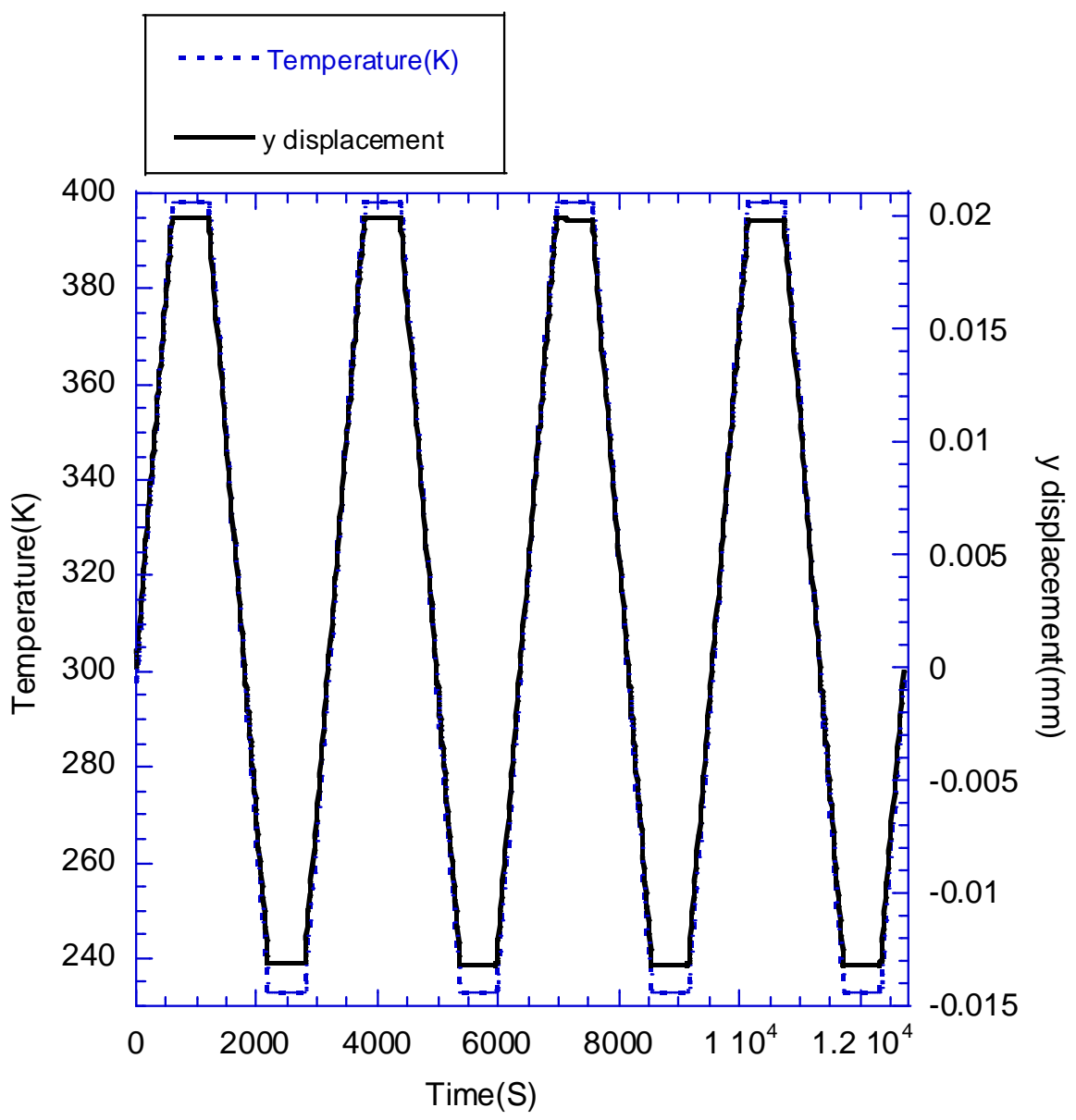

Figure 4-37 Maximum displacement in the y-direction during thermal cycling

From Figs. 4-36 and 4-37, for positive temperature change ( $\Delta \mathrm{T}>0)$, the chip scale package with the eBGA assembly bends upward (U-shape) because of the thermal expansion mismatch among the materials, while it bends downward for negative temperature changes $(\Delta T<0)$. It agrees with the previous linear elastic result of the chip scale package. The maximum y-displacement in the CSP with eBGA is obtained at the edge of the eBGA which is the same location with the previous linear elastic 
case. For positive temperature change $(\Delta \mathrm{T}>0)$, it is changed from $0.019952 \mathrm{~mm}$ at the start of the first hot $\left(\mathrm{T}_{\text {high }}\right)$ dwell to $0.019821 \mathrm{~mm}$ at the end of the fourth hot $\left(\mathrm{T}_{\text {high }}\right)$ dwell. The result of the previous linear elastic case which is $0.02006 \mathrm{~mm}$, for the viscoplastic case, it gradually decreases from $0.0539 \%$ to $1.191 \%$. When it is compared with the result of the previous viscoplastic response of the eBGA, it increases by $28.31 \%$ at the start of the first hot $\left(\mathrm{T}_{\text {high }}\right)$ dwell and $31.265 \%$ at the end of the fourth $\operatorname{hot}\left(\mathrm{T}_{\text {high }}\right)$ dwell. For negative temperature change $(\Delta \mathrm{T}<0)$, the maximum $\mathrm{y}$ displacement in the CSP with eBGA is changed from $-0.013144 \mathrm{~mm}$ at the start of the first cold $\left(\mathrm{T}_{\text {low }}\right)$ dwell to $-0.0132256 \mathrm{~mm}$ at the end of the fourth cold $\left(\mathrm{T}_{\text {low }}\right)$ dwell. The linear elastic case, it is $-0.01297 \mathrm{~mm}$, while, for the viscoplastic case for the CSP with eBGA, it increase in the negative direction from $1.34156 \%$ to $1.9707 \%$. When it is compared with the result of the previous viscoplastic case of the eBGA, it increases by $24.94 \%$ at the start of the first hot $\left(\mathrm{T}_{\text {high }}\right) \mathrm{dwell}$ and $21.89 \%$ at the end of the fourth $\operatorname{hot}\left(\mathrm{T}_{\text {high }}\right) \mathrm{dwell}$. 


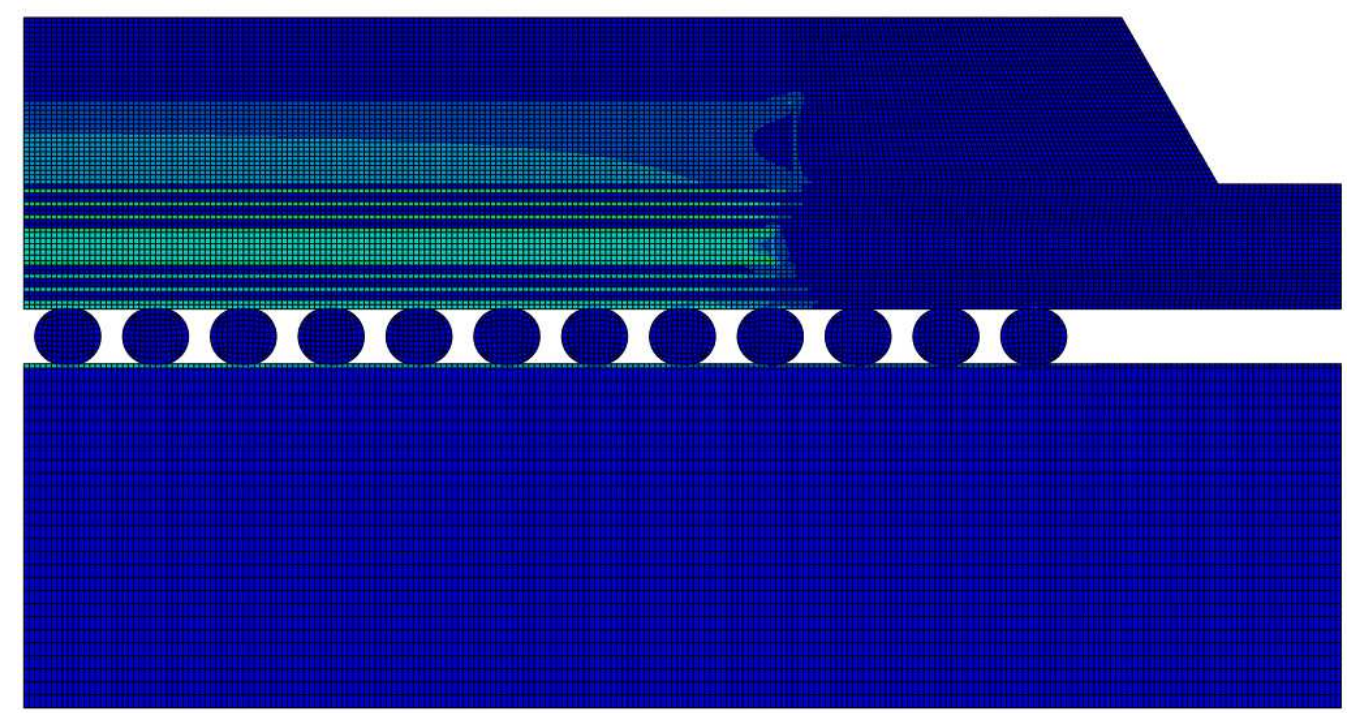

Figure 4-38 von Mises stress of CSP with eBGA at step1( $\left.\mathrm{T}_{\text {high }}\right)$

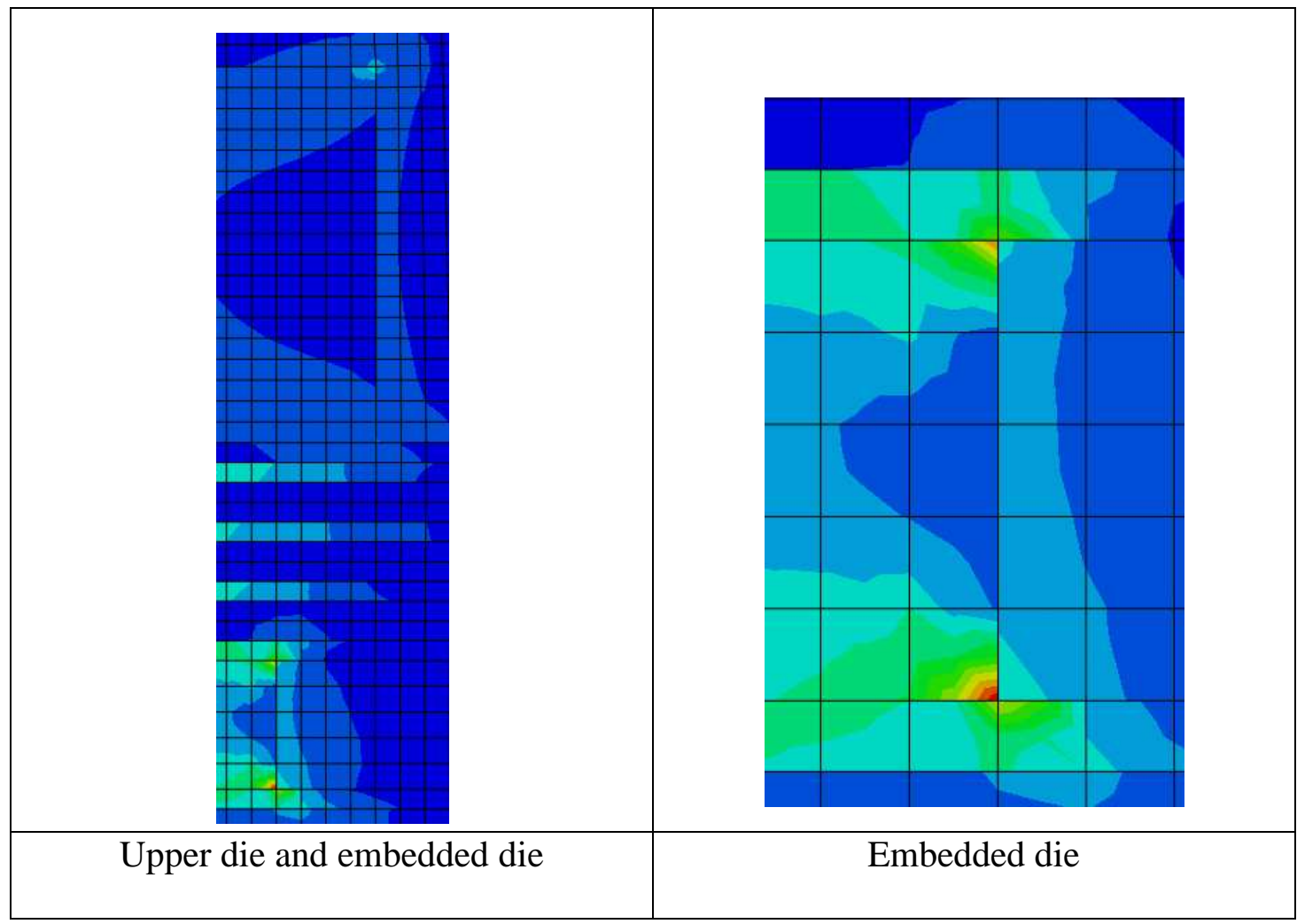

Figure 4-39 von Mises stress near die corner at $\operatorname{step}(1)\left(\mathrm{T}_{\text {high }}\right)$ 
As shown in Figs. 4-38 and 4-39, the highest von Mises stress $\left(S_{\text {mises }}\right)$ is observed at the contact area between the embedded die and the core. This agrees with the results of the previous linear elastic response. The von Mises stresses of the embedded die corner and all solder joints in the CSP with eBGA at step1 $\left(\mathrm{T}_{\text {high }}\right)$ are tabulated in Table 4-8.

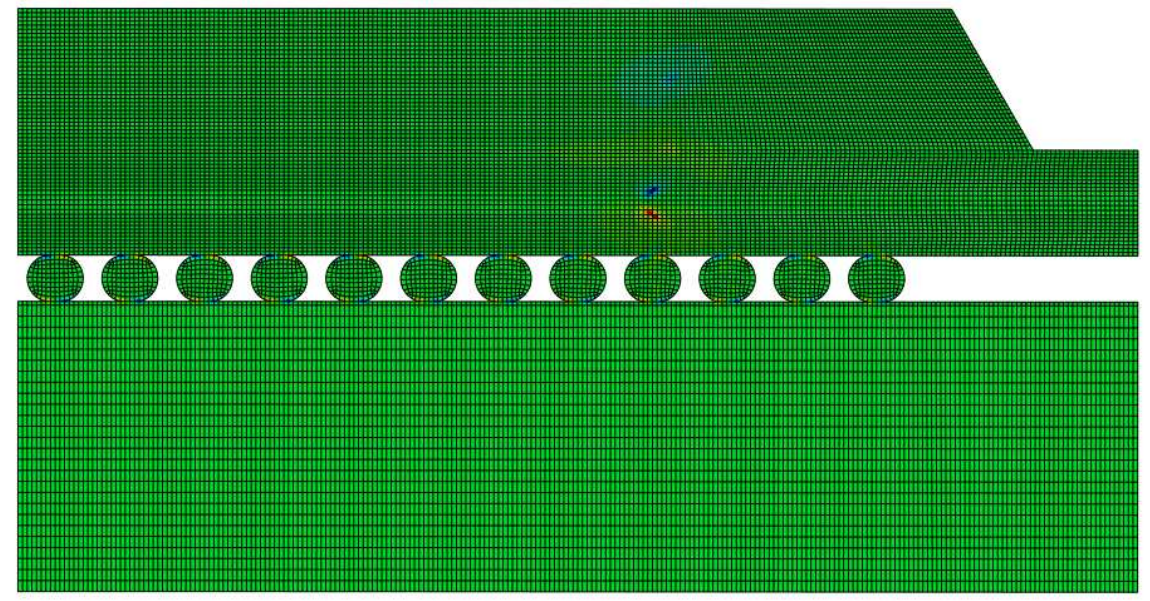

Figure 4-40 Shear stress $\mathrm{S}_{12}$ of CSP with eBGA $\mathrm{S} 12$ at step3( $\left.\mathrm{T}_{\text {low }}\right)$

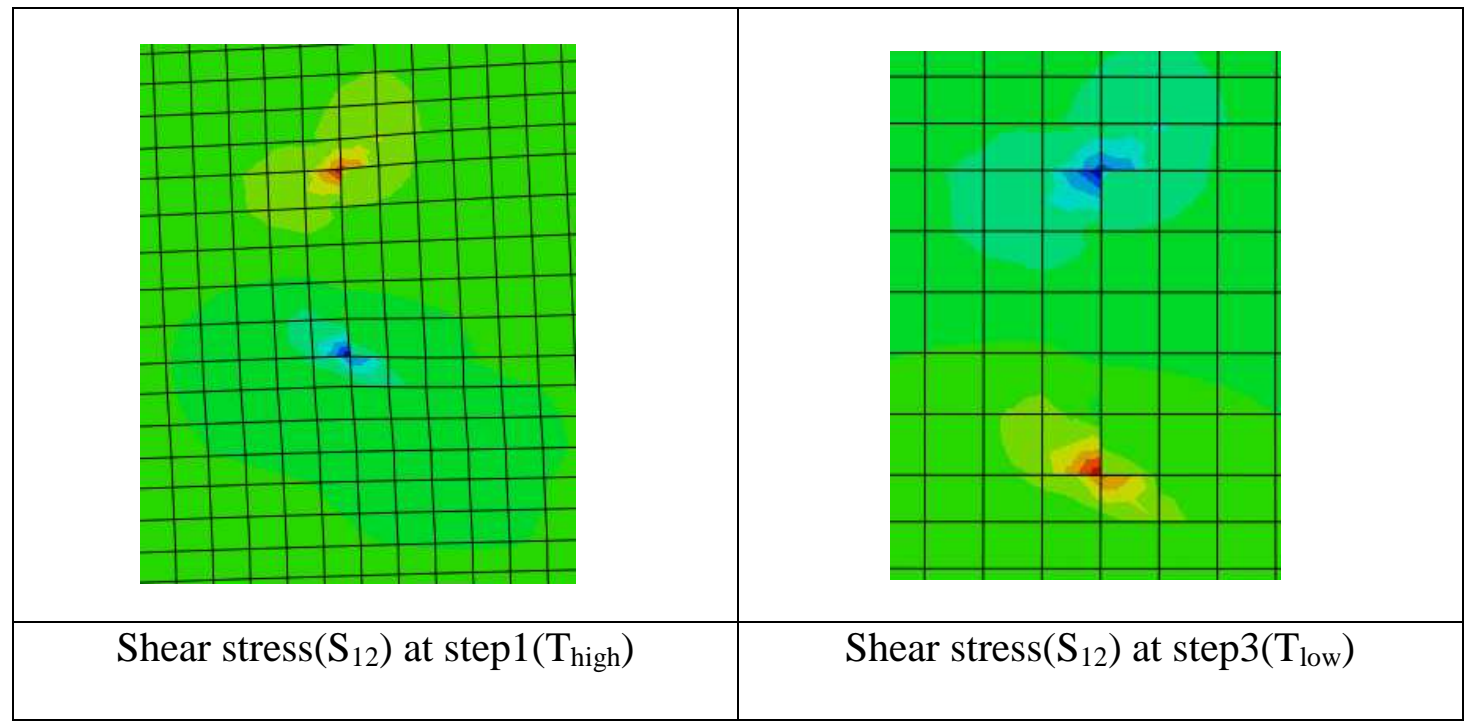

Figure 4-41 Shear stress $S_{12}$ in embedded die corner at step1( $\left.T_{\text {high }}\right)$ and step3( $\left.T_{\text {low }}\right)$ 57 


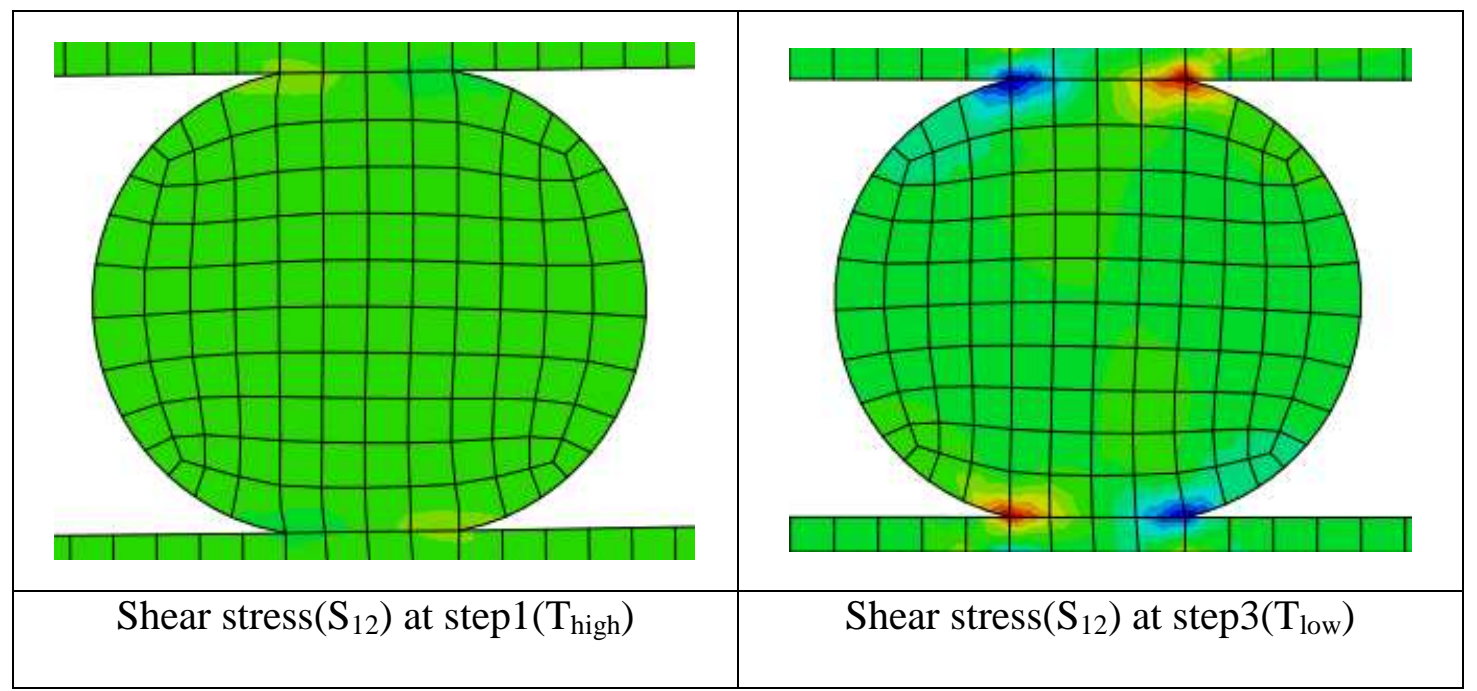

Figure 4-42 Shear Stress $S_{12}$ in Solder Joint at step1( $\left.T_{\text {high }}\right)$ and step3( $\left.T_{\text {low }}\right)$

As shown in Figs 4-40 to 4-the viscoplastic shear stress $\left(S_{2}\right)$ in the CSP with eBGA is smaller than one for the linear elastic case. However, The distributions of shear stress $\left(S_{12}\right)$ in solder joints and embedded die corner similar to those for linear elastic case. The shears stresses of the embedded die corner and all solder joints in the CSP eBGA at step1( $\left.\mathrm{T}_{\mathrm{high}}\right)$ are tabulated in Table 4-8.

Table 4-8 Stress comparison with the linear elastic case at step1( $\left.\mathrm{T}_{\text {high }}\right)$

\begin{tabular}{|c|c|c|c|c|c|c|c|c|}
\hline \multirow{2}{*}{ Solder } & \multicolumn{2}{|c|}{ Linear elastic case } & \multicolumn{2}{|c|}{ Viscoplastic case } & \multicolumn{2}{c|}{ Shear stress $\left(\mathrm{S}_{12}\right)$} & \multicolumn{2}{c|}{$\begin{array}{c}\text { von Mises stress } \\
\text { (Smises) }\end{array}$} \\
\cline { 2 - 9 } & $\begin{array}{c}\mathrm{S}_{12} \\
(\mathrm{MPa})\end{array}$ & $\begin{array}{c}\mathrm{S}_{\text {mises }} \\
(\mathrm{MPa})\end{array}$ & $\begin{array}{c}\mathrm{S}_{12} \\
(\mathrm{MPa})\end{array}$ & $\begin{array}{c}\mathrm{S}_{\text {mises }} \\
(\mathrm{MPa})\end{array}$ & $\begin{array}{c}\text { Diffe } \\
\text { rence }\end{array}$ & $\begin{array}{c}\text { Percent } \\
(\%)\end{array}$ & $\begin{array}{c}\text { Diffe } \\
\text { rence }\end{array}$ & $\begin{array}{c}\text { Percent } \\
(\%)\end{array}$ \\
\hline $1^{\text {st }}$ Solder & -15.01 & 36.37 & -5.21 & 9.85 & 9.80 & -65.30 & -26.52 & -72.91 \\
\hline $2^{\text {th }}$ Solder & -15.01 & 36.36 & -5.22 & 9.90 & 9.79 & -65.20 & -26.46 & -72.77 \\
\hline
\end{tabular}




\begin{tabular}{|c|c|c|c|c|c|c|c|c|}
\hline $3^{\text {th }}$ Solder & -14.47 & 33.92 & -5.15 & 9.81 & 9.33 & -64.45 & -24.11 & -71.09 \\
\hline $4^{\text {th }}$ Solder & -15.02 & 36.39 & -5.26 & 10.08 & 9.76 & -64.98 & -26.31 & -72.30 \\
\hline $5^{\text {th }}$ Solder & -15.06 & 36.41 & -5.31 & 10.21 & 9.75 & -64.75 & -26.20 & -71.96 \\
\hline $6^{\text {th }}$ Solder & -14.42 & 33.62 & -5.20 & 10.02 & 9.22 & -63.92 & -23.60 & -70.18 \\
\hline $7^{\text {th }}$ Solder & -14.77 & 34.13 & -5.44 & 10.35 & 9.32 & -63.13 & -23.79 & -69.68 \\
\hline $8^{\text {th }}$ Solder & -15.11 & 34.29 & -5.70 & 10.65 & 9.41 & -62.30 & -23.64 & -68.94 \\
\hline $9^{\text {th }}$ Solder & -16.61 & 37.10 & -5.89 & 12.39 & 10.72 & -64.56 & -24.71 & -66.60 \\
\hline $\begin{array}{c}10^{\text {th }} \text { Solder } \\
\text { of Embedded } \\
\text { Die }\end{array}$ & -13.19 & 30.43 & -5.36 & 11.87 & 7.83 & -59.35 & -18.56 & -60.98 \\
\hline $\begin{array}{c}\text { Upper corner } \\
11^{\text {th }} \text { Solder }\end{array}$ & -10.68 & 24.55 & -4.94 & 9.20 & 5.74 & -53.77 & -15.35 & -62.53 \\
\hline $\begin{array}{c}2^{\text {th }} \text { Solder } \\
\text { Dower coner }\end{array}$ & -7.89 & 23.53 & -4.01 & 11.38 & 3.88 & -49.20 & -12.15 & -51.65 \\
\hline
\end{tabular}

As seen from Table 4-8, in the viscoplastic response of the CSP with the eBGA, the shear stress and the von Mises stress in the solder tend to increase except the $3^{\text {th }}$ solder and the $6^{\text {th }}$ solder as the distance in the $\mathrm{x}$-direction increases until the $9^{\text {th }}$ solder. Then those stresses in the solder joint decrease as the $\mathrm{x}$ distance increases. This is similar to the linear elastic case. 
The viscoplastic shear stresses in the solder joints of the CSP with eBGA are $49.2 \%$ $\sim 65.3 \%$ less than the linear elastic ones, while the von Mises stresses of solder joints are $51.65 \% \sim 71.91 \%$ less. However, the magnitudes of those stresses at the embedded die corner are almost identical to the elastic ones. The differences of the shear stresses and the von Mises stress near the corner of the die are about $0.25 \%$ and $0.3 \%$, respectively. During thermal cycling, the various stresses including the normal stress, the shear stress, and the von Mises stress in the $9^{\text {th }}$ solder ball are plotted in Figs. 4-43 to $4-46$.

As plotted in Figs 4-43 to 4-46, the viscoplastic stresses in the CSP with eBGA are nonlinear and the magnitudes of stresses decrease during dwelling.

During the temperature ramp up, the magnitudes of stresses decrease due to reduction of Young's modulus of SAC305. The von Mises stress $\left(\mathrm{S}_{\text {mises }}\right)$ in the right corner of the $9^{\text {th }}$ solder ball decrease from $32.37 \mathrm{MPa}$ to $7.66 \mathrm{MPa}$ when temperature increases from $233 \mathrm{~K}$ to $308 \mathrm{~K}$, but it increases from $7.66 \mathrm{MPa}$ to $11.20 \mathrm{MPa}$ for when temperature increases further from $308 \mathrm{~K}$ to $377 \mathrm{~K}$. When temperature increases from $377 \mathrm{~K}$ to $398 \mathrm{~K}$, the von Mises stresses $\left(\mathrm{S}_{\text {mises }}\right)$ decrease slightly from 11.20MPa to 11.05MPa. During the cool or hot dwell period, the magnitudes of stresses decrease as stress relaxation occurs. The von Mises stress $\left(\mathrm{S}_{\text {mises }}\right)$ decreases from $34.64 \mathrm{MPa}$ to $32.8 \mathrm{MPa}$ for 600 seconds during the cool dwell period $(233 \mathrm{~K})$. 


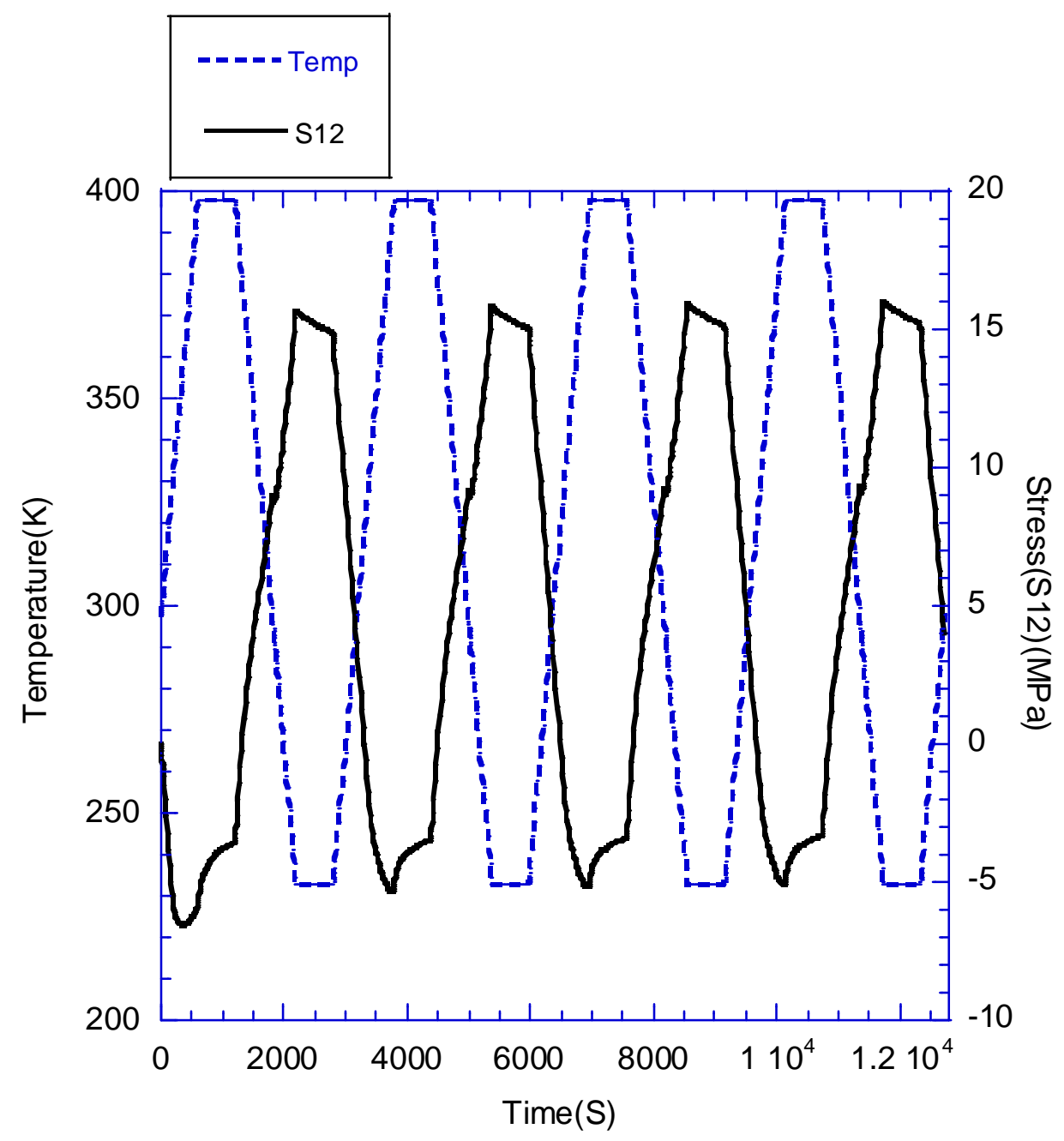

Figure 4-43 Variation of shear stress $S_{12}$ during thermal cycling 


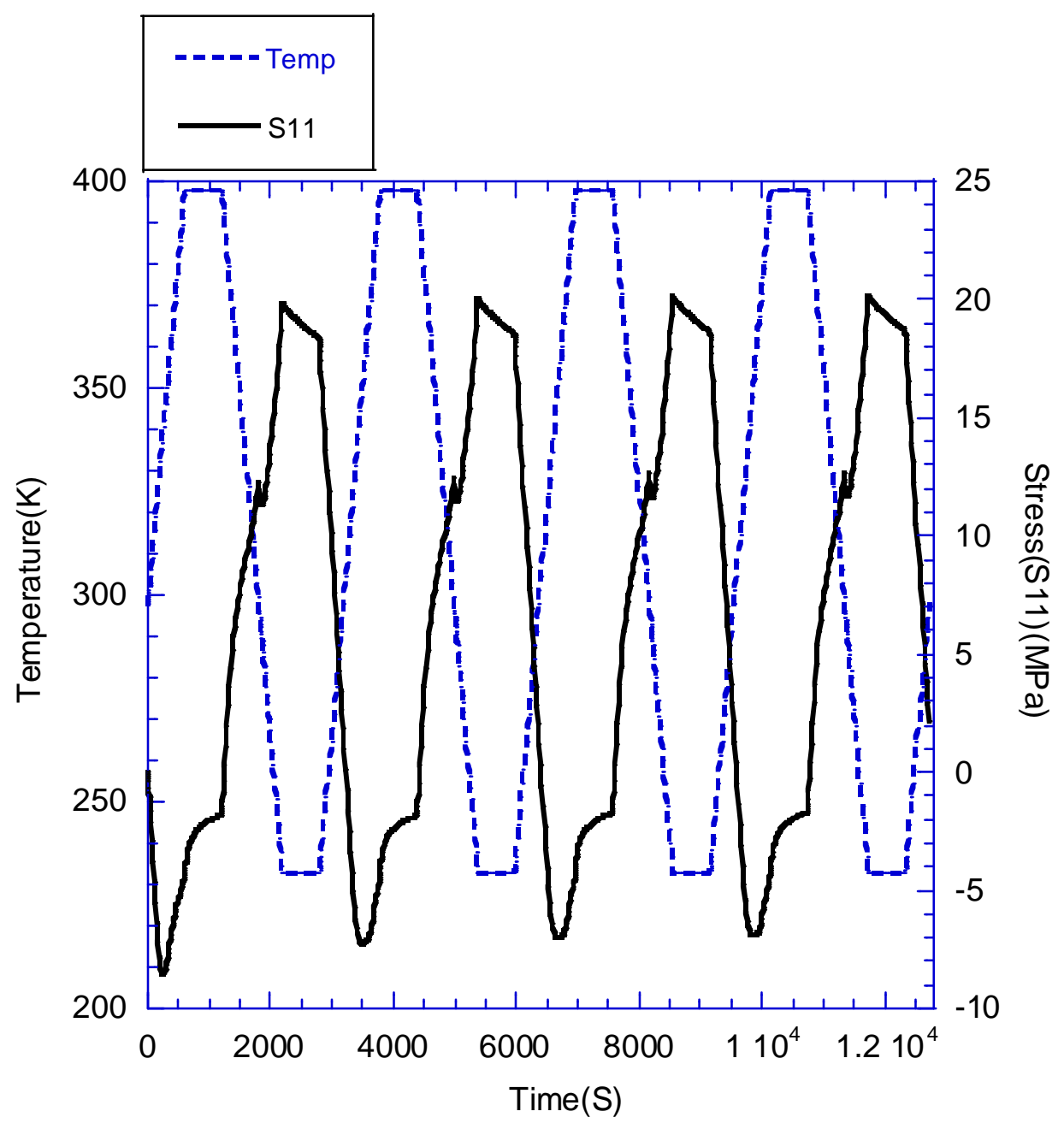

Figure 4-44 Variation of normal stress $S_{11}$ during thermal cycling 


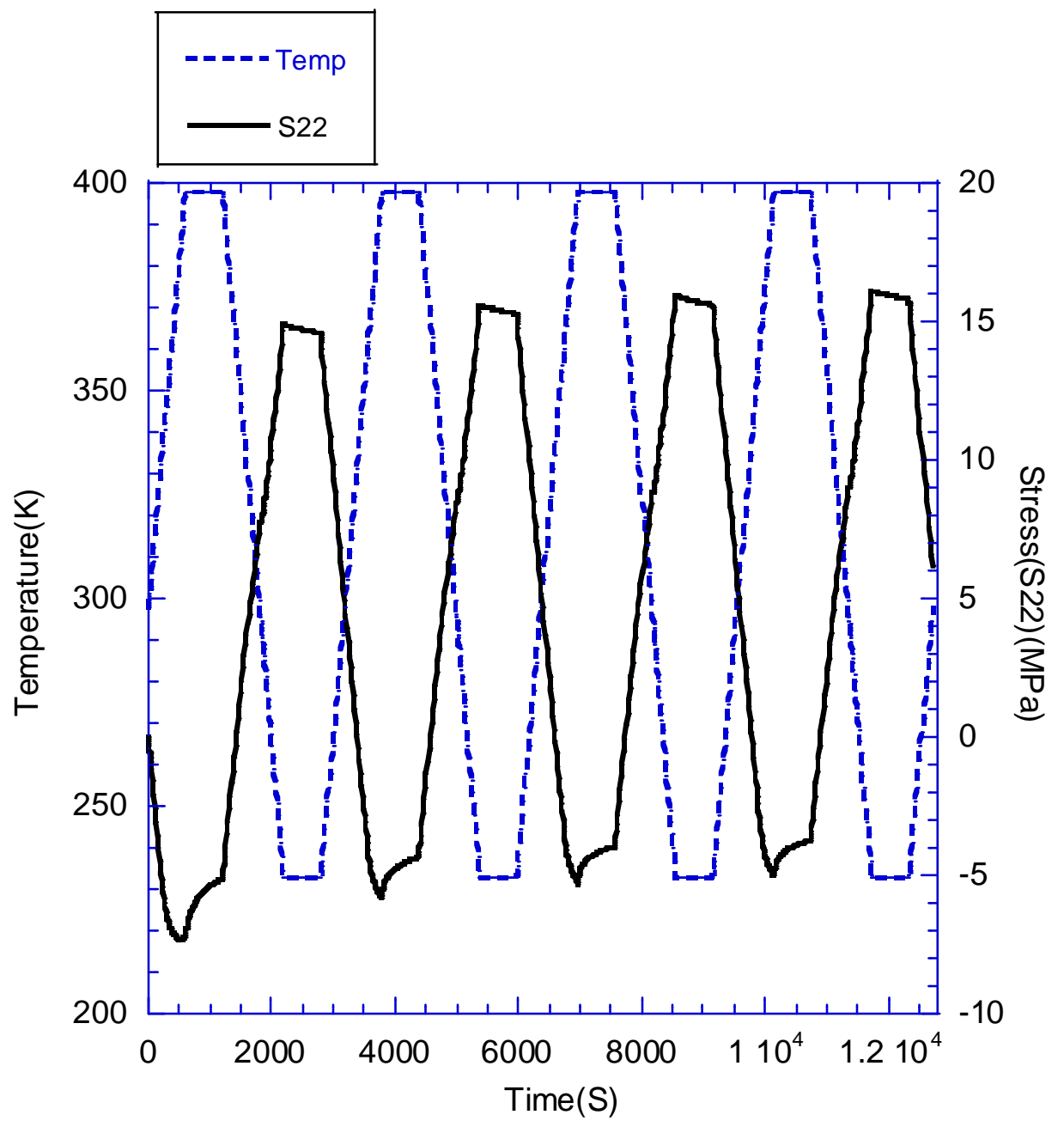

Figure 4-45 Variation of normal stress $\mathrm{S}_{22}$ during thermal cycling 


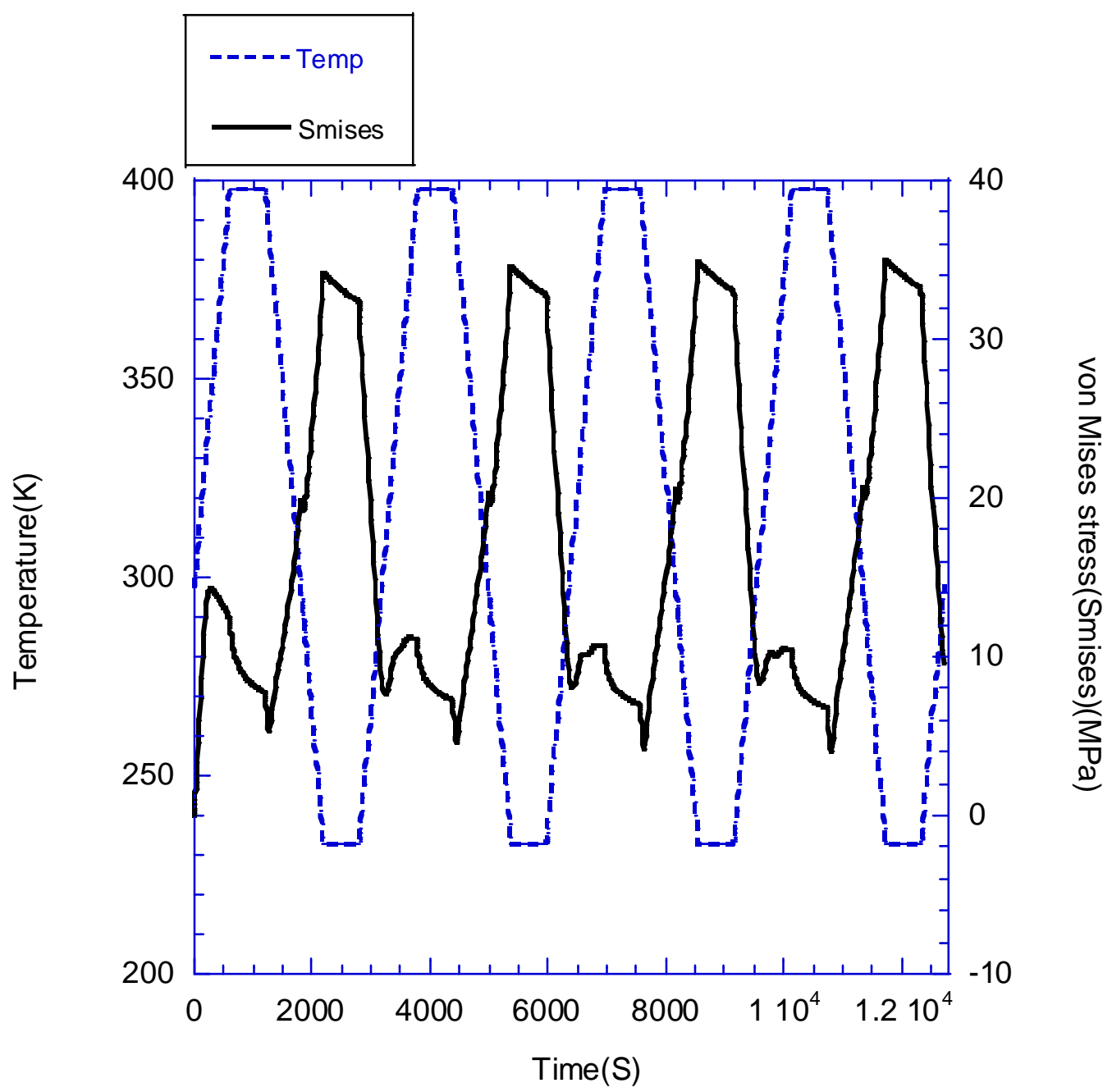

Figure 4-46 Variation of von Mises stress $\left(\mathrm{S}_{\text {mises }}\right)$ and during thermal cycling

During the temperature ramp down, the magnitudes of stresses increase due to increase of Young's modulus of the solder. The von Mises stress $\left(\mathrm{S}_{\mathrm{mises}}\right)$ in the right corner of the $9^{\text {th }}$ solder ball increases from $7.27 \mathrm{MPa}$ to $34.64 \mathrm{MPa}$, which is maximum, when temperature decreases from $398 \mathrm{~K}$ to $233 \mathrm{~K}$. 
During the cold dwell, cycle, the magnitudes of stresses decrease because of stress relaxation. As shown in Figure 4-43, the behavior of shear stress in the right corner of the $9^{\text {th }}$ solder ball is very similar to one of the von Mises stress. 


\section{Chapter 5. Conclusions}

In the present study, the thermal-mechanical behavior of the solder balls in the eBGA and the CSP with eBGA has under thermal cycling is successfully studied by the finite element analysis. The linear elastic and viscoplastic material behaviors of the solder are considered.

For positive temperature change $(\Delta \mathrm{T}>0)$, both of the eBGA and the CSP bend upward (U-shape) because of the mismatch of CTEs among the materials, while those bend downward for negative temperature changes $(\Delta \mathrm{T}<0)$.

The maximum displacement in the y-direction of the eBGA package is obtained at the edge of the eBGA. Based on the linear analysis, the maximum displacements in the $y-$ direction of the eBGA for $\Delta \mathrm{T}=100$ degree $\mathrm{C}$ and $\Delta \mathrm{T}=-65$ degree $\mathrm{C}$ are $0.01576 \mathrm{~mm}$ and $-0.0102 \mathrm{~mm}$, respectively.

For the CSP with the eBGA, the maximum displacement in the $y$-direction is $0.02006 \mathrm{~mm}$ for for $\Delta \mathrm{T}=100$ degree $\mathrm{C}$ and is increased by $27.3 \%$ when compared with the eBGA, while it is $-0.01297 \mathrm{~mm}$ for $\Delta \mathrm{T}=-65$ degree $\mathrm{C}$ and is increased by $27.15 \%$. For positive temperature change $(\Delta \mathrm{T}>0)$, the tensile normal stress along the $\mathrm{x}$ direction is developed in the embedded die, while the compressive normal stress is observed in the substrate around the embedded die since the surrounding of the embedded die tries to expand more than the embedded die. The opposite is observed for $\Delta \mathrm{T}<0$. 
For the linear elastic analysis, the maximum shear stress and von Mises stress are observed at the $9^{\text {th }}$ solder joint in both the eBGA and the CSP. The magnitudes of those stresses at the $9^{\text {th }}$ solder joint for both the eBAG and the CSP are almost identical.

For the viscoplastic analysis, the creep is observed. The y-displacement in the eBGA is $-0.01052 \mathrm{~mm}$ after temperature decrease and then it was further increased during the cool dwell period. The maximum y-displacement is $-0.01085 \mathrm{~mm}$ at the end of the fourth cold $\left(\mathrm{T}_{\text {low }}\right)$ dwell, which is $6.37 \%$ large compared with the elastic one.

The viscoplastic shear stresses of solder joints in the CSP with eBGA are $49.2 \% \sim 65.3 \%$ smaller than the linear elastic ones. The von Mises stresses based on the viscoplastic analysis is $51.65 \% \sim 71.91 \%$ smaller than the linear elastic ones.

The viscoplastic stresses in the eBGA and the CSP are highly nonlinear and relax during dwelling. During the temperature ramp up, the magnitudes of stresses decrease due to reduction of Young's modulus of the solder.

In the CSP, the von Mises stress $\left(S_{\text {mises }}\right)$ in the right corner of the $9^{\text {th }}$ solder ball decrease from $32.37 \mathrm{MPa}$ to $7.66 \mathrm{MPa}$ when temperature increases from $233 \mathrm{~K}$ to $308 \mathrm{~K}$, but it increases from 7.66MPa to $11.20 \mathrm{MPa}$ for when temperature increases further from $308 \mathrm{~K}$ to $377 \mathrm{~K}$. When temperature increases from $377 \mathrm{~K}$ to $398 \mathrm{~K}$, the von Mises stresses $\left(\mathrm{S}_{\text {mises }}\right)$ decrease slightly from 11.20MPa to $11.05 \mathrm{MPa}$. The von Mises stress $\left(\mathrm{S}_{\text {mises }}\right)$ decreases from $34.64 \mathrm{MPa}$ to $32.8 \mathrm{MPa}$ for 600 seconds during the cool dwell period (233K). 


\section{References}

Chu, Yin Fun, (2006) "Solder Joint Reliability Analysis Using a Viscoplastic Constitutive Model with Grain Size Effect", MS Thesis, Portland State University.

Chu, Yin Fun, Yi, Sung, and Geng, Phil, (2014) “Thermal Fatigue Life Prediction of Solder Joints of Plastic Ball Grid Array Packages", International Journal of Materials and Structural Integrity, 2014 (In Press).

Darveaus, R., and Banerji, K. (1992) 'Constitutive Relations for Tin-Based Solder

Joints,' IEEE Transaction on Components, Hybrids, and Manufacturing Technology,

Vol. 15, No. 6, pp. 1013-1024.

Joo, D. K. and Yu, J. (2002) 'Effects of Microstructure on the Creep Properties of Lead-free Sn-3.5Ag-Cu solders', Proceedings of 52nd Electronic Components and Technology Conference, pp 1221-1225..

Morris, J.W. Jr., Song, H.G. and Hua, F. (2003) 'Creep Resistance of Sn-rich Solder Joints', Proceedings of $53^{\text {rd }}$ Electronic Components and Technology Conference, pp. 54-57.

Schubert, A. and Dudek, R., (2003) 'Fatigue Life Model for $\mathrm{SnAgCu}$ and $\mathrm{SnPb}$ Solder Joints Evaluated by Experiment and Simulations', Proceedings of $53^{\text {rd }}$ Electronic components and Technology Conference, pp. 603-608.

Shen, Lianxi and Yi, Sung. (2001) 'A Damage Parameter Based on Fracture Surface for Fatigue Life Prediction of CSP Solder Joints', Proceedings of the 3rd 
International Conference on Electronic Materials and Packaging Conference, pp. $412-416$.

Syed, Ahmer. (2004) 'Accumulated Creep Strain and Energy Density Based Thermal Fatigue Life Prediction Models for $\mathrm{SnAgCu}$ Solder Joints', Proceedings of $54^{\text {th }}$ Electronic Components and Technology Conference, pp. 737-746.

Wiese, S. and Meusel, E. (2003) 'Microstructure Dependence of Constitutive Properties of Eutectic SnAg and SnAgCu Solder', Proceedings of $53^{\text {rd }}$ Electronic Components and Technology Conference, pp. 197-206.

Yi, Sung, Luo, G. and Chian, K.S. (2002) 'A Viscoplastic Constitutive Model for 63Sn37Pb Eutectic solders', ASME: Journal of Electronic Packaging, Vol. 124, pp. 91-96.

Yi, Sung, Daharwal, Paresh D., Lee, Yeong J. and Harknewss, Brain R. (2005) 'Effect of Low-modulus Die Attach Adhesive on Warpage and Damage of BGA', Proceedings of International Symposium on Electronic Materials and Pcakgaging, pp. 162-168.

Yi, Sung, Kim, Kyungo, Lee, Dongwan, Kim, Hongwon and Jung, Taesung, (2013) "Embedded passive device technology for wireless mobile devices", Microelectronics International, Vol. 30 Iss: 1, pp.33 - 39.

Yi, Sung and Lam, Tatiana M., (2012) "Analysis of warpage and residual stress in plastic ball grid array package after post mold cure", Microelectronics International, Vol. 29 Iss: 3, pp.163 - 171 
Ying, Ming and Chow, S. (2004) 'Fatigue Life Model of SnPb and $\mathrm{SnAgCu}$ Solder Joints with Experiment Correlation', Proceedings of the 6th International Conference on Electronic Materials and Packaging, pp 338-343.

Ying, Ming, Chow, S.G. and Emigh, R. (2004) 'A Study of Sectional-area Averaged Creep dissipation Energy Density for Solder Joint Fatigue Life Prediction', Proceedings of SEMI Technology Symposium, pp. 185-190.

Zhang, Q., Dasqupta, A., Nelson, D. and Pallavicini, H. (2005) 'Systematic Study on Thermo-Mechanical Durability of Pb-free Assemblies: Experiments and FE Analysis', ASME: Journal of Electronic Packaging, Vol.127, pp. 415-429, 2005.

Zhong, C.H. and Yi, S. (1998) 'Effects of Ball Pad Metallurgy and Ball Composition on Solder Ball Integrity of Plastic Ball Grid Array Packages', Proceedings of the 24th International Symposium for Testing and Failure Analysis, pp. 405-409.

Zhong, C. H. and Yi, Sung, (1999), 'Solder Joint Reliability of Plastic Ball Grid Array Packages', Soldering and Surface Mount Technology, UK, Vol. 11, No. 1, pp.4448.

Zhong, C.H., Yi, S., Whalley, D.C. (2002) 'Solder Ball Failure Mechanisms in Plastic Ball Grid Array Packages', Soldering and Surface mount Technology, Vol. 14 No. 2, pp.40-50. 